San Jose State University

SJSU ScholarWorks

Master's Theses

Master's Theses and Graduate Research

Summer 2014

\title{
Inelastic Analysis of Seismic Loading of Precast Concrete Cladding Using Commercially Available Software
}

Mohammad Ebrahim Mohammadi

San Jose State University

Follow this and additional works at: https://scholarworks.sjsu.edu/etd_theses

\section{Recommended Citation}

Mohammadi, Mohammad Ebrahim, "Inelastic Analysis of Seismic Loading of Precast Concrete Cladding Using Commercially Available Software" (2014). Master's Theses. 4475.

DOI: https://doi.org/10.31979/etd.x9bu-hk7j

https://scholarworks.sjsu.edu/etd_theses/4475

This Thesis is brought to you for free and open access by the Master's Theses and Graduate Research at SJSU ScholarWorks. It has been accepted for inclusion in Master's Theses by an authorized administrator of SJSU ScholarWorks. For more information, please contact scholarworks@sjsu.edu. 


\title{
INELASTIC ANALYSIS OF SEISMIC LOADING OF PRECAST CONCRETE CLADDING USING COMMERCIALLY AVAILABLE SOFTWARE
}

\author{
A Thesis \\ Presented to \\ The Faculty of the Department of Civil and Environmental Engineering \\ San José State University \\ In Partial Fulfillment \\ of the Requirements for the Degree \\ Master of Science
}

by

Mohammad Ebrahim Mohammadi

August 2014 
(C) 2014

Mohammad Ebrahim Mohammadi

ALL RIGHTS RESERVED 
The Designated Thesis Committee Approves the Thesis Titled

\title{
INELASTIC ANALYSIS OF SEISMIC LOADING OF PRECAST CONCRETE
} CLADDING USING COMMERCIALLY AVAILABLE SOFTWARE

\author{
by \\ Mohammad Ebrahim Mohammadi \\ APPROVED FOR THE DEPARTMENT OF CIVIL AND ENVIRONMENTAL \\ ENGINEERING
}

SAN JOSÉ STATE UNIVERSITY

August 2014
Dr. Kurt M. McMullin Department of Civil and Environmental Engineering Mr. Daniel Merrick Department of Civil and Environmental Engineering Mr. Mark Hildebrand President, Willis Construction Co., Inc.




\title{
ABSTRACT \\ INELASTIC ANALYSIS OF SEISMIC LOADING OF PRECAST CONCRETE CLADDING USING COMMERCIALLY AVAILABLE SOFTWARE
}

\author{
by Mohammad Ebrahim Mohammadi
}

Two nonlinear pushover analyses and three displacement-controlled time history analyses of two precast concrete panel assemblies were completed. The analytical software used was SAP2000 (version 15.0.0). The precast concrete panel modeled was a three-dimensional single panel connected to a one-story, one-bay, concrete-reinforced structural frame with four flexing rods and two bearing connections. The results showed that static analysis is suitable to predict only dynamic analysis with a long input period of vibrations (low acceleration vibrations). As the period of input vibration neared the fundamental period of vibration of the precast concrete panel, the maximum value of forces developed in connections increased. The amplification ratio for both models decreased as the period of the input vibrations varied from 100 to $0.32 \mathrm{~s}$, and the amount of time that each flexing rod experienced a local maximum of force changed for the periods of input vibrations of 100,1 , and $0.32 \mathrm{~s}$. 


\section{ACKNOWLEDGEMENTS}

My first and sincere appreciation goes to my supervisor, Dr. Kurt McMullin, PE, Professor of Civil Engineering in the Department of Civil and Environmental Engineering at San José State University. I am grateful for his continuous guidance and support in all stages of this research program. I would also like to thank him for all I have learned from him and for encouraging and helping me to shape my ideas and interests. I also thank Mr. Mark Hildebrand and Mr. Daniel Merrick for their time in reviewing my work and providing valuable feedback.

In addition, I would like to express my deep gratitude to my colleague Christopher Huffman for proofreading my thesis.

The financial support of the Charles Pankow Foundation is gratefully acknowledged.

I would like to thank Mr. Patrick Joice, a member of the technical staff of the Structural Laboratory at San José State University, for his technical assistance.

Last but not least, I would like to thank my parents for their unconditional love and support, financially and spiritually, throughout my life. Without them I would have never made it to this stage in my career. 


\section{Table of Contents}

List of Figures....................................................................................................................... ix

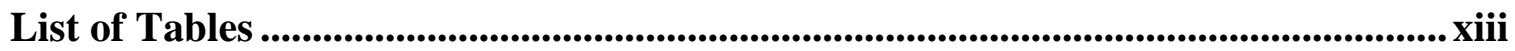

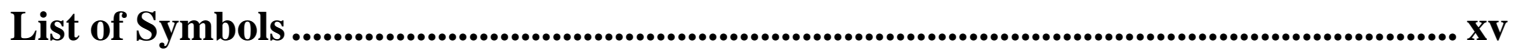

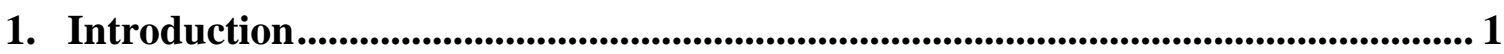

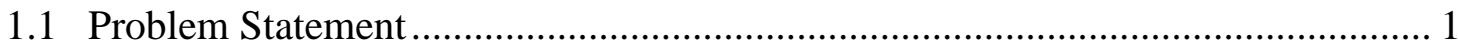

1.2 University of California, San Diego, Precast Concrete Cladding Subsystems—Detailing for Regions of High Seismicity .................................. 1

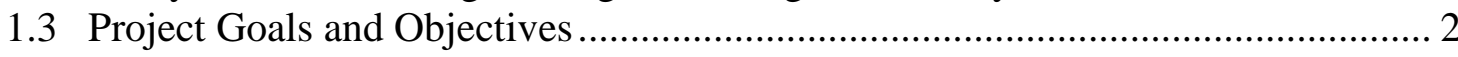

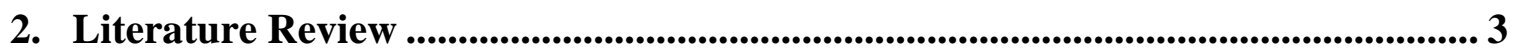

2.1 Analysis of the Panel Systems ................................................................... 3

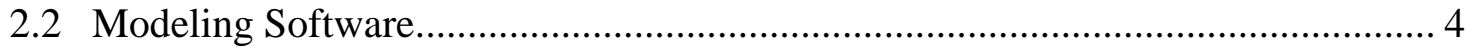

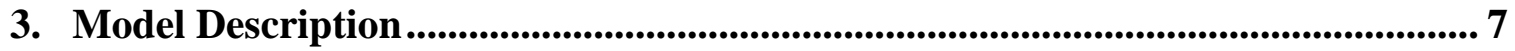

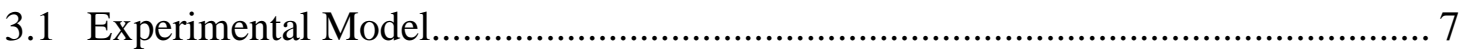

3.2 Analytical Model .......................................................................................... 10

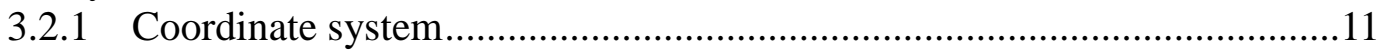

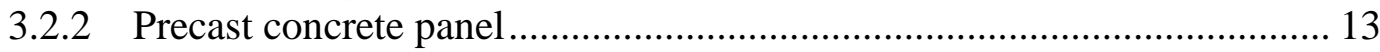

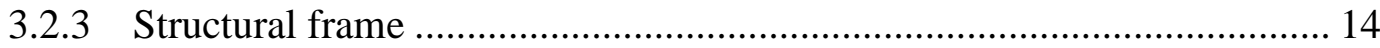

3.2.4 Nonlinear link element................................................................... 17

3.3 Loading Protocol.......................................................................................... 22

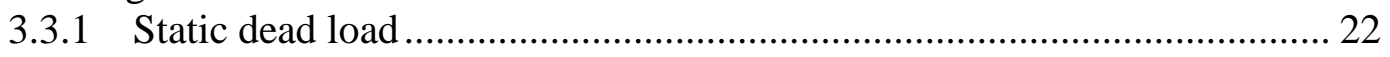

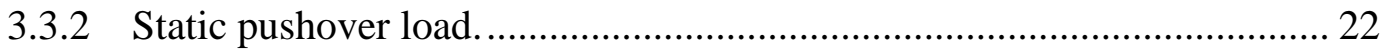

3.3.3 Displacement-controlled time history load ..................................... 24

4. Static Analysis Results......................................................................................................... 28

4.1 Overview of Analyses ................................................................................. 28

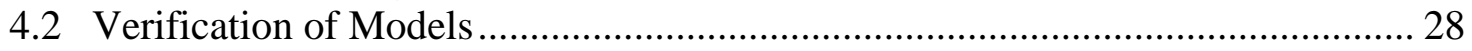

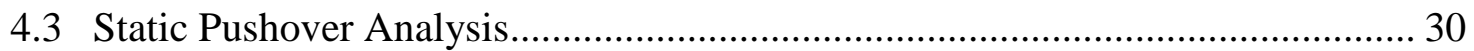

4.3.1 Top links in-plane direction analysis result for Model MD 1 .................. 31

4.3.2 Bottom links in-plane direction analysis result for Model MD 1 ............. 34

4.3.3 Bottom links vertical direction analysis result for Model MD 1 ............. 38

4.3.4 Drift ratio for Model MD 1 ................................................................. 40

4.3.5 Summary of analysis for Model MD 1 .............................................. 42

4.3.6 Top links in-plane direction analysis result for Model MD 2 ................. 44

4.3.7 Bottom links in-plane direction analysis result for Model MD 2 ........... 47

4.3.8 Bottom links vertical direction analysis result for Model MD 2 ............. 51

4.3.9 Drift ratio for Model MD 2 ............................................................... 53

4.3.10 Summary of analysis for Model MD 2 ….......................................... 54 
5. Displacement-Controlled Time History Analysis Results .......................................... 57

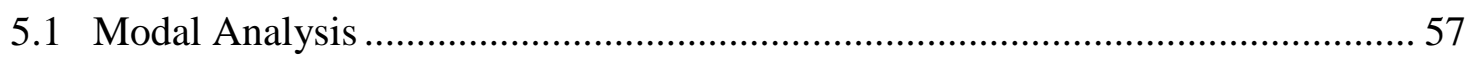

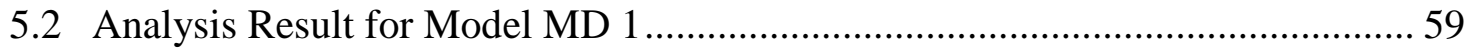

5.2.1 Top links force-time relationship for Model MD 1 ............................... 59

5.2.2 Top links analysis result for Model MD 1 under dynamic load for a period of 100 seconds in the in-plane direction ........................................ 62

5.2.3 Bottom links analysis result for Model MD 1 under dynamic load for a period of 100 seconds in the vertical direction.................................. 65

5.2.4 Acceleration and displacement result for Model MD 1 under

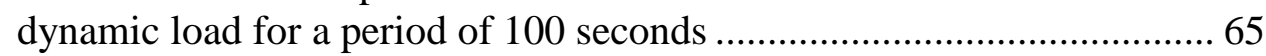

5.2.5 Top links analysis result for Model MD 1 under dynamic load for a period of 1 second in the in-plane direction.............................................. 68

5.2.6 Bottom links analysis result for Model MD 1 under dynamic load for a period of 1 second in the vertical direction ...................................... 70

5.2.7 Acceleration and displacement result for Model MD1 under dynamic load for a period of 1 second ................................................... 70

5.2.8 Top links analysis result for Model MD 1 under dynamic load for a period of 0.32 seconds in the in-plane direction ....................................... 73

5.2.9 Bottom links analysis result for Model MD 1 under dynamic load for a period of 0.32 seconds in the in-plane direction............................... 75

5.2.10 Acceleration and displacement result for Model MD 1 under dynamic load for a period of 0.32 seconds. ............................................. 75

5.3 Analysis Result for Model MD 2 ………………........................................ 79

5.3.1 Top links force-time relationship for Model MD 2 .............................. 79

5.3.2 Top links analysis result for Model MD 2 under dynamic load for a period of 100 seconds in the in-plane direction...................................... 82

5.3.3 Bottom links analysis result for Model MD 2 under dynamic load for a period of 100 seconds in the vertical direction................................. 85

5.3.4 Acceleration and displacement result for Model MD 2 under dynamic load for a period of 100 seconds. ............................................... 85

5.3.5 Top links analysis result for Model MD 2 under dynamic load for a period of 1 second in the in-plane direction............................................. 88

5.3.6 Bottom links analysis result for Model MD 2 under dynamic load for a period of 1 second in the vertical direction ..................................... 90

5.3.7 Acceleration and displacement result for Model MD 2 under dynamic load for a period of 1 second

5.3.8 Top links analysis result for Model MD 2 under dynamic load for a period of 0.32 seconds in the in-plane direction ....................................... 93

5.3.9 Bottom links analysis result for Model MD 2 under dynamic load for a period of 0.32 seconds in the vertical direction................................ 95

5.3.10 Acceleration and displacement for Model MD 2 under dynamic load for a period of 0.32 seconds. 
6. Conclusions and Recommendations ..............................................................98

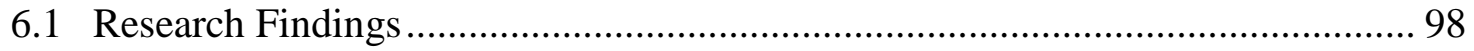

6.2 Recommendations for Future Work............................................................ 100

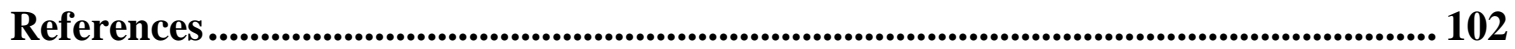

Appendix A: Force-Deformation Experimental Data for Flexing Rods.................. 103

Appendix B: Summary of Figures for Analyses............................................................. 107 


\section{List of Figures}

Figure 1. Photograph of the flexing rod connection at UCSD ..................................... 9

Figure 2. Photograph of the bearing connection at UCSD ......................................... 10

Figure 3. Three-dimensional geometry of the analytical model .....................................11

Figure 4. Local axes sign convention for link ......................................................... 13

Figure 5. Precast concrete panel layout ...................................................................... 14

Figure 6. Structural frame layout ……………………............................................... 15

Figure 7. Elements of the structural frame analytical model ......................................... 16

Figure 8. Force-deformation graphs input for flexing rods ........................................... 21

Figure 9. Point of input for displacement-controlled time history analysis and

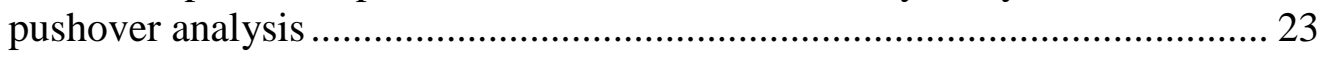

Figure 10. Protocol for control displacement for static pushover analysis ...................... 24

Figure 11. Sine wave function for analytical model ................................................... 26

Figure 12. Free body diagram of the precast concrete panel and links for the dead

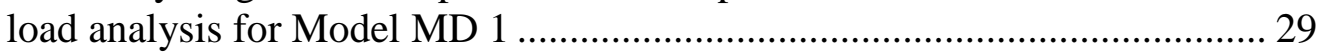

Figure 13. Free body diagram of the precast concrete panel and links for the dead

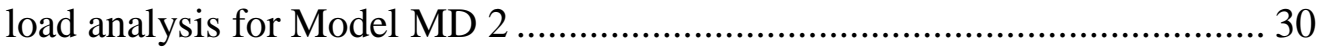

Figure 14. Total force developed in all flexing rod links for loading protocols P1 and $\mathrm{P} 2$

Figure 15. Force developed in the exterior flexing rod in the $\mathrm{X}$ direction versus the link displacement in the $\mathrm{X}$ direction for loading protocols $\mathrm{P} 1$ and $\mathrm{P} 2$

Figure 16. Force developed in the interior flexing rod in the $\mathrm{X}$ direction versus the link displacement in the $\mathrm{X}$ direction for loading protocols $\mathrm{P} 1$ and $\mathrm{P} 2$

Figure 17. Force developed in Link 5 in the $\mathrm{X}$ direction versus the link displacement in the $\mathrm{X}$ direction for loading protocol P1

Figure 18. Force developed in Link 5 in the $\mathrm{X}$ direction versus the link displacement in the $\mathrm{X}$ direction for loading protocol $\mathrm{P} 2$.

Figure 19. Force developed in Link 6 in the $X$ direction versus the link displacement in the $\mathrm{X}$ direction for loading protocol P1

Figure 20. Force developed in Link 6 in the $\mathrm{X}$ direction versus the link displacement in the $\mathrm{X}$ direction for loading protocol P2 
Figure 21. Force developed in Link 5 in the $\mathrm{Z}$ direction versus the link displacement in the $\mathrm{Z}$ direction for loading protocols $\mathrm{P} 1$ and $\mathrm{P} 2$ 39

Figure 22. Force developed in Link 6 in the $\mathrm{Z}$ direction versus the link displacement in the $\mathrm{Z}$ direction for loading protocols $\mathrm{P} 1$ and $\mathrm{P} 2$

Figure 23. Shear strain of the precast concrete panel versus drift ratio of the structural frame

Figure 24. Free body diagram of the precast concrete panel at final step of analysis for loading protocol P1

Figure 25. Total force developed in all flexing rod links for loading protocols P1 and $\mathrm{P} 2$

Figure 26. Force developed in the exterior flexing rod in the $\mathrm{X}$ direction versus the link displacement in the $\mathrm{X}$ direction for loading protocols P1 and P2

Figure 27. Force developed in the interior flexing rod in the $\mathrm{X}$ direction versus the link displacement in the $\mathrm{X}$ direction for loading protocols $\mathrm{P} 1$ and $\mathrm{P} 2$

Figure 28. Force developed in Link 5 in the $\mathrm{X}$ direction versus the link displacement in the $\mathrm{X}$ direction for loading protocol $\mathrm{P} 1$ 48

Figure 29. Force developed in Link 5 in the $X$ direction versus the link displacement in the $\mathrm{X}$ direction for loading protocol $\mathrm{P} 2$

Figure 30. Force developed in Link 6 in the $X$ direction versus the link displacement in the $\mathrm{X}$ direction for loading protocol $\mathrm{P} 1$

Figure 31. Force developed in Link 6 in the $\mathrm{X}$ direction versus the link displacement in the $\mathrm{X}$ direction for loading protocol $\mathrm{P} 2$

Figure 32. Force developed in Link 5 in the $\mathrm{Z}$ direction versus the link displacement in the $\mathrm{Z}$ direction for loading protocols P1 and P2

Figure 33. Force developed in Link 6 in the $\mathrm{Z}$ direction versus the link displacement in the $\mathrm{Z}$ direction for loading protocols $\mathrm{P} 1$ and $\mathrm{P} 2$

Figure 34. Shear strain of the precast concrete panel versus drift ratio of the structural frame

Figure 35. Free body diagram of the precast concrete panel at final step of analysis for loading protocol P1

Figure 36. Force developed in the exterior flexing rod versus time for $\mathrm{T}=100$ seconds

Figure 37. Force developed in the interior flexing rod versus time for $\mathrm{T}=100$ seconds 
Figure 38. Force developed in the exterior flexing rod versus time for $\mathrm{T}=1$ second

Figure 39. Force developed in the interior flexing rod versus time for $\mathrm{T}=1$ second

Figure 40. Force developed in the exterior flexing rod versus time for $\mathrm{T}=0.32$ seconds

Figure 41. Force developed in the exterior flexing rod versus time for $\mathrm{T}=0.32$ seconds

Figure 42. Forces developed in all flexing rod links versus the structural frame displacement

Figure 43. Force developed in the exterior flexing rod versus the exterior link displacement 64

Figure 44. Force developed in the interior flexing rod versus the interior link displacement 64

Figure 45. Precast concrete panel acceleration in the $\mathrm{X}$ direction versus time......... 66

Figure 46. Precast concrete panel displacement in the $\mathrm{X}$ direction versus time 67

Figure 47. Precast concrete panel displacement in the $\mathrm{Z}$ direction versus time. 68

Figure 48. Force developed in the exterior flexing rod versus the exterior link displacement

Figure 49. Force developed in the interior flexing rod versus the interior link displacement

Figure 50. Acceleration of the precast concrete panel in the $\mathrm{X}$ direction versus time 71

Figure 51. Precast concrete panel displacement in the $\mathrm{X}$ direction versus time 72

Figure 52. Precast concrete panel displacement in the $\mathrm{Z}$ direction versus time..... 73

Figure 53. Force developed in the exterior flexing rod versus the exterior link displacement

Figure 54. Force developed in the interior flexing rod versus the interior link displacement

Figure 55. Acceleration of the precast concrete panel in the $\mathrm{X}$ direction versus time 76

Figure 56. Precast concrete panel displacement in the $\mathrm{X}$ direction versus time .............. 77

Figure 57. Precast concrete panel displacement in the $\mathrm{X}$ direction versus time ............. 78

Figure 58. Force developed in the exterior flexing rod versus time for $\mathrm{T}=100$ seconds 
Figure 59. Force developed in the interior flexing rod versus time for $\mathrm{T}=100$ seconds

Figure 60. Force developed in the exterior flexing rod versus time for $\mathrm{T}=1$ second ..... 80

Figure 61. Force developed in the interior flexing $\operatorname{rod}$ for $\mathrm{T}=1$ second 81

Figure 62. Force developed in the exterior flexing rod versus time for $\mathrm{T}=0.32$ seconds

Figure 63. Force developed in the interior flexing rod versus time for $\mathrm{T}=0.32$ seconds

Figure 64. Forces developed in all flexing rod links versus the structural frame displacement

Figure 65. Force developed in the exterior flexing rod versus the exterior link displacement

Figure 66. Force developed in the interior flexing rod versus the interior link displacement

Figure 67. Acceleration of the precast concrete panel in the $\mathrm{X}$ direction versus time 86

Figure 68. Precast concrete panel displacement in the $\mathrm{X}$ direction versus time 87

Figure 69. Precast concrete panel displacement in the $\mathrm{Z}$ direction versus time. 87

Figure 70. Force developed in the exterior flexing rod versus the exterior link displacement

Figure 71. Force developed in the interior flexing rod versus the interior link displacement

Figure 72. Acceleration of the precast concrete panel in the $X$ direction versus time 91

Figure 73. Precast concrete panel displacement in the $\mathrm{X}$ direction versus time ............. 92

Figure 74. Precast concrete panel displacement in the $\mathrm{Z}$ direction versus time. 92

Figure 75. Force developed in the exterior flexing rod versus the exterior link displacement

Figure 76. Force developed in the interior flexing rod versus the interior link displacement 94

Figure 77. Acceleration of the precast concrete panel in the $\mathrm{X}$ direction ....................... 96

Figure 78. Precast concrete panel displacement in the $\mathrm{X}$ direction versus time ............. 97

Figure 79. Precast concrete panel displacement in the $\mathrm{Z}$ direction versus time. 97 


\section{List of Tables}

Table 1. Experimental Testing Rod Placement ...................................................... 8

Table 2. Sign Convention for Model Developed in SAP2000.................................... 12

Table 3. Support Frame and Precast Concrete Panel Material ................................... 17

Table 4. Beam, Column, and Link Support Dimensions ........................................ 17

Table 5. Connection Type and Force-Deformation Relationship for Connections....... 18

Table 6. SAP2000 Input Parameters and Location of Link Elements .......................... 19

Table 7. Analytical Model Rod Placement ............................................................ 20

Table 8. Pushover Load Cases Summary................................................................ 24

Table 9. Sine Wave Function Periods and Duration of Analysis ............................... 25

Table 10. Thesis Section for Load Case Result of Each Model .................................. 27

Table 11. Forces Developed in the Vertical Direction in Both Models and Links ......... 29

Table 12. Summary Table of Displacement Ratios With Respect to Control Displacement of the Structural Frame for Model MD 1 in the X Direction ..................................................................................... 42

Table 13. Summary of Horizontal Forces for P1 and P2 Loading Protocols................. 44

Table 14. Summary Table of Displacement Ratios With Respect to Control Displacement of the Structural Frame for Model MD 2 in the X

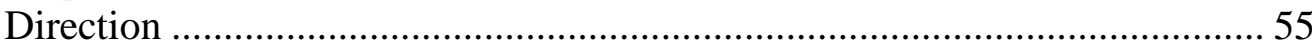

Table 15. Summary of Horizontal Forces for P1 and P2 Loading Protocols.................. 56

Table 16. Modal Participation Mass Ratio for Model MD 1 ........................................ 58

Table 17. Modal Participation Mass Ratio for Model MD 2 ...................................... 58

Table 18. Force-Deformation Relationships for Bottom Links in the X Direction ........ 65

Table 19. Force-Deformation Relationships for Bottom Links in the Z Direction......... 65

Table 20. Force-Deformation Relationships for Bottom Links in the X Direction ........ 70

Table 21. Force-Deformation Relationships for Bottom Links in the Z Direction......... 70

Table 22. Force-Deformation Relationships for Bottom Links in the X Direction ........ 75

Table 23. Force-Deformation Relationships for Bottom Links in the Z Direction......... 75

Table 24. Force-Deformation Relationships for Bottom Links in the X Direction ........ 85

Table 25. Force-Deformation Relationships for Bottom Links in the Z Direction......... 85

Table 26. Force-Deformation Relationships for Bottom Links in the X Direction ........ 89 
Table 27. Force-Deformation Relationships for Bottom Links in the Z Direction......... 90

Table 28. Force-Deformation Relationships for Bottom Links in the X Direction ........ 94

Table 29. Force-Deformation Relationships for Bottom Links in the Z Direction......... 95

Table 30. Amplification Ratios With Respect to Periods of Input Vibrations ................ 99 


\section{List of Symbols}

a

a Panel

a Frame

AP

d

DR

$\alpha_{\text {Frame }}$

F

$\mathrm{n}$

$\mathrm{T}$

$\gamma$
Acceleration

Acceleration of panel

Acceleration of structural frame

Amplification ratio

Displacement

Displacement ratio of a local link element

Drift ratio of the structural frame

Local reaction force of a link element

Number of steps for pushover analysis

Period of vibration of loading

Shear strain of the precast concrete panel 


\section{Introduction}

\subsection{Problem Statement}

The response of nonstructural building components such as architectural, electrical, mechanical, and façade systems can be important during earthquakes. A building can lose its functionality due to nonstructural component damage. Nonstructural components consist of a wide variety of elements, from mechanical and electrical equipment to architectural parts and exterior claddings. Therefore, nonstructural components — particularly façade systems_-are critical components related to improving building performance in the event of an earthquake. Because of this, research has recently been conducted to study the behavior of nonstructural components for both static and dynamic loads to promote improved analysis and design methods, as nonstructural components make up a large portion of construction costs. For the purpose of this study, exterior cladding and its connections with the structural frame was selected as the research subject.

\subsection{University of California, San Diego, Precast Concrete Cladding Subsystems- Detailing for Regions of High Seismicity}

An experimental study of precast concrete cladding façade systems for seismic loading was recently conducted on the Large High Performance Outdoor Shake Table facility in San Diego (McMullin \& Nagar, 2012). The experimental study included a realistic assessment of precast concrete cladding with steel connections to resist dynamic loads. As a supplement to that experimental study, the work for this thesis was completed using computer analytical software to analyze the façade system under two 
loading protocols: an inelastic, nonlinear, monotonic pushover and an inelastic, nonlinear, displacement-controlled time history load with three input functions.

\subsection{Project Goals and Objectives}

The goal of this project was to extend the body of knowledge of seismic behavior of precast concrete panels and their supporting connections to the structural frame.

Specific project objectives included the following:

1. Developing a nonlinear analytical model of a one-story, one-bay precast concrete façade system with different combinations of flexural link elements.

2. Establishing a suitable modeling technique to perform a nonlinear dynamic analysis of cladding without requiring a detailed model of the supporting structural frame.

3. Performing inelastic, nonlinear, monotonic pushover and displacement-controlled time history analyses of the precast concrete façade system with different pairs of flexural link elements.

4. Identifying suitable force-deformation relationships for each of the link elements in all three directions (U1, U2, and U3) for all analyses.

5. Comparing the results of static pushover load with displacement-controlled dynamic load with three different periods of vibration.

6. Studying the dynamic behavior of the precast concrete façade system. 


\section{Literature Review}

\subsection{Analysis of the Panel Systems}

Cheung (2010) performed a nonlinear pushover analysis on a precast concrete cladding system. The model represented the three-dimensional corner of the first floor of a nine-story building. Thirty-one linear and nonlinear link elements were used to simulate the cladding connections. The results of the study showed that the inelastic behavior of the nonlinear link elements controls the behavior of the overall cladding system. Two coordinate systems were used to create the model: global and local. A local coordinate system was defined for each link element. For each link element, the origin is located at the first joint of the link on the structure. The local U1 axis was in the horizontal, out-of-plane direction, which lies along the link element and is perpendicular to the face of the concrete panel. The positive direction for $\mathrm{U} 1$ is toward the concrete panel. The local U2 axis was in the vertical direction, and the upward direction was considered positive. The local U3 axis was in the horizontal, in-plane direction, which is parallel to the face on the concrete panel, and the positive direction is determined by the cross-product of vectors $\mathrm{U} 1$ and $\mathrm{U} 2$.

In another study, Nagar (2012) illustrated a nonlinear analysis to investigate the damage event of the precast concrete cladding specimen with a window opening. A pushover analysis and user-defined displacement-controlled time history analysis were conducted on a one-bay, one-story, precast concrete cladding panel with a window opening using SAP2000 software. The precast concrete cladding system was connected to the supporting frame via six link elements: two bearing connections and four push-pull 
sliding connections. The author concluded that inelastic behavior of connections is the governing factor in the overall behavior of the precast concrete panel for the pushover loads.

McMullin and Nagar (2012) studied the seismic performance of precast concrete cladding with a combination of steel connections based on the full-scale test conducted in April 2012 at UC San Diego Large High Performance Outdoor Shake Table. The top two stories of the five-story, two-bay by one-bay building were fully enclosed with precast concrete cladding. The expected test data contained interstory drift, floor acceleration, panel accelerations, and photographic documentation of the connection behavior and panel movement. The drift ratio of the cladding panels is defined in three ways. Interstory drift ratio is calculated as lateral deflection divided by the distance between the tops of the two floor slabs. The connection drift ratio is defined as the lateral deflection divided by the vertical distance between the horizontal centerlines of the top and bottom connections on a panel. Panel drift ratio is defined as the lateral deflection divided by the physical height of the panel.

\subsection{Modeling Software}

The CSI Analysis Reference Manual for SAP2000 ${ }^{\circledR}, E T A B S^{\circledR}, S A F E^{\circledR}$, and CSiBridge $^{\circledR}$ (2011) defines the linear support stiffness as the total elastic stiffness to be used for all linear analysis and nonlinear analysis that start from zero as the initial conditions. A nonlinear link element is defined as an element composed of six separate springs, one for each of the six deformational degrees of freedom. These springs have two sets of properties: linear effective stiffness and effective damping properties-used 
for linear analysis—and the nonlinear force-deformation relationship_ — used for nonlinear time history analysis. During the nonlinear time-history analysis, the nonlinear forcedeformation relationships are used at all degrees of freedom for which a nonlinear property is specified. For all other degrees of freedom, the linear effective stiffness is used during the nonlinear analysis. The type of nonlinear behavior of the link can be modeled with the nonlinear element for each of the six degrees of freedom. These elements include the following: a nonlinear viscous damper; a gap; a hook; a multilinear elastic; a multilinear plastic, rubber isolator, and friction isolator or base isolator; plastic (Wen); and a T/C friction isolator. A nonlinear viscous damper is suited for modeling viscous dampers that have a nonlinear force-velocity relationship. The multilinear plastic elements can have three different loading and unloading behaviors: Kinematic, Takeda, and Pivot Hysteretic.

The multilinear kinematic plasticity element is based on the kinematic hardening behavior that is observed in metals. The first slope on either side of the origin is elastic; the remaining segment represents plastic deformation. If the deformation reverses, it follows the two elastic segments before beginning plastic deformation in the reverse direction.

The multilinear Takeda plasticity element has similar behavior to the kinematic element, but the degrading hysteretic loop is based on the Takeda model. In particular, during the unloading phase, the curve follows a secant path to the backbone forcedeformation relationship for the opposite loading direction. In the multilinear pivot hysteretic plasticity element, the behavior of the element is similar to the Takeda element, 
but additional parameters control the degrading hysteretic loop. The unloading phase and reverse loading phase tend to be directed to specific points named pivot points.

The CSi Wiki knowledge base (2013) describes the procedure to input displacement time history load cases in SAP2000 software. An earthquake load pattern is applied at the node point of application of time history. The load pattern is a unit value of joint displacement, having a zero self-weight multiplier. The node at which a time history load pattern is applied in SAP2000 is also required to be restrained in the direction of application of time history. A time history load case is then defined, which describes the variation of displacement with time.

The CSi Wiki knowledge base (2014) characterized the inelastic behavior by a force-deformation relationship. The force-deformation curve measures strength against translation or rotational deformation. The general force-deformation graph indicates nonlinear behavior for a member in the structure. It points out that once a member achieves its yield strength, additional loading will cause the response to deviate from the initial elastic behavior. If loading increases, the nonlinear response may reach an ultimate point before degrading to a residual strength value. 


\section{Model Description}

\subsection{Experimental Model}

The nonstructural precast concrete cladding panel evaluated for this study was mounted on a 5-story building constructed at full scale and furnished with several types of nonstructural components, including partition walls, cladding and glazing systems, piping, HVAC, ceiling, sprinklers, and passive and active fire systems at the University of California, San Diego (Nagar, 2012). Eight different precast concrete façade systems were tested. The precast concrete façade system selected to model in this study was a solid panel with a thickness of 5 inches attached to the structure with four flexing rod elements at the top and two bearing connections at the bottom. The UCSD prototype structure contained eight different pairs of connection rods as top link elements, as shown in Table 1. 
Table 1

Experimental Testing Rod Placement

\begin{tabular}{|c|c|c|c|c|}
\hline \multirow[b]{2}{*}{$\begin{array}{l}\text { Panel } \\
\text { Location }\end{array}$} & \multicolumn{4}{|c|}{$\begin{array}{l}\text { Connecting Rod Length Location on the Panel } \\
\text { (inches) }\end{array}$} \\
\hline & Exterior Left & Inner Left & Inner Right & Exterior Right \\
\hline \multicolumn{5}{|l|}{ Flexing Rod } \\
\hline $\begin{array}{l}4^{\text {th }} \text { Floor } \\
\text { Northeast }\end{array}$ & 16 & 20 & 20 & 16 \\
\hline $\begin{array}{l}4^{\text {th }} \text { Floor } \\
\text { Southeast }\end{array}$ & 16 & 12 & 12 & 16 \\
\hline $\begin{array}{l}5^{\text {th }} \text { Floor } \\
\text { Northeast }\end{array}$ & 16 & 12 & 12 & 16 \\
\hline $\begin{array}{l}5^{\text {th }} \text { Floor } \\
\text { Southeast }\end{array}$ & 16 & 20 & 20 & 16 \\
\hline \multicolumn{5}{|l|}{$\underline{\text { Sliding Rod }}$} \\
\hline $\begin{array}{l}4^{\mathrm{nn}} \text { Floor } \\
\text { Northwest }\end{array}$ & 0 & $71 / 2$ & $71 / 2$ & 0 \\
\hline $\begin{array}{l}4^{\text {th }} \text { Floor } \\
\text { Southwest }\end{array}$ & 0 & $71 / 2$ & $71 / 2$ & 0 \\
\hline $\begin{array}{l}5^{\text {th }} \text { Floor } \\
\text { Northwest }\end{array}$ & 0 & 4 & 4 & 0 \\
\hline $\begin{array}{l}5^{\text {th }} \text { Floor } \\
\text { Southwest }\end{array}$ & 0 & 4 & 4 & 0 \\
\hline
\end{tabular}

The flexing rod connection can be built with varying lengths of coil rod. For the testing conducted at UCSD, three different ranges of length were defined: a long rod, an intermediate rod, and a short rod. Figure 1 shows one of the flexing rod connections used at the San Diego experiment site. 


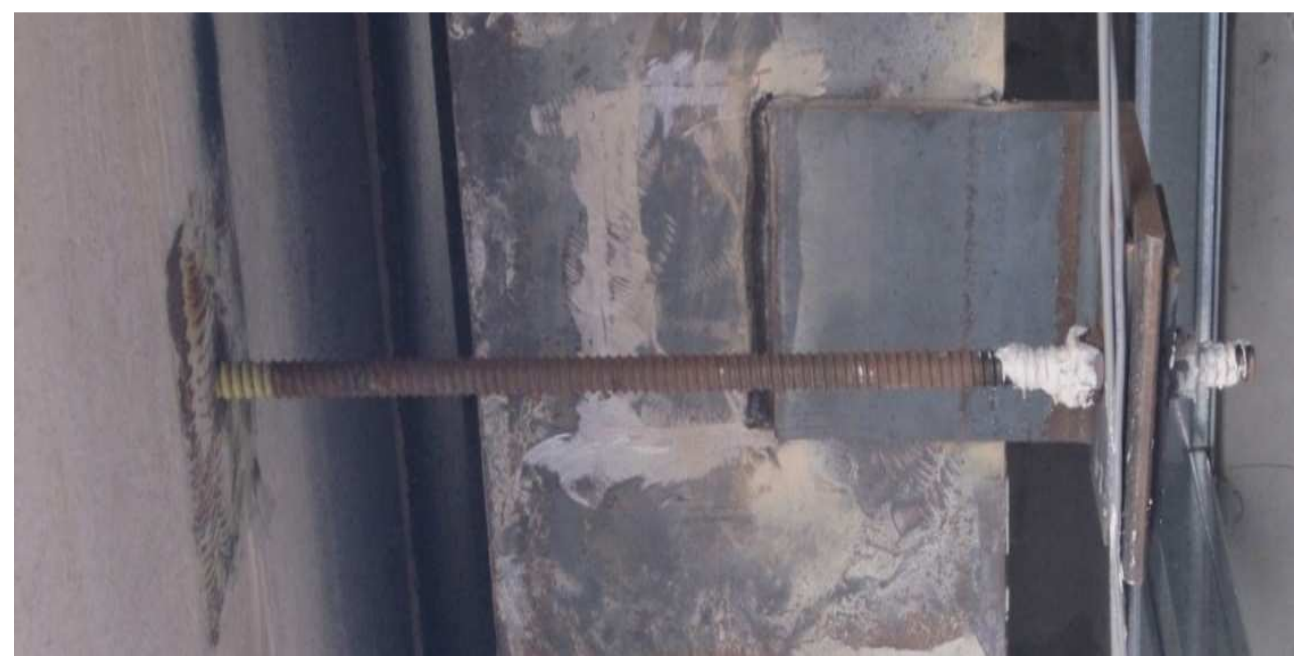

Figure 1. Photograph of the flexing rod connection at UCSD (personal communication, June 2013) (reprinted with permission from Kurt McMullin).

The bearing connection was fabricated from steel, as shown in Figure 2. During casting of the structural concrete beam, a steel plate is embedded in the top of the downturned beam of the supporting frame. Similarly, during casting of the concrete panel, another steel plate is embedded in the panel, providing a cantilevered steel assembly to project from the panel. A leveling bolt is inserted through the cantilevered plate and used to adjust the elevation of the panel on the building. After the panel is positioned, vertical steel plates are welded between the cantilevered panel embed and the structural beam embed. These plates provide the resistance for in-plane and out-of-plane loading (U3 or X direction, and U1 or Y direction). 


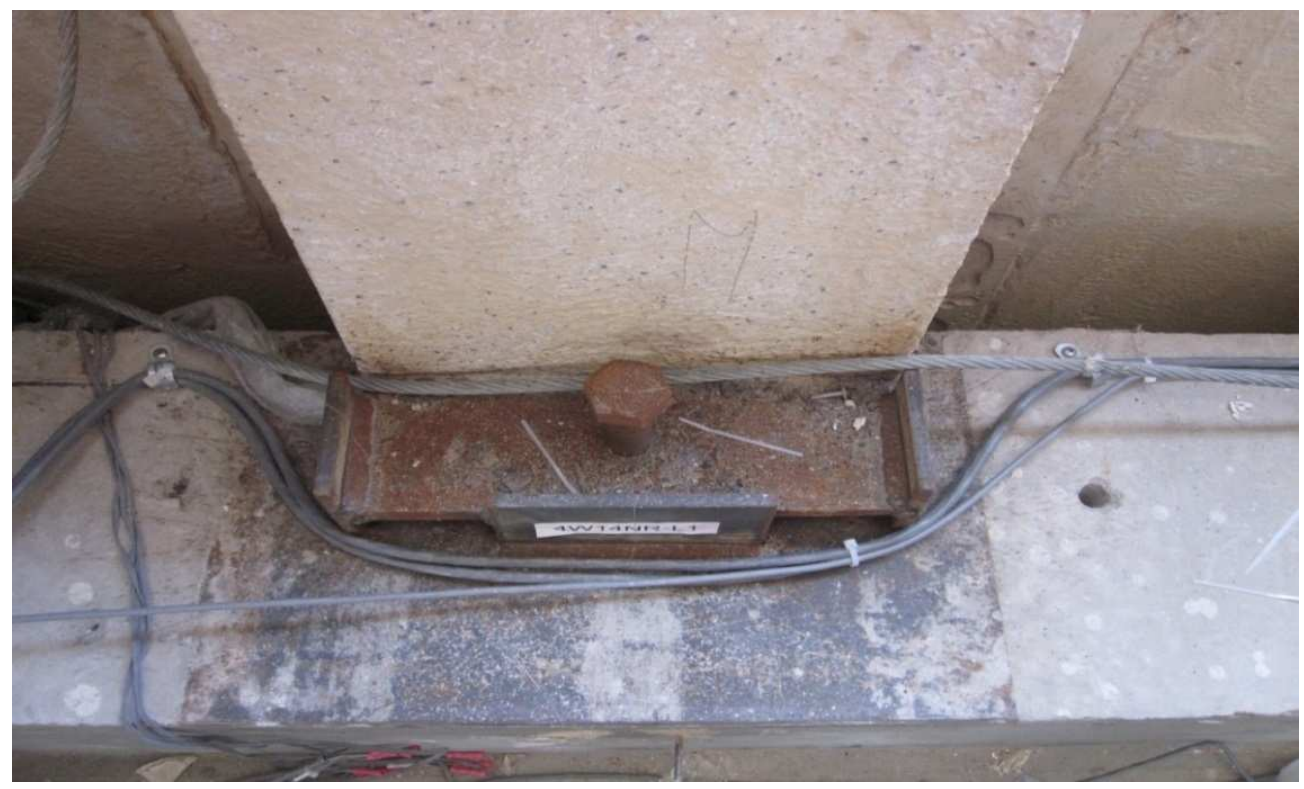

Figure 2. Photograph of the bearing connection at UCSD (personal communication, June 2013) (reprinted with permission from Kurt McMullin).

\subsection{Analytical Model}

This thesis discusses the three dimensional analytical cladding panel shown in Figure 3. It covers a one-story and one-bay area of the structural frame. The analytical model of the cladding panel represents a concrete cladding panel, the structural frame, and six link elements. The precast concrete cladding panel was connected to the structural frame with flexing rod connections at the top and bearing connections at the bottom. 


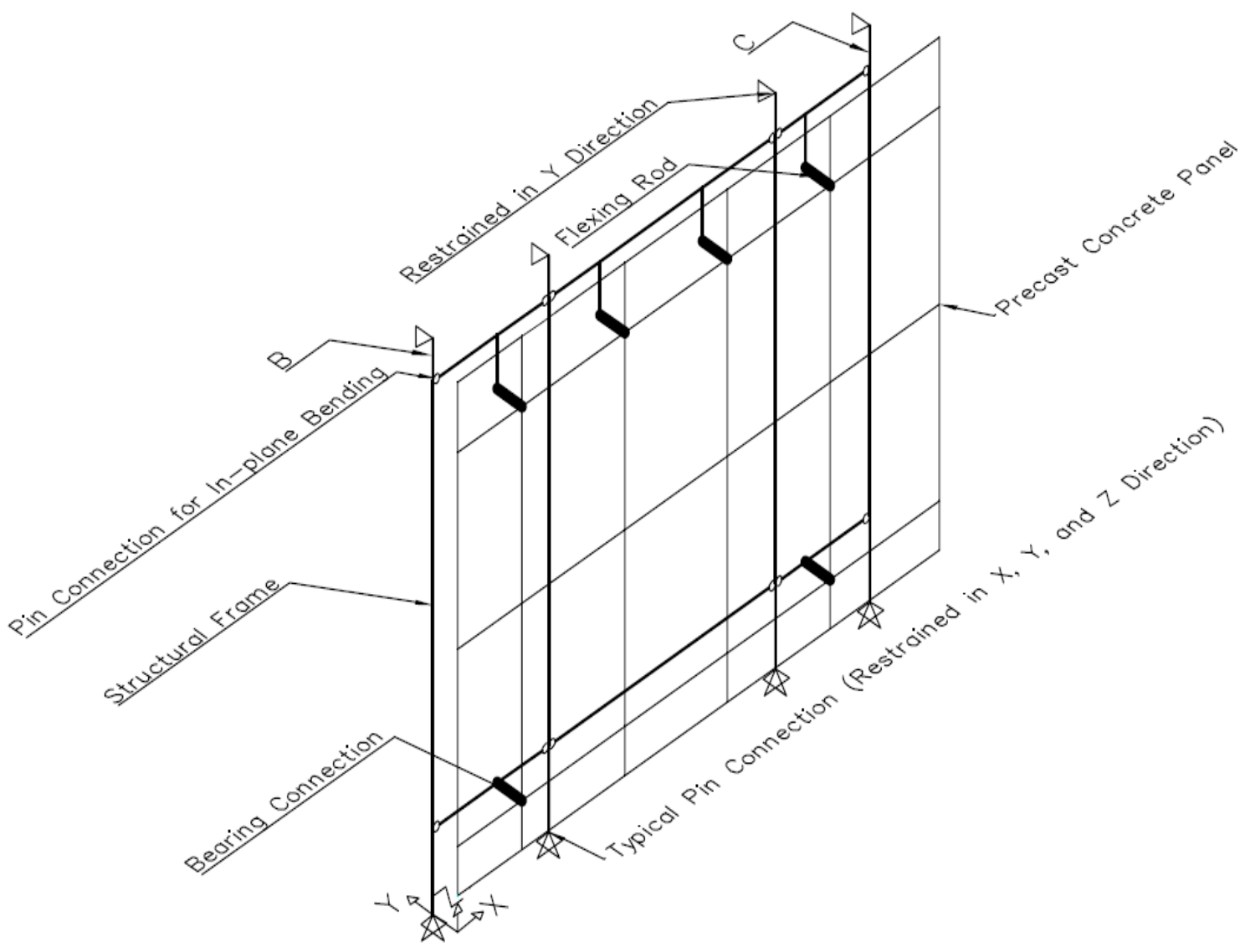

Figure 3. Three-dimensional geometry of the analytical model.

3.2.1 Coordinate system. Two coordinate systems were used for the analytical model in SAP2000: a local and a global coordinate system. Table 2 shows the link elements' sign convention for the local and global coordinate system. The origin of the global coordinate system is 12 inches below the base of the panel along grid line B, as shown in Figure 4. For the global coordinate system, the global X direction is parallel to the plane of the panel along its length, the global $\mathrm{Y}$ direction is perpendicular to the plane of panel, and the global $\mathrm{Z}$ is the vertical dimension. 
Table 2

Sign Convention for Model Developed in SAP2000

\begin{tabular}{|c|c|c|c|c|}
\hline System & Origin & \multicolumn{2}{|c|}{ Orientation of Axis } & $\begin{array}{l}\text { Positive Direction of Local } \\
\text { Axis With Respect to }\end{array}$ \\
\hline \multirow[t]{3}{*}{ Global } & 12 " below & $\mathrm{X}$ & Length of panel & \multirow{3}{*}{ N/A } \\
\hline & & $\mathrm{Y}$ & Thickness of panel & \\
\hline & & $\mathrm{Z}$ & Vertical & \\
\hline \multirow[t]{3}{*}{ Local } & \multirow{3}{*}{$\begin{array}{l}1^{\text {st }} \text { Joint of } \\
\text { each Link } \\
\text { element } \\
\text { starting from } \\
\text { structural } \\
\text { frame }\end{array}$} & $\mathrm{U} 1$ & $\begin{array}{l}\text { Out-of-Plane } \\
\text { Horizontal }\end{array}$ & $-\mathrm{Y}$ \\
\hline & & $\mathrm{U} 2$ & Vertical & $+\mathrm{Z}$ \\
\hline & & U3 & In-Plane Horizontal & $-X$ \\
\hline
\end{tabular}

A standardized definition for local coordinates of panel connections has been developed (Chueng, 2010). To be consistent with this definition, the local coordinate system for the link element (which connects the precast concrete panel to the structural frame) was defined according to the first node defining the link element at the structural frame. Figure 4 shows a typical link element representing a flexing rod connection in the local coordinate system. The local U1 axis is parallel to the length of the link element with the positive direction pointing toward the exterior of the building; hence, the positive direction of the local $\mathrm{U} 1$ axis is in the negative $\mathrm{Y}$ direction. The local $\mathrm{U} 2$ axis is in the vertical direction pointing up and therefore is in the positive $\mathrm{Z}$ direction, and the local $\mathrm{U} 3$ is the vector product of $\mathrm{U} 1$ and $\mathrm{U} 2$ and therefore is in the negative $\mathrm{X}$ direction. 


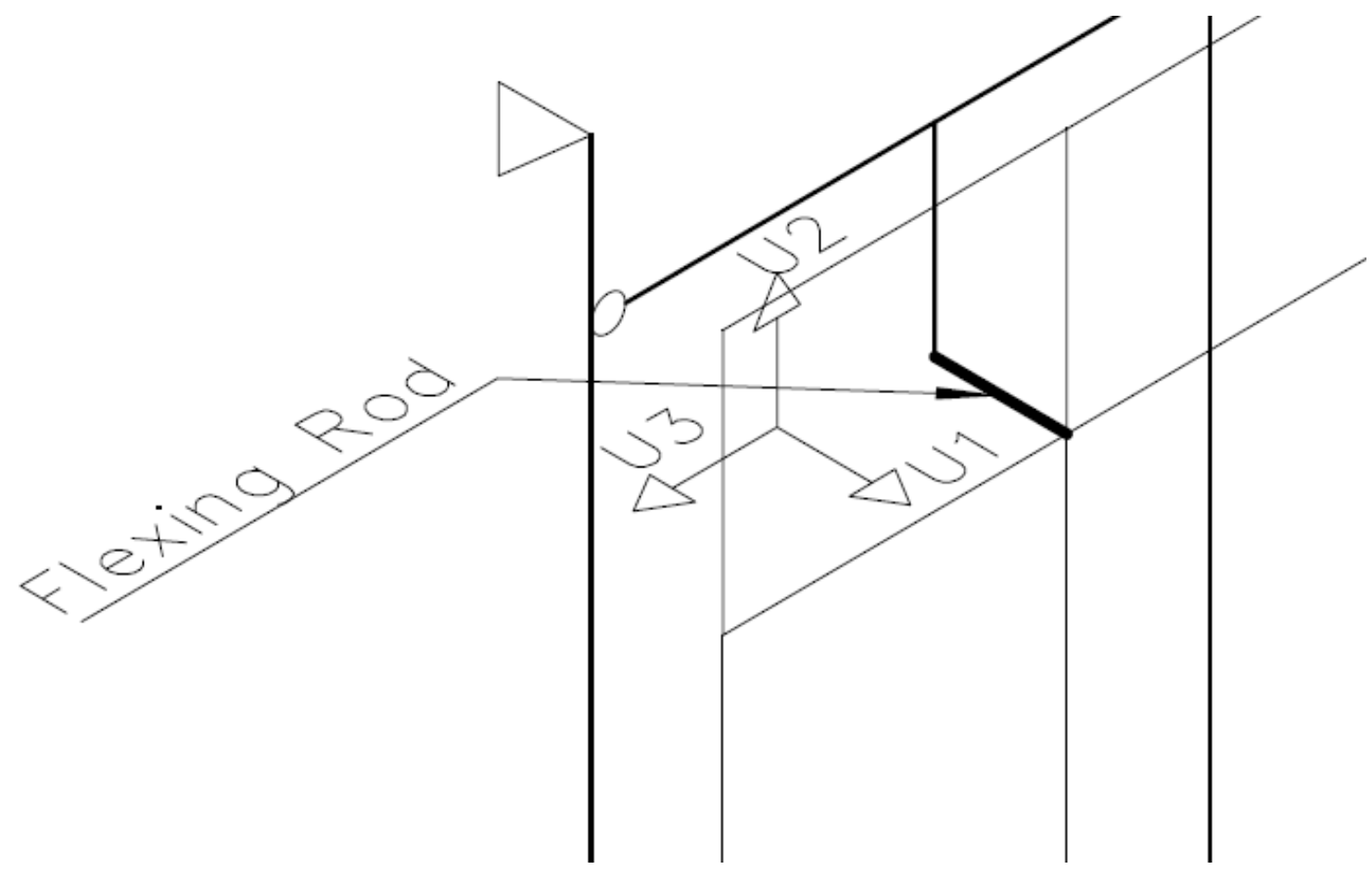

Figure 4. Local axes sign convention for link.

3.2.2 Precast concrete panel. Twenty thin shell elements were used to model the precast concrete panel with an assigned thickness of 5 inches and a compressive strength of $4 \mathrm{ksi}$. The concrete is assumed uncracked with a unit weight of $150 \mathrm{lb} / \mathrm{ft}^{3}$. Figure 5 shows the spatial arrangement of the shell elements. The aspect ratio of the shell elements ranged from 1.3 to 3 . 


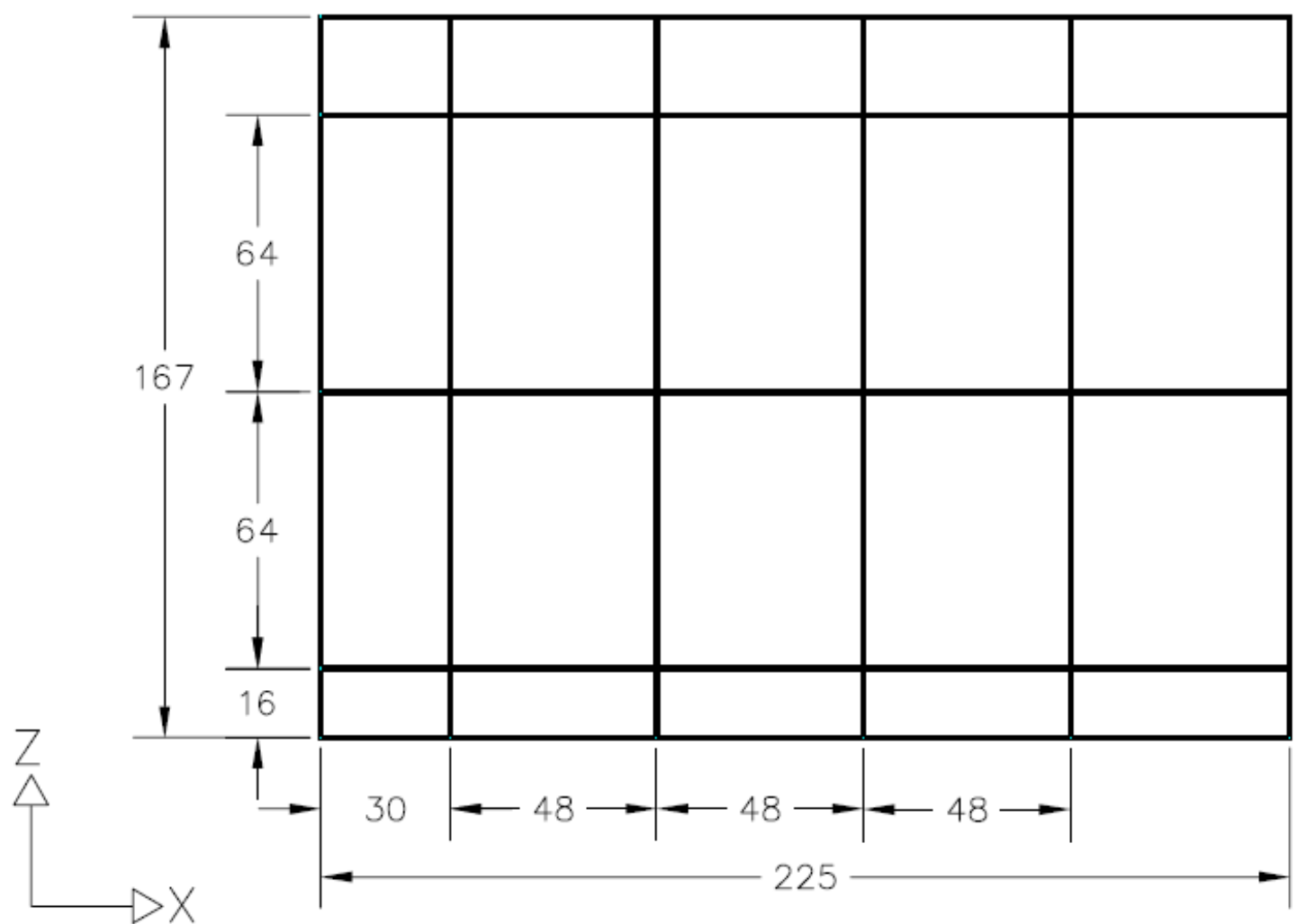

Figure 5. Precast concrete panel layout (all dimensions are presented in inches).

3.2.3 Structural frame. The structural frame, which supported the concrete panel, was modeled using rigid beam elements. Two extra inner columns were provided in the analytical model to increase vertical strength of the structural frame, as shown in Figure 6. All beam-column connections in the structural frame were modeled as fixed for torsion in the $\mathrm{M}_{11}$ direction of beam elements ( $\mathrm{M}_{\mathrm{XX}}$ in the global coordinate system), fixed for out-of-plane rotation in the $\mathrm{M}_{22}$ direction of beam elements $\left(\mathrm{M}_{\mathrm{ZZ}}\right.$ in the global coordinate system), and released for in-plane rotation in the $\mathrm{M}_{33}$ direction of beam elements ( $\mathrm{M}_{\mathrm{YY}}$ in the global coordinate system) in SAP2000. Therefore, beam-column connections of the structural frame are assumed to be pin connections for in-plane 
bending, thus providing the desired articulation of the frame. The goal of making an articulated frame was to have an analytical model where only the link elements and precast concrete panel provide resistance to in-plane loading. Short cantilevered beam elements (link supports) extend vertically from the frame beams at the location of link elements, as shown in Figures 6 and 7. These cantilevered elements are rigidly connected to their supporting beam to resist translation and moment in all directions.

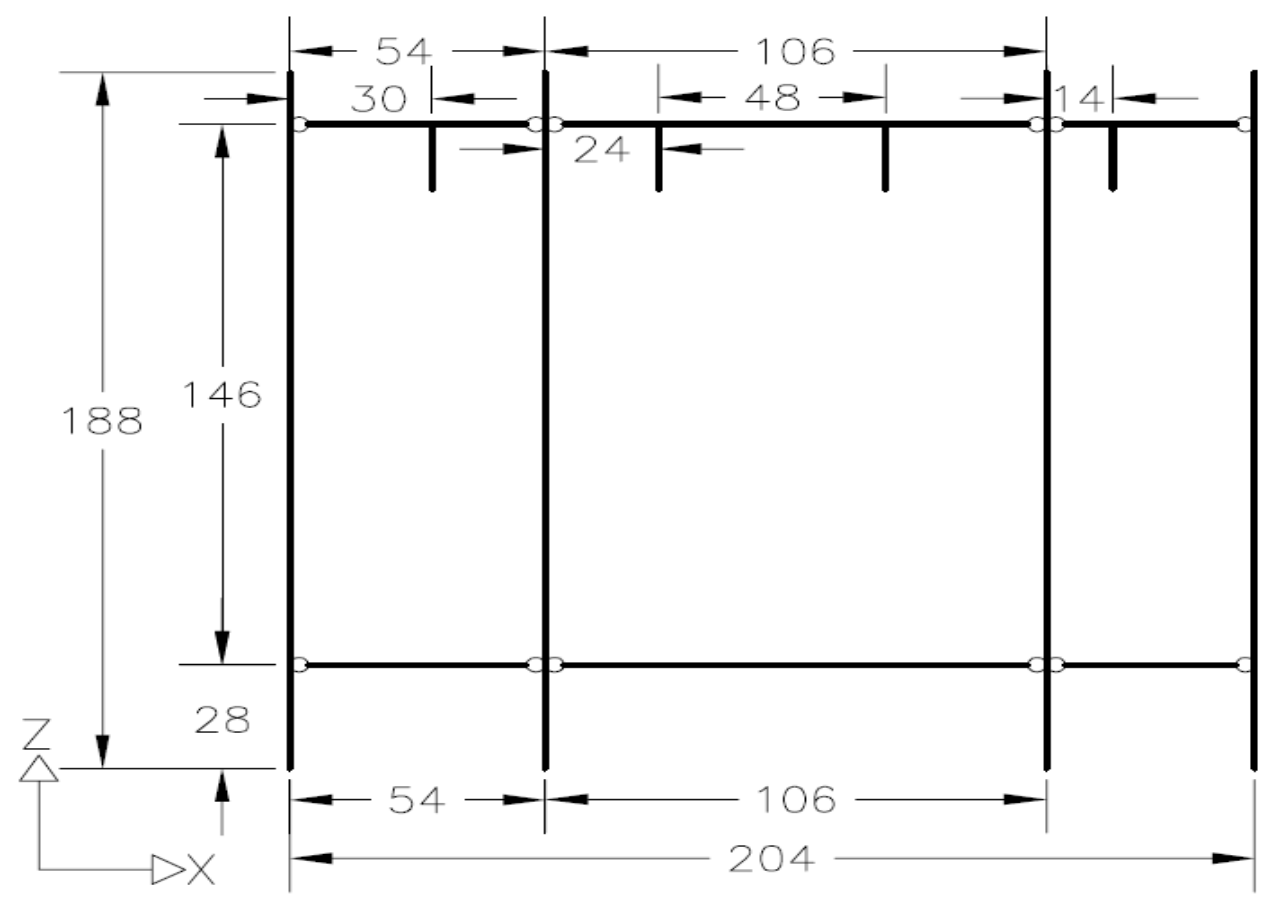

Figure 6. Structural frame layout (all dimensions in inches). 


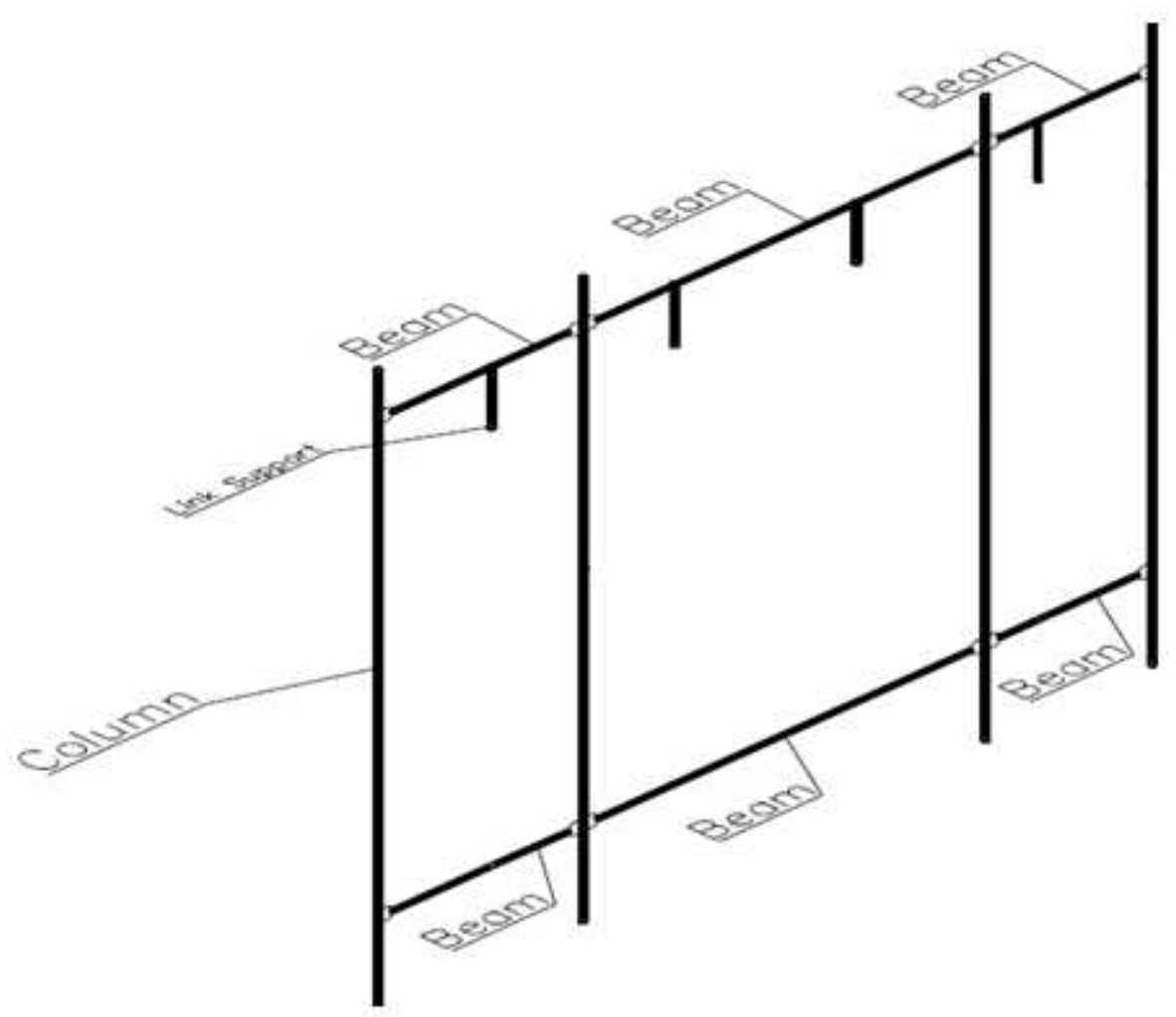

Figure 7. Elements of the structural frame analytical model.

All shell and beam elements were modeled as normal weight concrete with the modulus of the elasticity of $3600 \mathrm{ksi}$. Tables 3 and 4 list the material properties and dimensions of the structural frame. All columns were reinforced by eight no. 9 bars, beams were reinforced by eight no. 8 bars, and link supports were reinforced by eight no. 9 bars. For shear reinforcement, no. 4 bars were used. 
Table 3

Support Frame and Precast Concrete Panel Material

\begin{tabular}{ccccc}
\hline Material & Type & $\begin{array}{c}\text { Compressive } \\
\text { Yield Strength } \\
(\mathrm{ksi})\end{array}$ & $\begin{array}{c}\text { Weight per } \\
\text { Unit Volume } \\
\left(\mathrm{lb} / \mathrm{ft}^{3}\right)\end{array}$ & $\begin{array}{c}\text { Modulus of } \\
\text { Elasticity (ksi) }\end{array}$ \\
\hline Concrete & $\begin{array}{c}\text { Normal } \\
\text { Weight } \\
\text { Concrete }\end{array}$ & $\mathrm{f}_{\mathrm{c}}{ }^{\prime}=4$ & 150 & $\mathrm{E}=3600$ \\
$\begin{array}{c}\text { Reinforcing } \\
\text { Steel }\end{array}$ & A615Gr60 & $\mathrm{F}_{\mathrm{y}}=60$ & 490 & $\mathrm{E}=29000$ \\
\hline
\end{tabular}

Table 4

Beam, Column, and Link Support Dimensions

\begin{tabular}{cclc}
\hline Member & $\begin{array}{c}\text { Dimensions of Cross } \\
\text { Section (in. } \times \text { in.) }\end{array}$ & Material & $\begin{array}{c}\text { Longitudinal } \\
\text { Reinforcement }\end{array}$ \\
\hline Beam & $14 \times 28$ & Concrete & $8-\# 8$ \\
Column & $18 \times 28$ & Concrete & $8-\# 9$ \\
Link support & $10 \times 10$ & Concrete & $8-\# 9$ \\
\hline
\end{tabular}

Vertical loads on the structural frame were supported by pin reactions provided at the base of each column. These pin supports are restrained from translation in all directions (X, Y, and $\mathrm{Z}$ ) but are free to rotate about the $\mathrm{X}, \mathrm{Y}$, and $\mathrm{Z}$ axes. All columns are restrained from out-of-plane (Y direction) translation at the top of the structural frame.

3.2.4 Nonlinear link element. In the model, the precast concrete panel was connected to the structural frame using two different types of connections: flexing rod 
connections and bearing connections. Three different link elements were used to model the link elements: Type 1, Type 2, and Type 3. Table 5 shows the connection type and corresponding force-displacement relationship of each link element. Table 6 shows the global position and location on the panel from a front view for each link element. The starting node of each link is at the structural frame, and the end node connects to the panel. The force-deformation relationship obtained from experimental tests was used along the local U2 and U3 direction for Links 1, 2, 3, and 4, based on Table 5.

Table 5

Connection Type and Force-Deformation Relationship for Connections

\begin{tabular}{|c|c|c|c|}
\hline $\begin{array}{c}\text { Connection } \\
\text { Type }\end{array}$ & $\begin{array}{l}\text { Connection } \\
\text { Name }\end{array}$ & Local Coordinate & $\begin{array}{c}\text { Force- } \\
\text { Deformation } \\
\text { Relationship }\end{array}$ \\
\hline \multirow{3}{*}{ Type 1} & \multirow{3}{*}{ Flexing rod connection } & U1 & Pin \\
\hline & & U2 & Figure 8 \\
\hline & & U3 & Figure 8 \\
\hline \multirow{3}{*}{ Type 2} & \multirow{3}{*}{ Bearing connection 1} & $\mathrm{U} 1$ & Pin \\
\hline & & $\mathrm{U} 2$ & Pin \\
\hline & & U3 & Pin \\
\hline \multirow{3}{*}{ Type 3} & \multirow{3}{*}{ Bearing connection 2} & $\mathrm{U} 1$ & Pin \\
\hline & & $\mathrm{U} 2$ & Pin \\
\hline & & U3 & Pin \\
\hline
\end{tabular}


Table 6

SAP2000 Input Parameters and Location of Link Elements

\begin{tabular}{|c|c|c|c|c|c|}
\hline \multirow[b]{2}{*}{$\begin{array}{l}\text { Location in } \\
\text { Panel }\end{array}$} & \multirow[b]{2}{*}{$\begin{array}{c}\text { SAP2000 } \\
\text { Link Element }\end{array}$} & \multirow[b]{2}{*}{$\begin{array}{l}\text { Connection } \\
\text { Type }\end{array}$} & \multicolumn{3}{|c|}{$\begin{array}{l}\text { Global Coordinates of i-Node } \\
\text { (inches) }\end{array}$} \\
\hline & & & $\mathrm{X}$ & $\mathrm{Y}$ & $\mathrm{Z}$ \\
\hline $\begin{array}{l}\text { Top Left } \\
\text { Exterior }\end{array}$ & Link 1 & Type 1 & 30 & 11.5 & 156.5 \\
\hline $\begin{array}{l}\text { Top Left } \\
\text { Interior }\end{array}$ & Link 2 & Type 1 & 78 & 11.5 & 156.5 \\
\hline $\begin{array}{l}\text { Top Right } \\
\text { Interior }\end{array}$ & Link 3 & Type 1 & 126 & 11.5 & 156.5 \\
\hline $\begin{array}{l}\text { Top Right } \\
\text { Exterior }\end{array}$ & Link 4 & Type 1 & 174 & 11.5 & 156.5 \\
\hline Bottom Left & Link 5 & Type 2 & 30 & 11.5 & 28 \\
\hline $\begin{array}{c}\text { Bottom } \\
\text { Right }\end{array}$ & Link 6 & Type 3 & 174 & 11.5 & 28 \\
\hline
\end{tabular}

Table 7 shows the placement of the flexing rod for two analytical models. For each rod listed, the first number represents the length and the second number represents the diameter of each rod. Both analytical models had the same structural frame, bearing connections, and precast concrete panel. The only difference was between the top link elements. 
Table 7

Analytical Model Rod Placement

\begin{tabular}{cccccc}
\hline & & \multicolumn{3}{c}{ Top Link Elements (length in. $\times$ diameter in.) } \\
\cline { 3 - 6 } $\begin{array}{c}\text { Model } \\
\text { No. }\end{array}$ & $\begin{array}{c}\text { Model } \\
\text { ID }\end{array}$ & $\begin{array}{c}\text { Exterior Left } \\
(\text { Link 1) }\end{array}$ & $\begin{array}{c}\text { Interior Left } \\
(\text { Link 2) }\end{array}$ & $\begin{array}{c}\text { Interior Right } \\
(\text { Link 3) }\end{array}$ & $\begin{array}{c}\text { Exterior Right } \\
(\text { Link 4) }\end{array}$ \\
\hline Model 1 & MD1 & $16 \times 3 / 4$ & $12 \times 3 / 4$ & $12 \times 3 / 4$ & $16 \times 3 / 4$ \\
Model 2 & MD2 & $16 \times 1$ & $12 \times 3 / 4$ & $12 \times 3 / 4$ & $16 \times 1$ \\
\hline
\end{tabular}

3.2.4.1 Flexing rod elements. For analytical modeling, the flexing rod connections were modeled as nonlinear links, defined as multilinear plastic elements with kinematic hysteretic behavior. To quantify the force and displacement of a rod due to bending, experiments of flexing rod connection were conducted at San José State University in December 2011. However, the results of the experiment could not be directly inputted to the element in SAP2000 because the program cannot accept two inputs with different $\mathbf{y}$ values and same $\mathbf{x}$ values. Therefore, the revised forcedisplacement graph for the three different experimental specimens used for modeling with SAP2000 were used, as shown in Figure 8. 


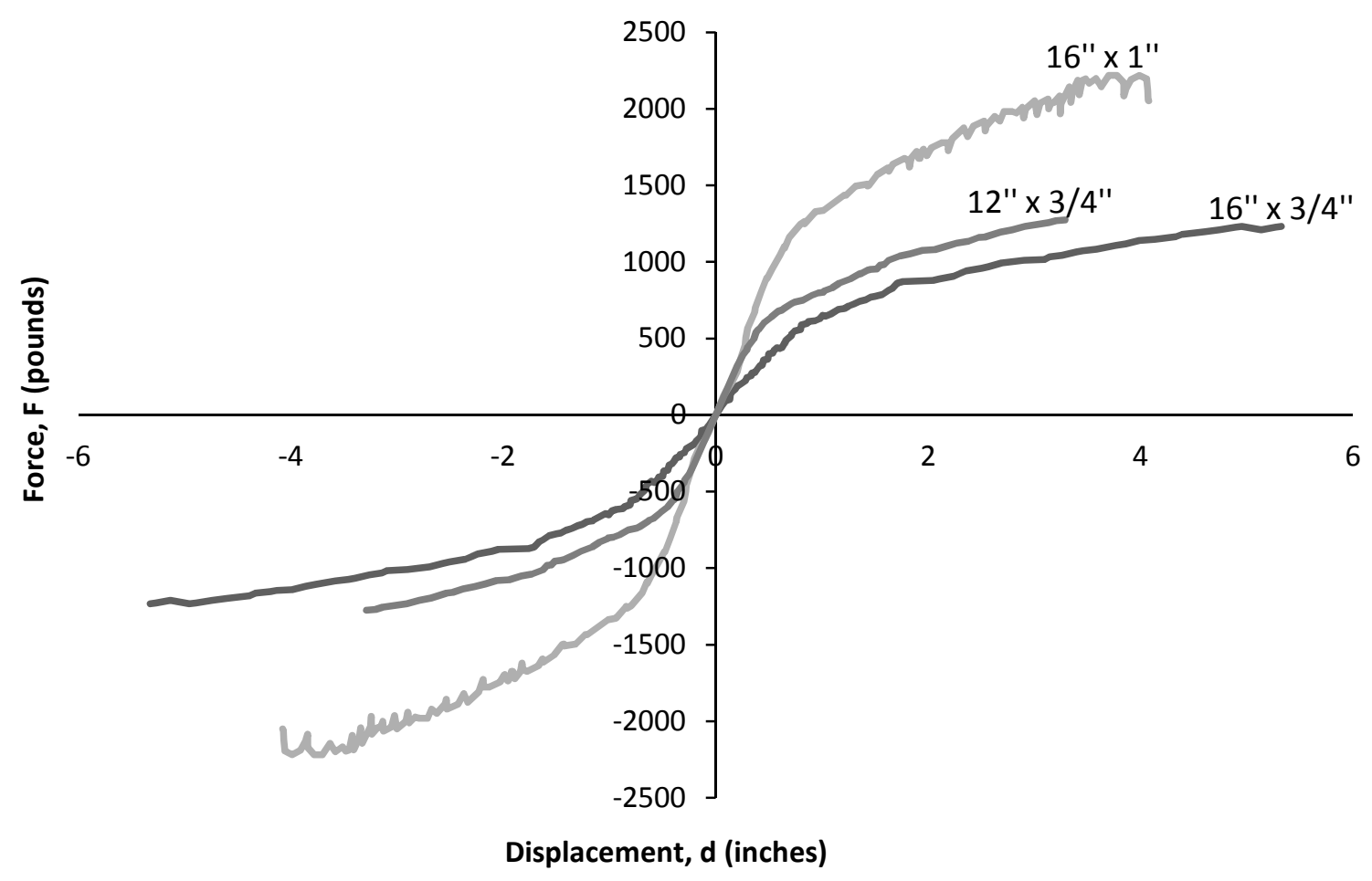

Figure 8. Force-deformation graphs input for flexing rods.

3.2.4.2 Bearing connection. Two bearing connections were included in the model. Both bearing connections were considered pin connections, implying that the connection resists movement in all three directions. The primary role of the connections was to support the vertical gravity load of the panel while also providing in-plane and out-of-plane resistance for gravity, wind, and seismic loads. These connections were assumed not to provide rotational resistance about any axis.

For the analytical model, Link 5 was assigned as a linear link element with a stiffness of 10,000 kip/in all three translational directions to simulate the high level of stiffness that the connection provides. Link 6 was assigned as a linear element with a stiffness of 10,000 kip/in for both U1 and U2 (Y and Z directions) and a linear stiffness 
of 1,000 kip/in for U3 (X direction) to prevent the analytical model from artificially stiffening the structure due to second-order effects along the direction of the bottom connections.

\subsection{Loading Protocol}

The two analytical models were used to analyze three different load cases: static dead load analysis, static nonlinear pushover analysis, and displacement-controlled time history analysis.

3.3.1 Static dead load. The dead load of the model consists of the self-weight of all members, including beams, link supports, panel, and columns of the structural frame. The software calculates the self-weight based on the defined density of materials as presented in Table 3 and the volume of the members.

3.3.2 Static pushover load. A nonlinear, inelastic, monotonic, displacementcontrolled pushover analysis was conducted by applying a displacement in the $\mathrm{X}$ direction at midspan of the upper beam (node No. 39) in the structural frame, as shown in Figure 9. 


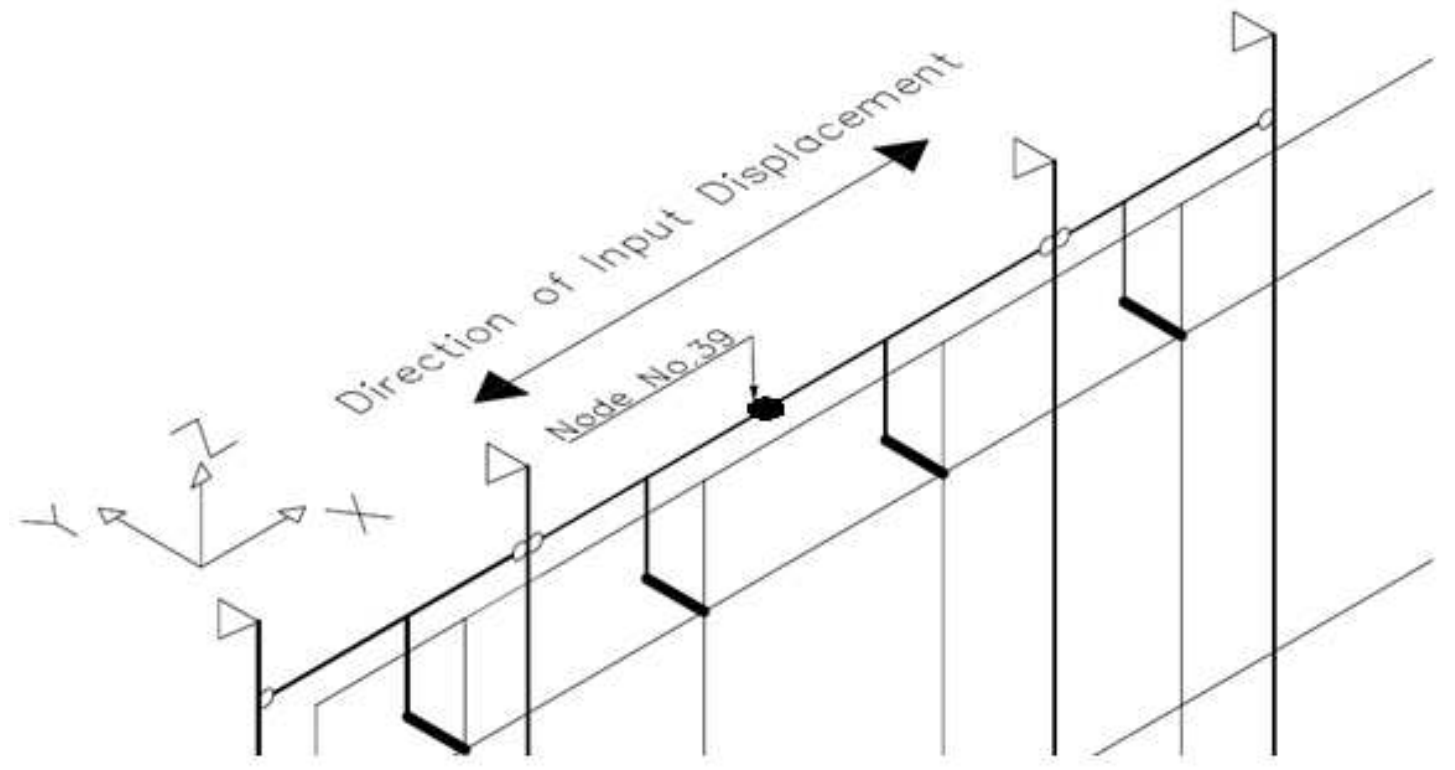

Figure 9. Point of input for displacement-controlled time history analysis and pushover analysis.

Two pushover analyses were conducted on each model. The first analysis was conducted with a maximum monotonic displacement of 3.2 inches in the positive $\mathrm{X}$ direction (P1). The second analysis for the negative direction used a displacement of 3.2 inches in the negative $\mathrm{X}$ direction (P2). An incremental increase of a 0.032-inch displacement was used for both analyses for a total of 100 steps to reach the peak displacement. Figure 10 shows input displacement for the pushover analysis, and Table 8 shows the summary of the static pushover loads. Both pushover load cases started from the deformed state after completion of the dead load analysis. 


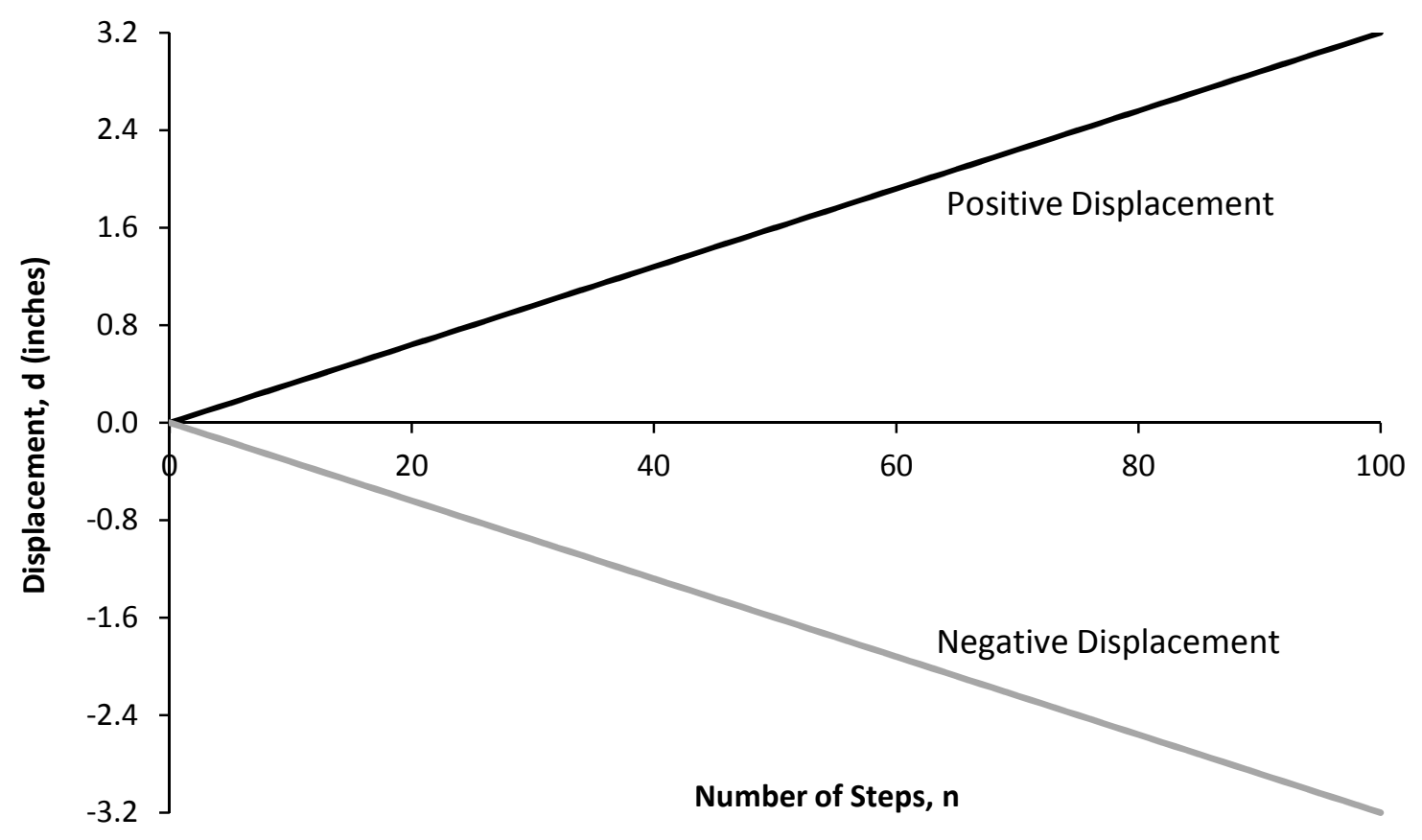

Figure 10. Protocol for control displacement for static pushover analysis.

Table 8

Pushover Load Cases Summary

\begin{tabular}{cccc}
\hline Pushover Load ID & $\begin{array}{c}\text { Direction of } \\
\text { Displacement }\end{array}$ & $\begin{array}{c}\text { Number of Steps to } \\
\text { Reach Peak Value }\end{array}$ & $\begin{array}{c}\text { Peak Value } \\
\text { (inches) }\end{array}$ \\
\hline P1 & Positive X Direction & 100 & 3.2 \\
P2 & Negative X Direction & 100 & -3.2 \\
\hline
\end{tabular}

3.3.3 Displacement-controlled time history load. A total of three displacementcontrolled time history analyses were completed for each model. A static load case with a magnitude of $1 \mathrm{kip}$ in the positive $\mathrm{X}$ direction was assigned to node No. 39, which is located at midspan of the upper beam of the structural frame, as shown in Figure 10. A 
time history function for displacement was then defined. All displacement-controlled time history analyses started from the deformed state after completion of the dead load analysis.

Three one-cycle sine functions were used to define the control-displacement time history. All functions had a maximum amplitude of 3.2 inches. The three functions had different periods and duration of analysis, as shown in Table 9 and Figure 11.

Table 9

Sine Wave Function Periods and Duration of Analysis

\begin{tabular}{ccc}
\hline Function & Period, T (sec.) & Duration of Analysis, t (sec.) \\
\hline F 1 & 100 & 100 \\
F 2 & 1 & 1 \\
F 3 & 0.32 & 0.32 \\
\hline
\end{tabular}




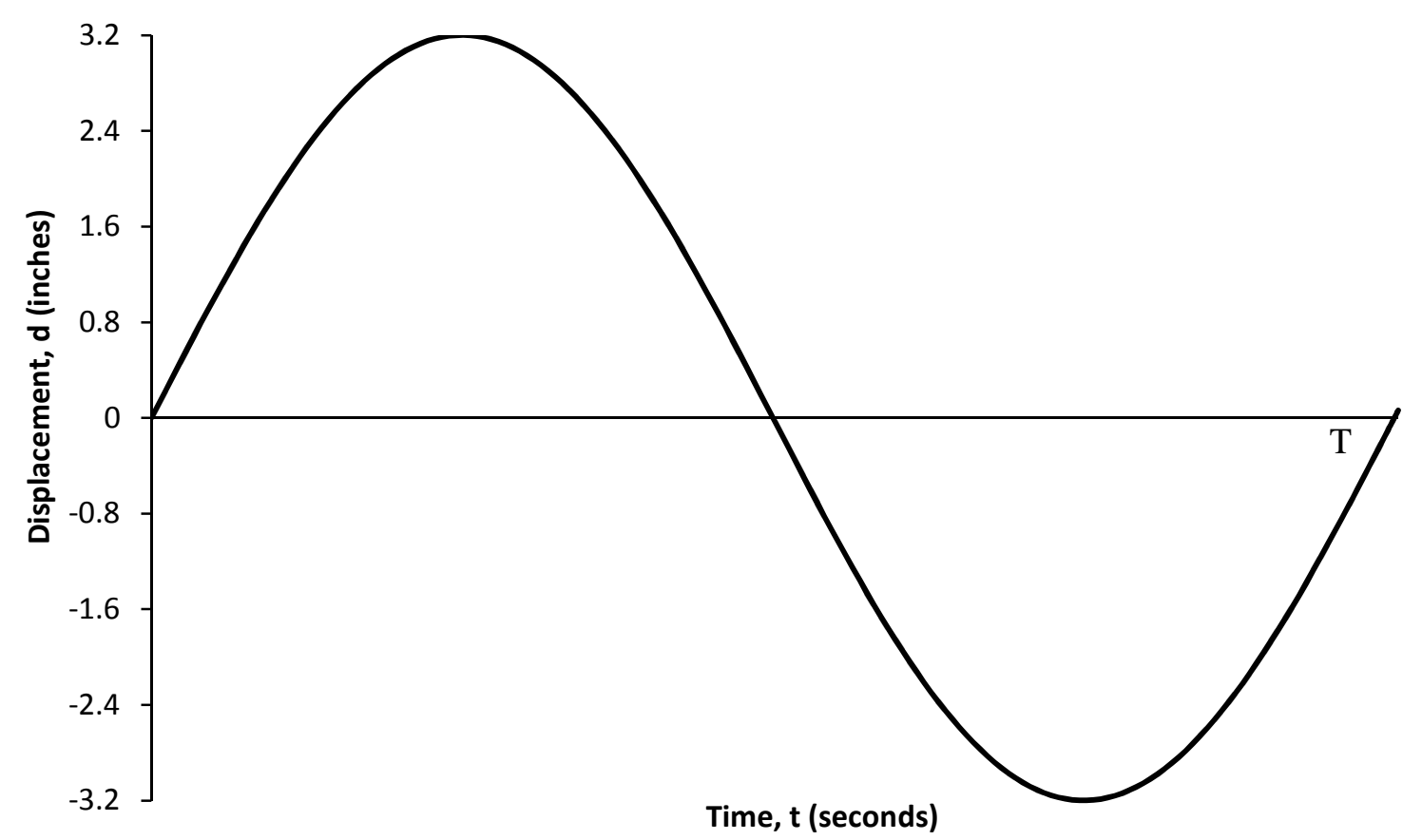

Figure 11. Sine wave function for analytical model.

The choice of the three periods for loading was made to capture specific dynamic behaviors of the system. The sine function for a period of $100 \mathrm{~s}$ was used to represent a slow displacement of the structural frame, thus developing very low accelerations of the model mass. This was done with the expectation that low acceleration could be compared with the static pushover analysis. The sine function for a period of $0.32 \mathrm{~s}$ was selected because this time period corresponds to the mode with the largest mass participation ratio of the model. The period of $1 \mathrm{~s}$ was selected to capture the dynamic corresponding with the fundamental period of vibration of a midrise structure.

The two models were developed to carry out dead load analysis, pushover analysis, modal analysis, and displacement-controlled time history analysis. The results of each analysis are shown in Table 10. 
Table 10

Thesis Section for Load Case Result of Each Model

\begin{tabular}{ccccc}
\hline & \multicolumn{4}{c}{ Load Cases Results Sections } \\
\cline { 2 - 5 } Model ID & $\begin{array}{c}\text { Dead } \\
\text { Load }\end{array}$ & $\begin{array}{c}\text { Pushover } \\
\text { Loads }\end{array}$ & $\begin{array}{c}\text { Modal } \\
\text { Analysis }\end{array}$ & $\begin{array}{c}\text { Displacement-controlled } \\
\text { Time History Loads }\end{array}$ \\
\hline MD 1 & 4.2 & 4.3 .1 to 4.3 .5 & 5.1 & 5.2 \\
MD 2 & 4.2 & 4.3 .6 to 4.3 .10 & 5.1 & 5.3 \\
\hline
\end{tabular}




\section{Static Analysis Results}

\subsection{Overview of Analyses}

The static dead load analysis was conducted to evaluate the accuracy of both models. To determine the nonlinear force-deformation relationship of individual components of Models MD 1 and MD 2, pushover analyses were conducted.

\subsection{Verification of Models}

The static dead load analysis was conducted on both models. The accuracy of the two models of the precast concrete facade panel was then verified by comparing the sum of the models' vertical reaction of all link elements to a value manually calculated as the self-weight of the precast concrete panel. Table 11 shows the summary of verification for both models. For additional verification, analytical output showed deflection values on the order of 0.01inches, a small value as expected for both Models MD 1 and MD 2. Moreover, as expected, the larger flexing rod of Model MD 2 resists more gravity load than the smaller rod of Model MD 1. Figures 12 and 13 show the free body diagram of Models MD 1 and MD 2 for dead load analysis, respectively. Note that the panel geometry is slightly nonsymmetric about the vertical axis. The effect of this nonsymmetry can be seen in the distribution of forces in the $\mathrm{U} 3$ direction. 
Table 11

Forces Developed in the Vertical Direction in Both Models and Links

\begin{tabular}{cccccccccc}
\hline $\begin{array}{c}\text { Model } \\
\text { ID }\end{array}$ & Link 1 & Link 2 & Link 3 & Link 4 & Link 5 & Link 6 & $\begin{array}{c}\text { Link Force } \\
\text { Summation } \\
\text { in Vertical } \\
\text { Direction }\end{array}$ & $\begin{array}{c}\text { Weight of } \\
\text { the Panel } \\
\text { Manually } \\
\text { Calculated }\end{array}$ \\
\hline MD 1 & 8 & 1 & 1 & 10 & 6968 & 9344 & 16333 & 16333 \\
MD 2 & 16 & 1 & 1 & 17 & 6962 & 9335 & 16333 & 16333 \\
\hline
\end{tabular}

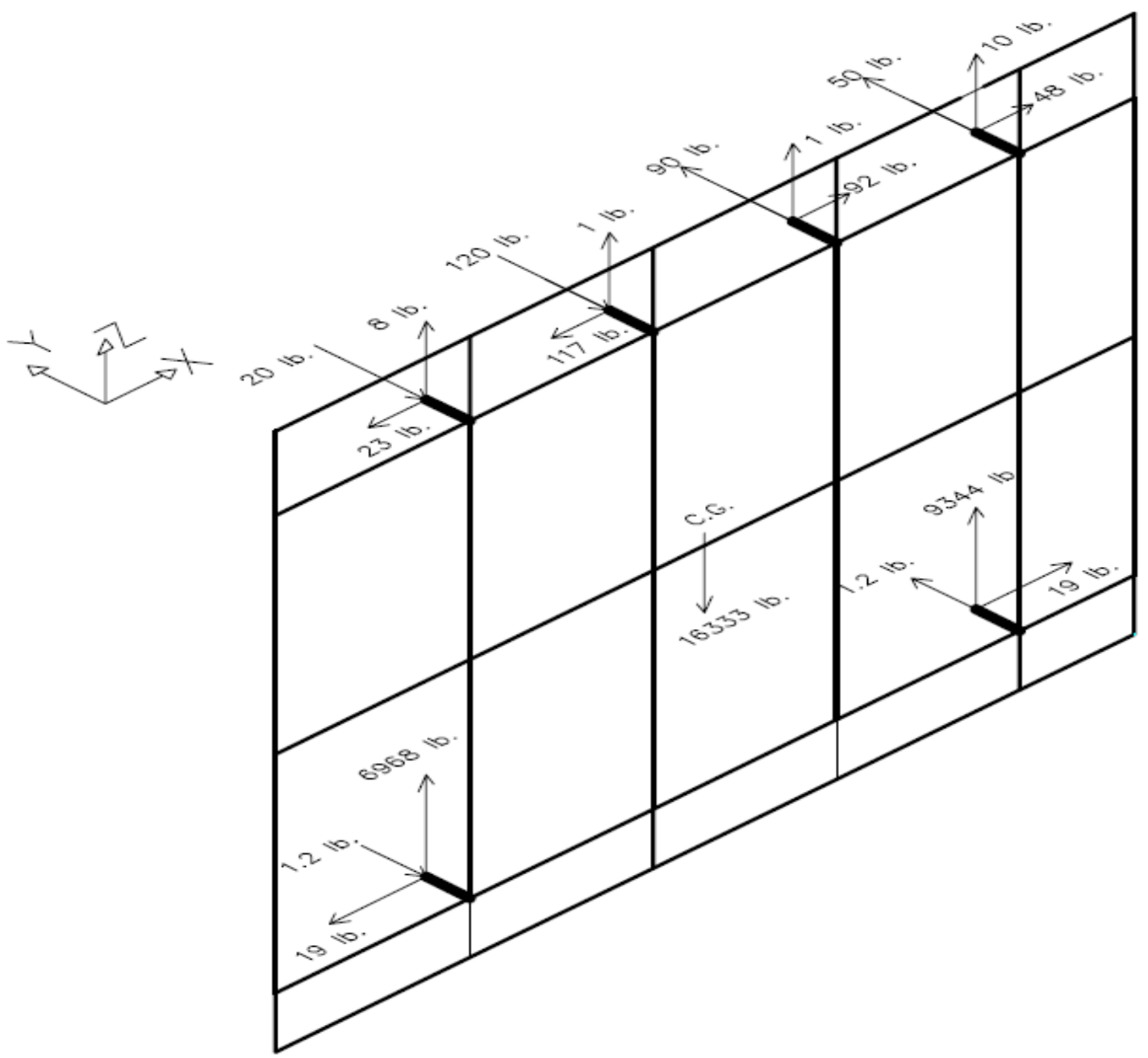

Figure 12. Free body diagram of the precast concrete panel and links for the dead load analysis for Model MD 1. 


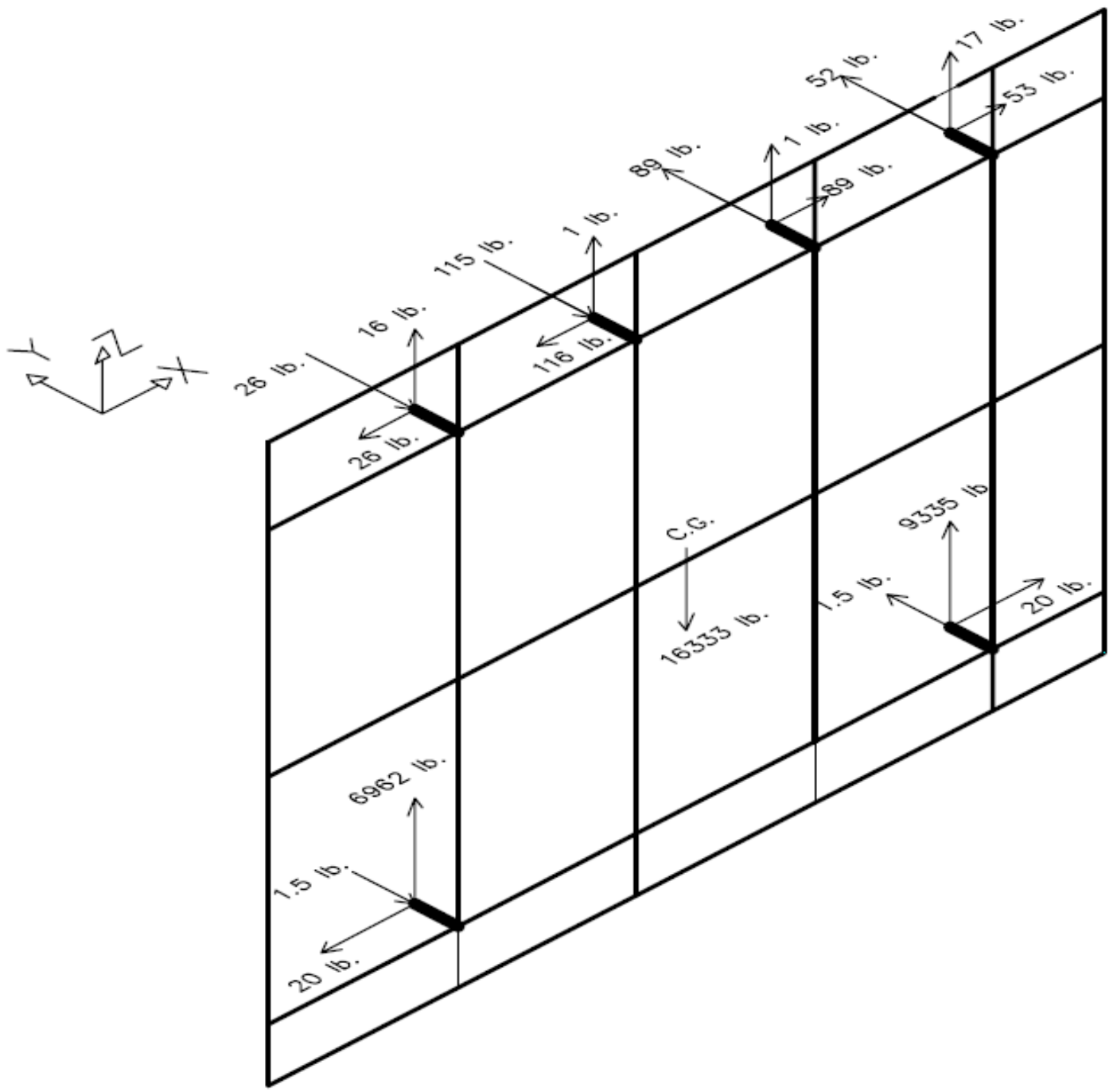

Figure 13. Free body diagram of the precast concrete panel and links for the dead load analysis for Model MD 2.

\subsection{Static Pushover Analysis}

The global force-deformation relationships for the in-plane direction (X direction) of the flexing rods are the primary interest of the analytical modeling. The out-of-plane and the vertical ( $\mathrm{Y}$ and $\mathrm{Z}$ direction) deformation for the flexing rods is significantly small for static pushover analyses of both Models MD 1 and MD 2; hence, these force- 
deformation relationships are not reported. The bearing connection force-deformation relations are presented for both the in-plane and the vertical directions. The out-of-plane direction deformations of the bearing connections were small, and therefore their forcedeformations are not discussed.

\subsubsection{Top links in-plane direction analysis result for Model MD 1. The}

pushover analysis of Model MD 1 was conducted. As the structural frame moves in the $\mathrm{X}$ direction, the precast concrete panel deforms in the same direction as the structural frame, but the displacements of the panel are about $15 \%$ of the structural frame displacement. Therefore, the panel is essentially undeformed. Meanwhile, the links actually deform in the opposite direction to accommodate the relative displacement between the two ends.

Figure 14 defines the global pushover curve for both the positive and negative displacement of the structural frame (loads P1 and P2). Figure 15 shows the relationship between the absolute value of the summation of the horizontal shear forces developed in the four flexing rod links and the absolute value of the control displacement of the structural frame. The behavior is essentially linear until the displacement nears a magnitude of 0.5 inches. As the control displacement exceeds the magnitude of 0.5 inches, the relationship remains linear but with a different slope. As shown in Figure 4.3, both positive and negatives curves lie on each other. 


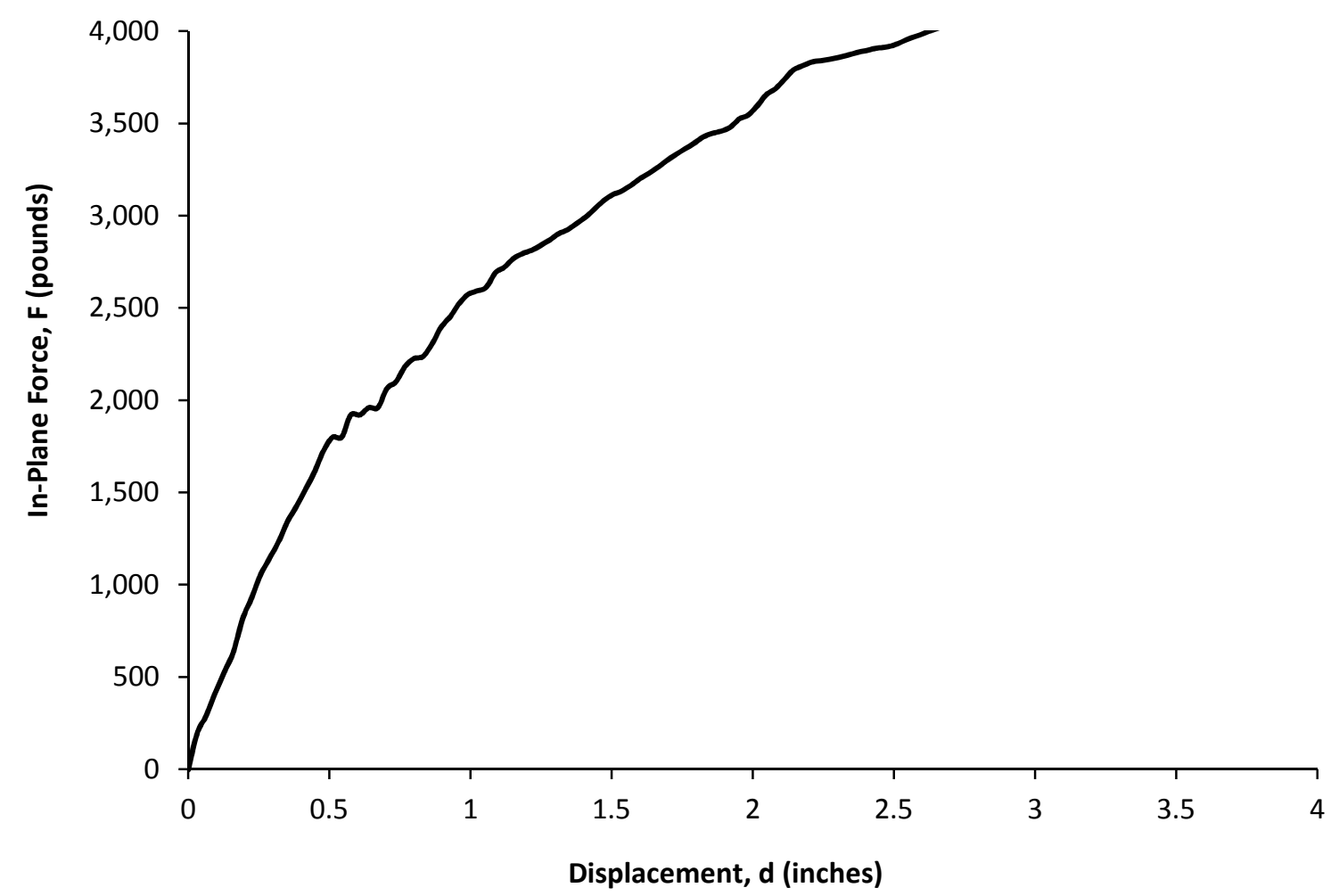

Figure 14. Total force developed in all flexing rod links for loading protocols P1 and P2.

Figure 15 shows the results for Link 1 and Link 4 for both the positive and negative global displacement of the structural frame. It shows the relationship between the force developed in the exterior flexing rod link in the $\mathrm{X}$ direction and the link displacement in the $\mathrm{X}$ direction as the structural frame moves. A linear relationship exists until the displacement nears a magnitude of $1 \mathrm{inch}$. As the control displacement exceeds the magnitude of 1 inch, the relationship remains linear but with a different slope. As shown, both the positive and negatives curves lie on each other. The force developed in the flexing rod link for the negative displacement of the structural frame was in the opposite direction but with the same magnitude of force developed in the link for the positive displacement of the structural frame. 


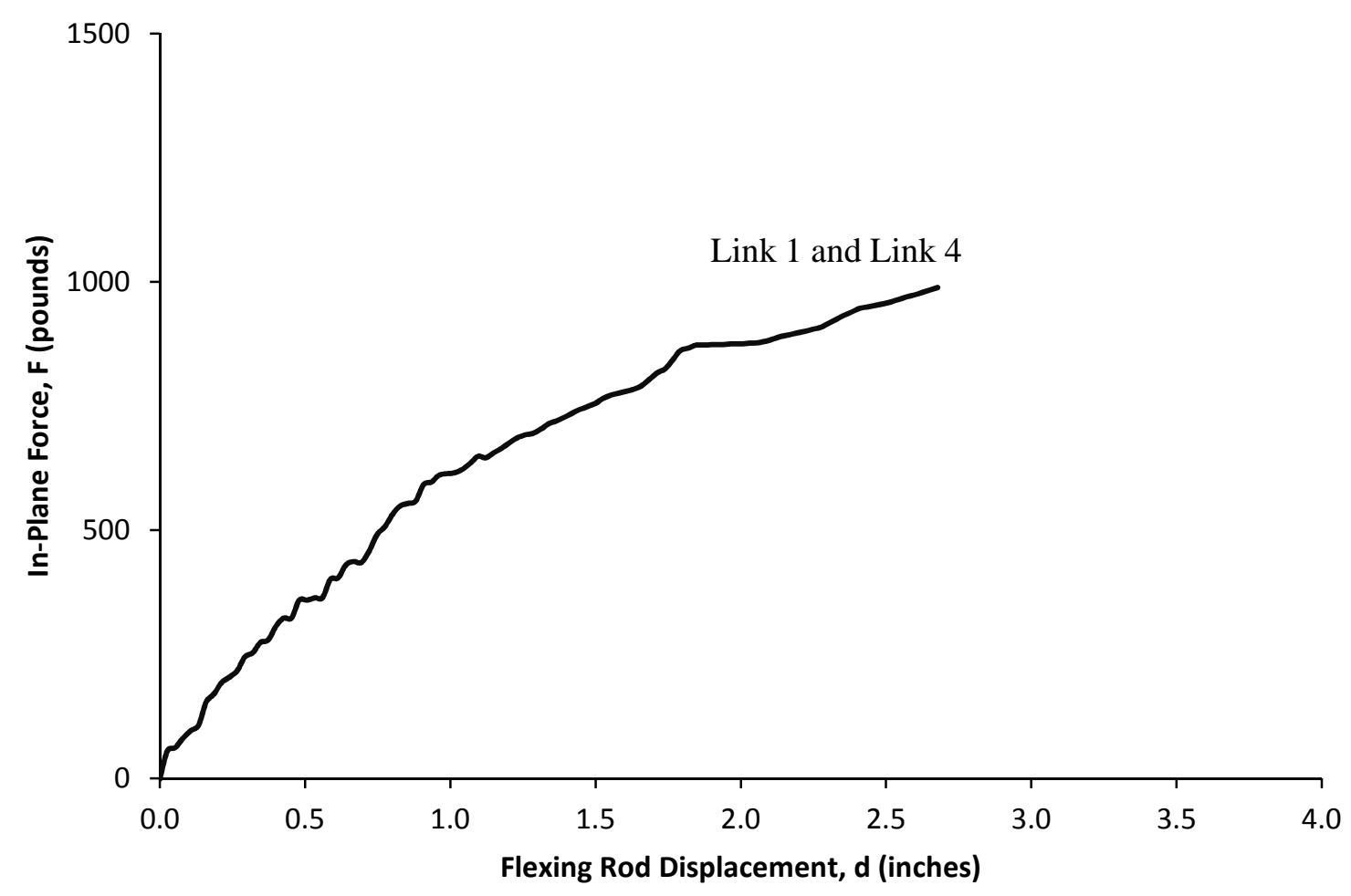

Figure 15. Force developed in the exterior flexing rod in the $\mathrm{X}$ direction versus the link displacement in the $\mathrm{X}$ direction for loading protocols $\mathrm{P} 1$ and $\mathrm{P} 2$.

Figure 16 shows the results for Link 2 and Link 3 for the both positive and negative global displacement of the structural frame. It shows the relationship between the force developed in the interior flexing rod link in the $\mathrm{X}$ direction and the link displacement in the $\mathrm{X}$ direction as the structural frame moves. A linear relationship exists until the displacement nears a magnitude of 0.5 inches. As the link displacement exceeds the magnitude of 0.5 inches, the relationship remains linear but with a different slope. As shown, both positive and negatives curves lie on each other. Similar to the previous graphs, the force developed in the flexing rod link for the negative displacement 
of the structural frame was in the opposite direction but with the same magnitude of force developed in the link for the positive displacement of the structural frame.

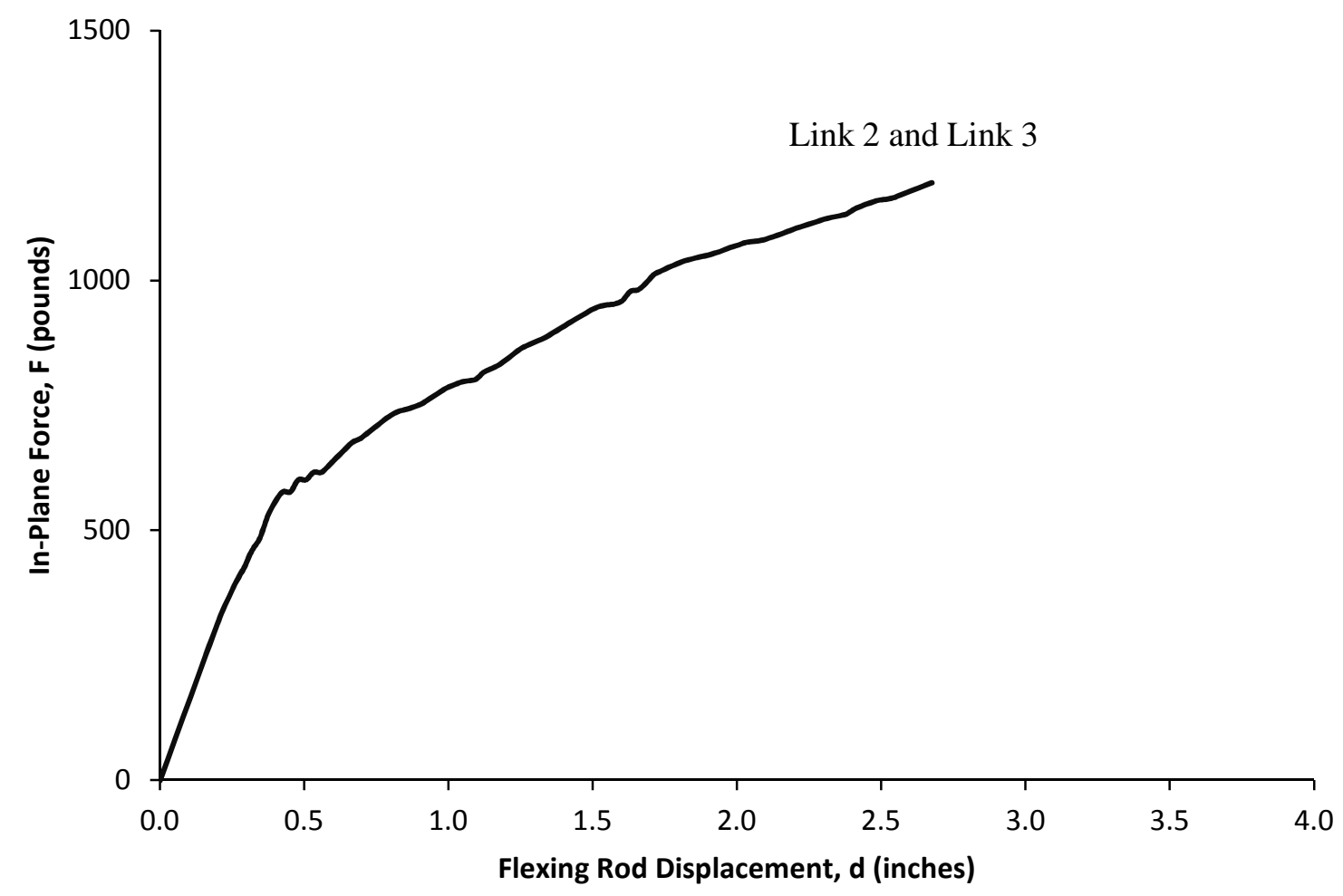

Figure 16. Force developed in the interior flexing rod in the $\mathrm{X}$ direction versus the link displacement in the X direction for loading protocols P1 and P2.

\subsubsection{Bottom links in-plane direction analysis result for Model MD 1. The}

bottom link graphs do not start from the origin because both Link 5 and Link 6 (left and right bottom links) carry part of the weight of the panel.

Figure 17 shows the results for Link 5 (left side, bottom link) for the positive global displacement of the structural frame. It shows the relationship between the force developed in the left bottom link in the $\mathrm{X}$ direction and the link displacement in the $\mathrm{X}$ direction as the structural frame moves. The graph does not start at the origin because 
Link 5 carries part of the weight of the precast concrete panel due to eccentricity. The relationship is linear throughout the loading, as shown in Figure 17.

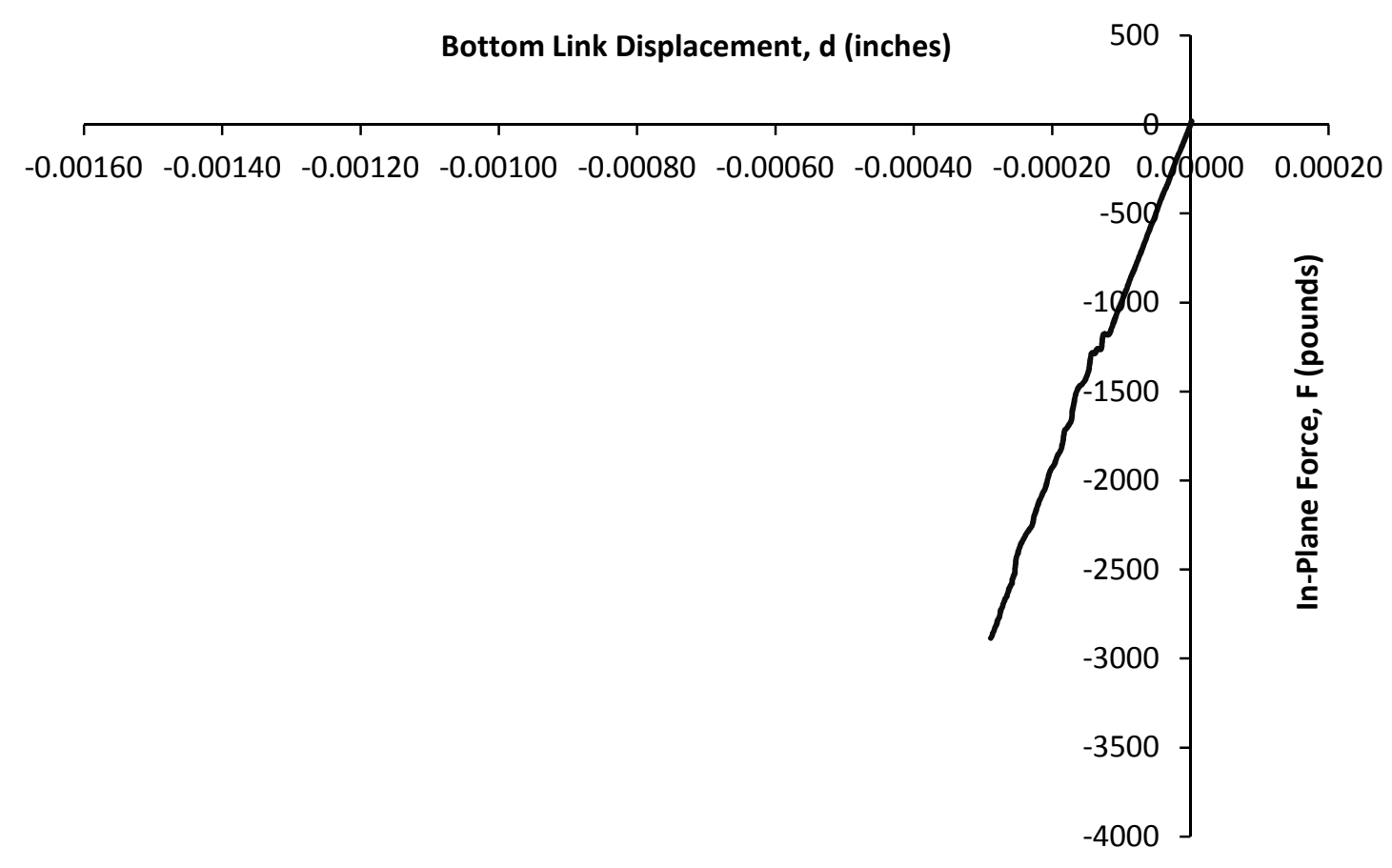

Figure 17. Force developed in Link 5 in the $\mathrm{X}$ direction versus the link displacement in the $\mathrm{X}$ direction for loading protocol $\mathrm{P} 1$.

A similar behavior was observed for the negative global displacement of the structural frame for the Link 5. The relationship is linear throughout the loading, as shown in Figure 18. 


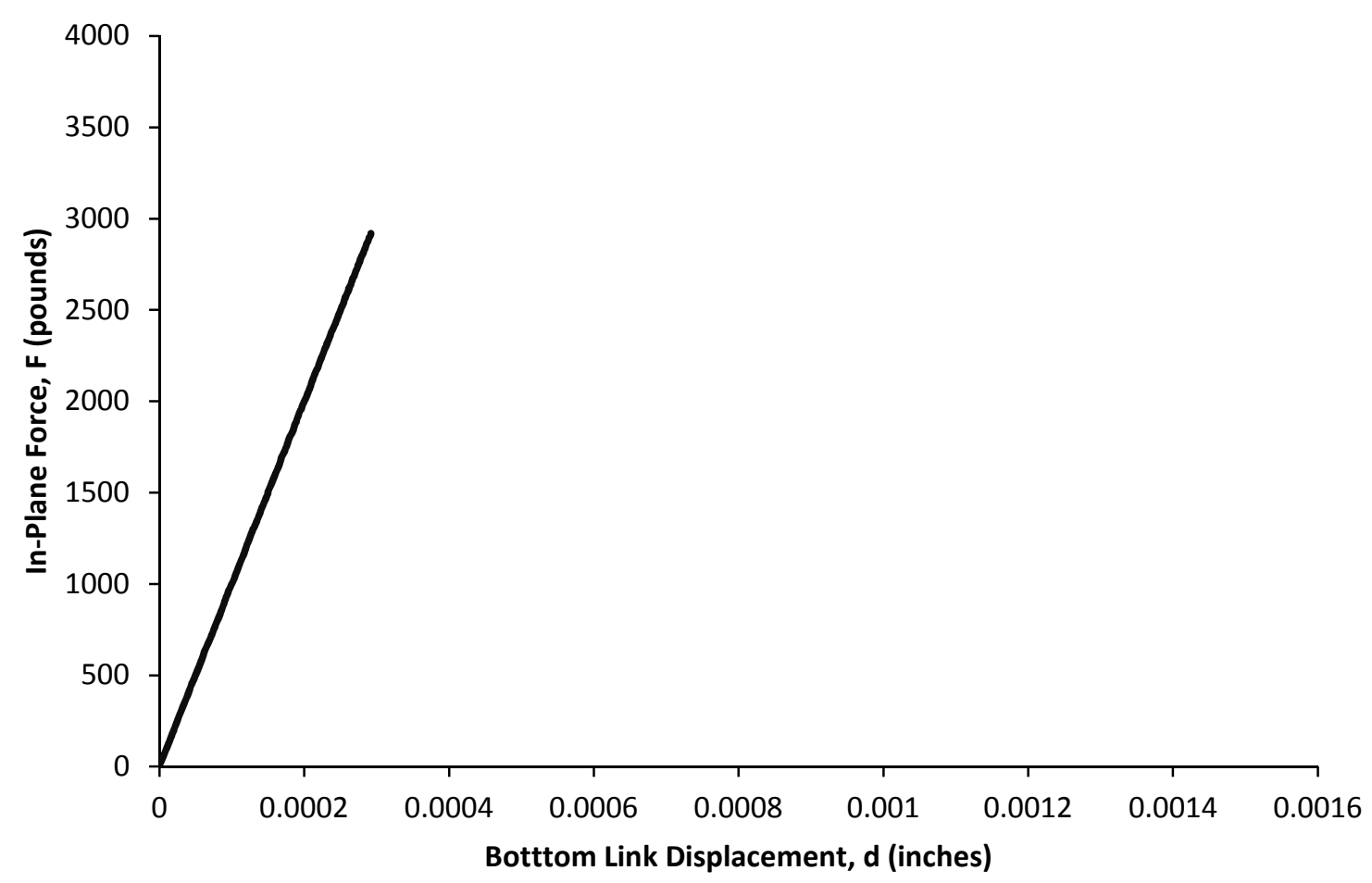

Figure 18. Force developed in Link 5 in the $\mathrm{X}$ direction versus the link displacement in the $\mathrm{X}$ direction for loading protocol $\mathrm{P} 2$.

Figure 19 shows the results for Link 6 (right side, bottom link) for the positive global displacement of the structural frame. It shows the relationship between the force developed in the right bottom link in the $\mathrm{X}$ direction and the link displacement in the $\mathrm{X}$ direction as the structural frame moves. The graph does not start at origin because Link 6 carries part of the weight of the precast concrete panel due to eccentricity. A linear relationship exists throughout the loading, as shown in the Figure 19. 


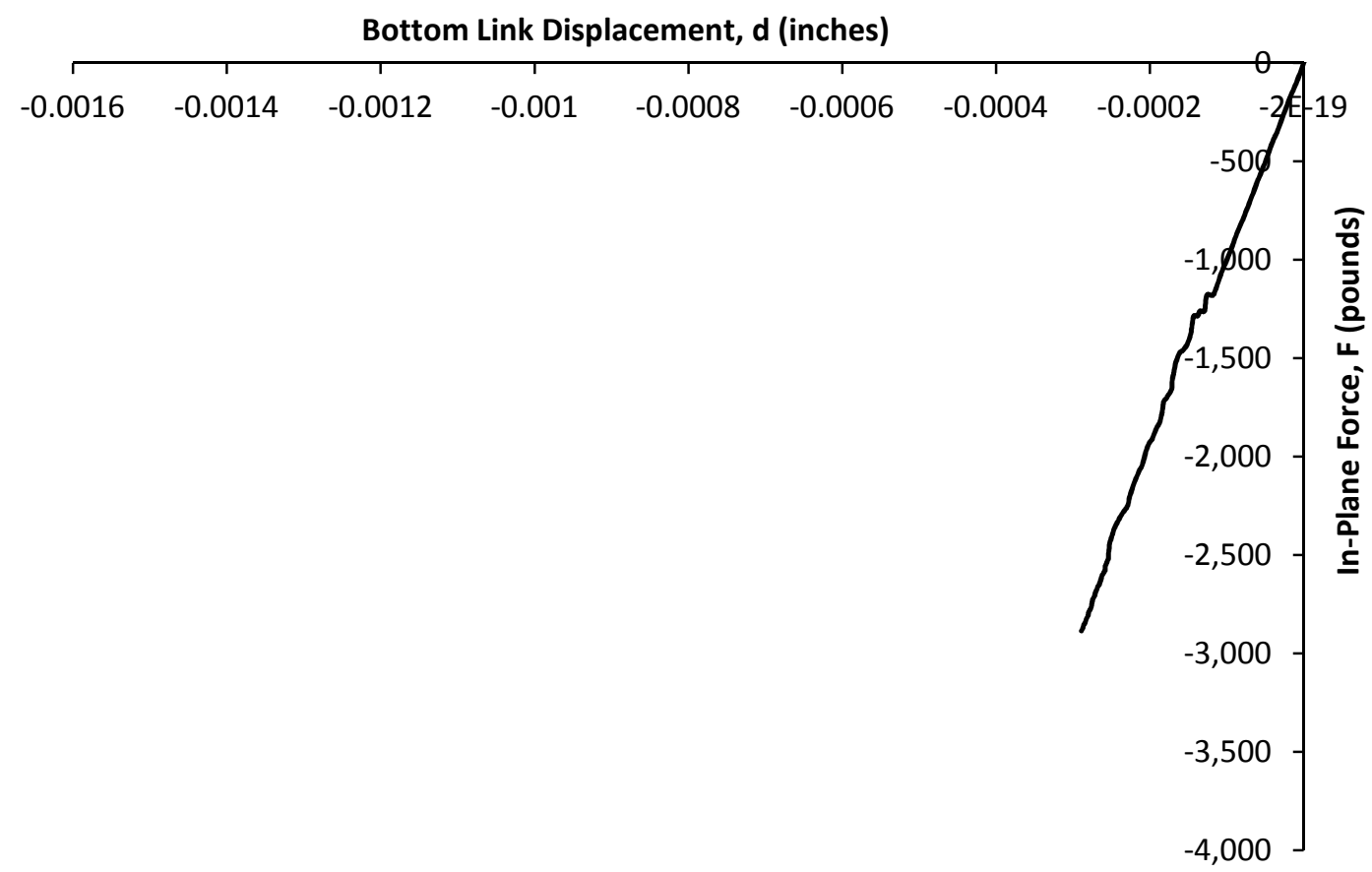

Figure 19. Force developed in Link 6 in the $\mathrm{X}$ direction versus the link displacement in the $\mathrm{X}$ direction for loading protocol $\mathrm{P} 1$.

Similar behavior was observed for the negative global displacement of the structural frame for the Link 6. The relationship is linear throughout the loading, as shown in Figure 20. 


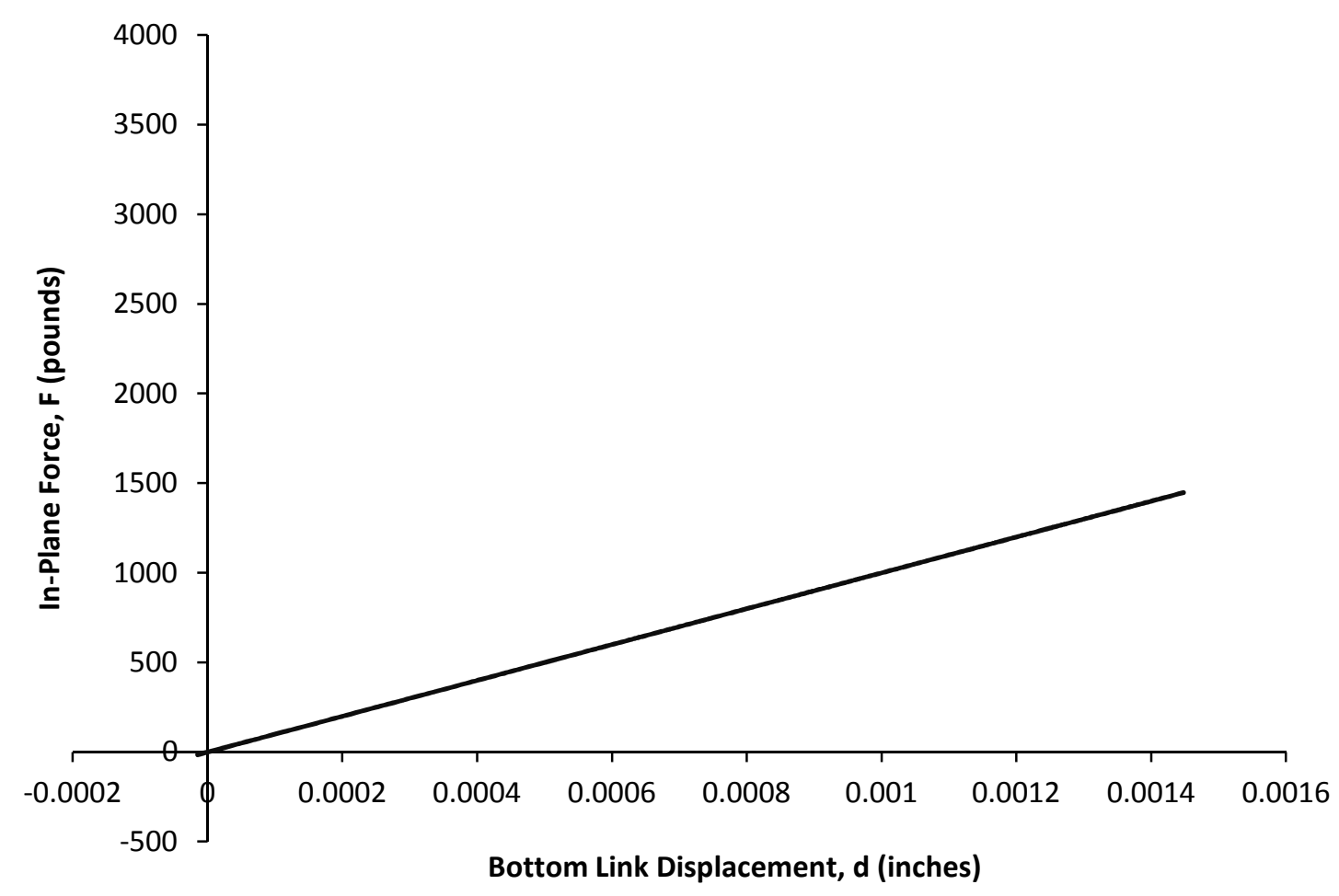

Figure 20. Force developed in Link 6 in the $\mathrm{X}$ direction versus the link displacement in the $\mathrm{X}$ direction for loading protocol P2.

\subsubsection{Bottom links vertical direction analysis result for Model MD 1. In the}

following plots, the origins of the drawings do not start at the origin due to links carrying the main portion of the weight of the precast concrete panel.

Figure 21 shows the results of Link 5 (left side, bottom link) for the positive and negative global displacements of the structural frame. It shows the relationship between the force developed in the left bottom link in the $\mathrm{Z}$ direction and the link displacement in the $\mathrm{Z}$ direction for loading protocols $\mathrm{P} 1$ and $\mathrm{P} 2$. The relationship is linear throughout the loading, as shown in the Figure 21. 


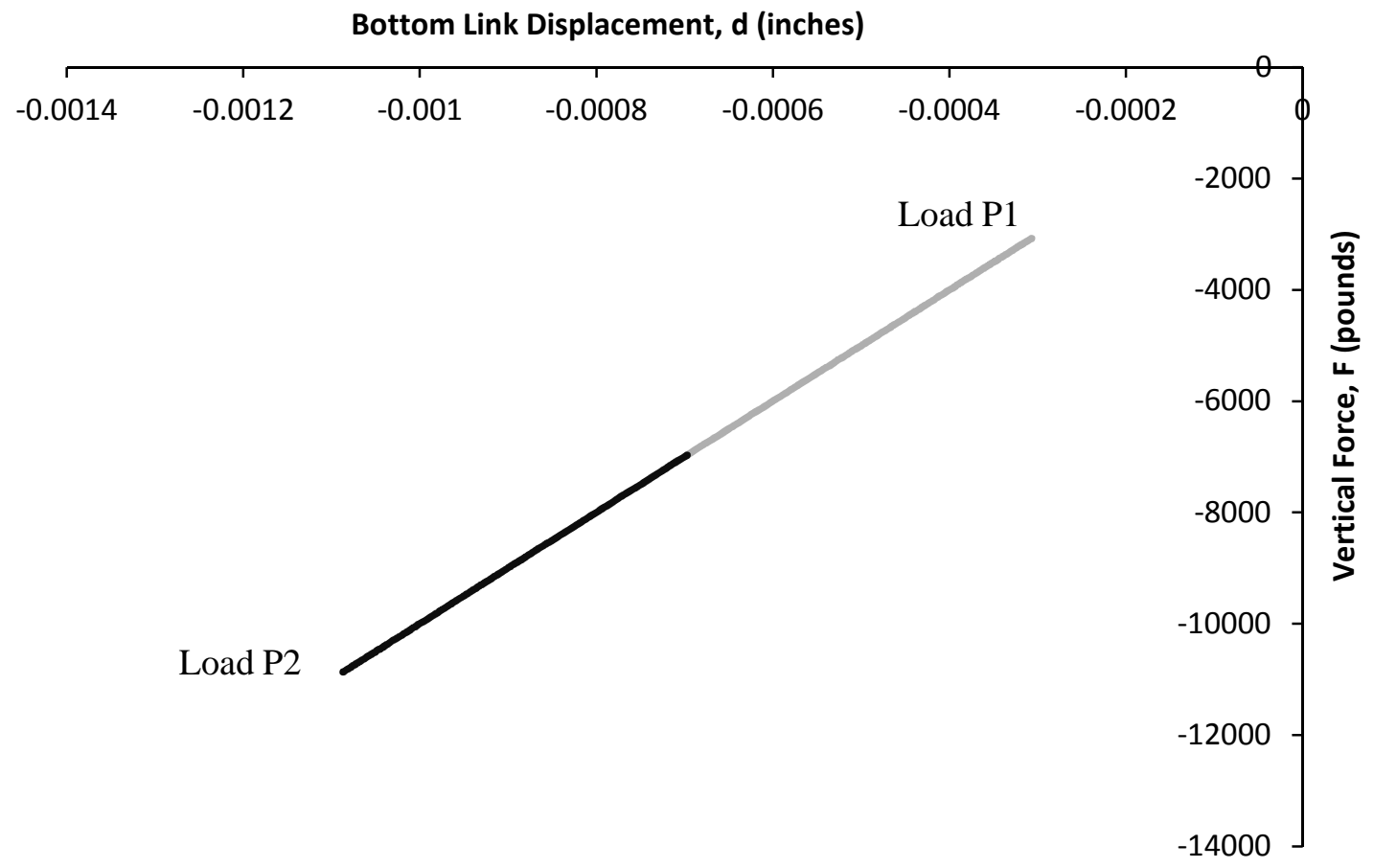

Figure 21. Force developed in Link 5 in the $\mathrm{Z}$ direction versus the link displacement in the $\mathrm{Z}$ direction for loading protocols $\mathrm{P} 1$ and $\mathrm{P} 2$.

Figure 22 shows the results for Link 6 (right side, bottom link) for the positive and negative global displacements of the structural frame. It shows the relationship between the force developed in the right bottom link in the $\mathrm{Z}$ direction and the link displacement in the $\mathrm{Z}$ direction for loading protocols $\mathrm{P} 1$ and $\mathrm{P} 2$. The relationship is linear throughout the loading, as shown in the Figure 22. 


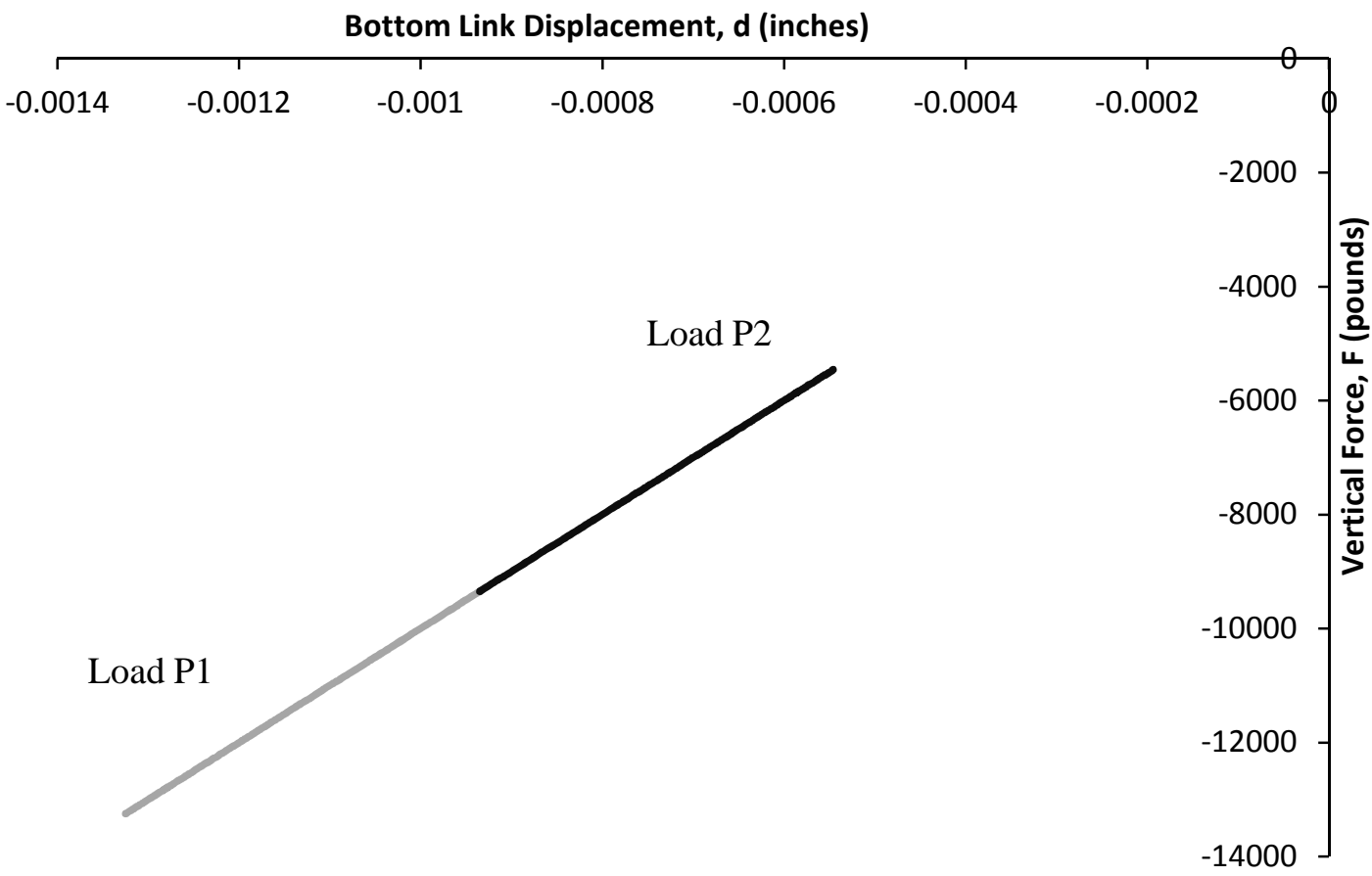

Figure 22. Force developed in Link 6 in the $\mathrm{Z}$ direction versus the link displacement in the $\mathrm{Z}$ direction for loading protocols $\mathrm{P} 1$ and $\mathrm{P} 2$.

4.3.4 Drift ratio for Model MD 1. Panel shear strain is a critical value related to panel design. Panel shear strain $(\gamma)$ is the lateral deflection divided by the total height of the panel (equivalent to the panel drift ratio defined in section 2.1). The structural frame drift ratio $\left(\alpha_{\text {Frame }}\right)$ is the lateral deflection of the structural frame divided by the vertical distance between floor levels (equivalent to the interstory drift ratio of section 2.1).

Sample calculations for both $\alpha_{\text {Frame }}$ and $\gamma$ are provided here for the last step of the positive displacement of the structural frame in the $\mathrm{X}$ direction (P1 loading protocol).

$$
\begin{aligned}
& \boldsymbol{\alpha}_{\text {Frame }}=\frac{\text { Frame Top Lateral Deflection-Frame Bottom Lateral Deflection }}{\text { Floor Level Vertical Distance }} \quad \text { Equation } 1 \\
& \alpha_{\text {Frame }}=\frac{3.2 \mathrm{in} .-0.516 \mathrm{in} .}{146 \mathrm{in} .}=0.0183 \text { radians }
\end{aligned}
$$




$$
\begin{aligned}
& \gamma=\frac{\text { Panel Top Lateral Deflection-Panel Bottom Lateral Deflection }}{\text { Panel Height }} \quad \text { Equation } 2 \\
& \gamma=\frac{0.521 \mathrm{in} .-0.518 \mathrm{in} .}{167 \mathrm{in} .}=1.8 \times 10^{-5} \text { radians }
\end{aligned}
$$

Figure 23 shows the shear strain developed in the precast concrete panel versus the drift ratio of the structural frame graph for the positive global displacements of the structural frame. A linear relationship exists until the structural frame drift ratio is 0.0005. As the drift ratio of the structural frame exceeds the 0.005 , the relationship remains linear but with a different slope. The same results were observed for the negative displacement of the structural frame.

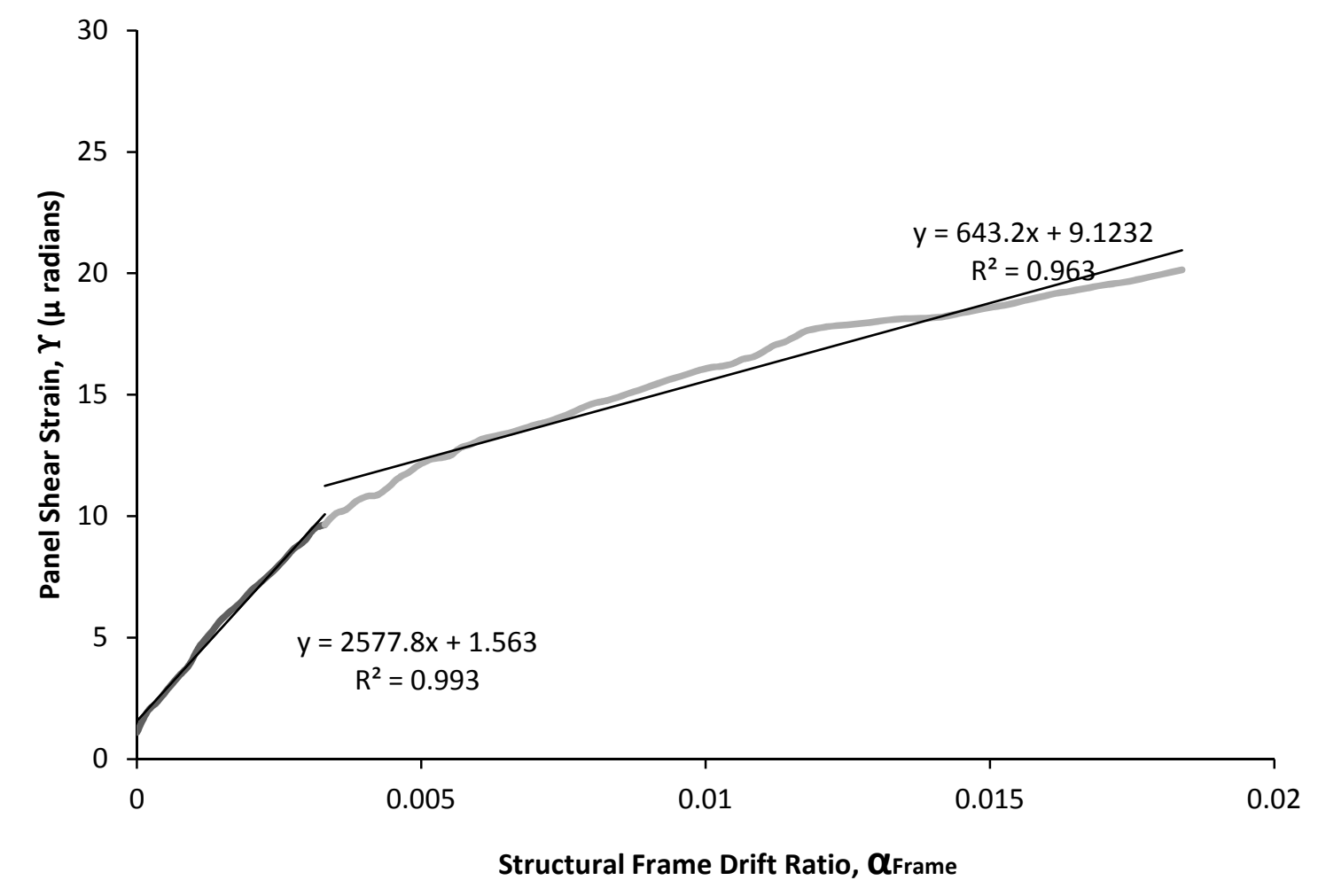

Figure 23. Shear strain of the precast concrete panel versus drift ratio of the structural frame. 
4.3.5 Summary of analysis for Model MD 1. Table 12 shows the summary of the maximum displacement recorded for each link in the $\mathrm{X}$ direction divided by the maximum control displacement of the structural frame.

$D R=\frac{\text { Max. Displacement Recorded of the Link }}{\text { Max. Control Displacement }}$

Equation 3

Table 12 shows that the displacements do not vary based on their locations along the length of the panel.

Table 12

Summary Table of Displacement Ratios With Respect to Control Displacement of the Structural Frame for Model MD 1 in the X Direction

\begin{tabular}{lllll}
\hline Pushover Analysis & Link 1 & Link 2 & Link 3 & Link 4 \\
\hline $\begin{array}{l}\text { Positive X Direction, } \\
\begin{array}{l}\text { Displacement 3.2 in. } \\
\text { Negative X Direction, }\end{array}\end{array}$ & 0.837 & 0.837 & 0.837 & 0.837 \\
\begin{tabular}{l} 
Displacement 3.2 in. \\
\hline
\end{tabular}
\end{tabular}

Figure 24 shows the free body diagram of the precast concrete panel at the final point of analysis for the P1 loading protocol. The same magnitudes of forces were observed in the links for the P2 loading protocol, but the forces were in the opposite directions. The forces in the flexing rods of the same size are equal, and the bearing connections resist much higher horizontal forces compared to the flexing rod links, as shown in Figure 24. Table 13 shows horizontal forces developed in the last step of the P1 loading protocol. 


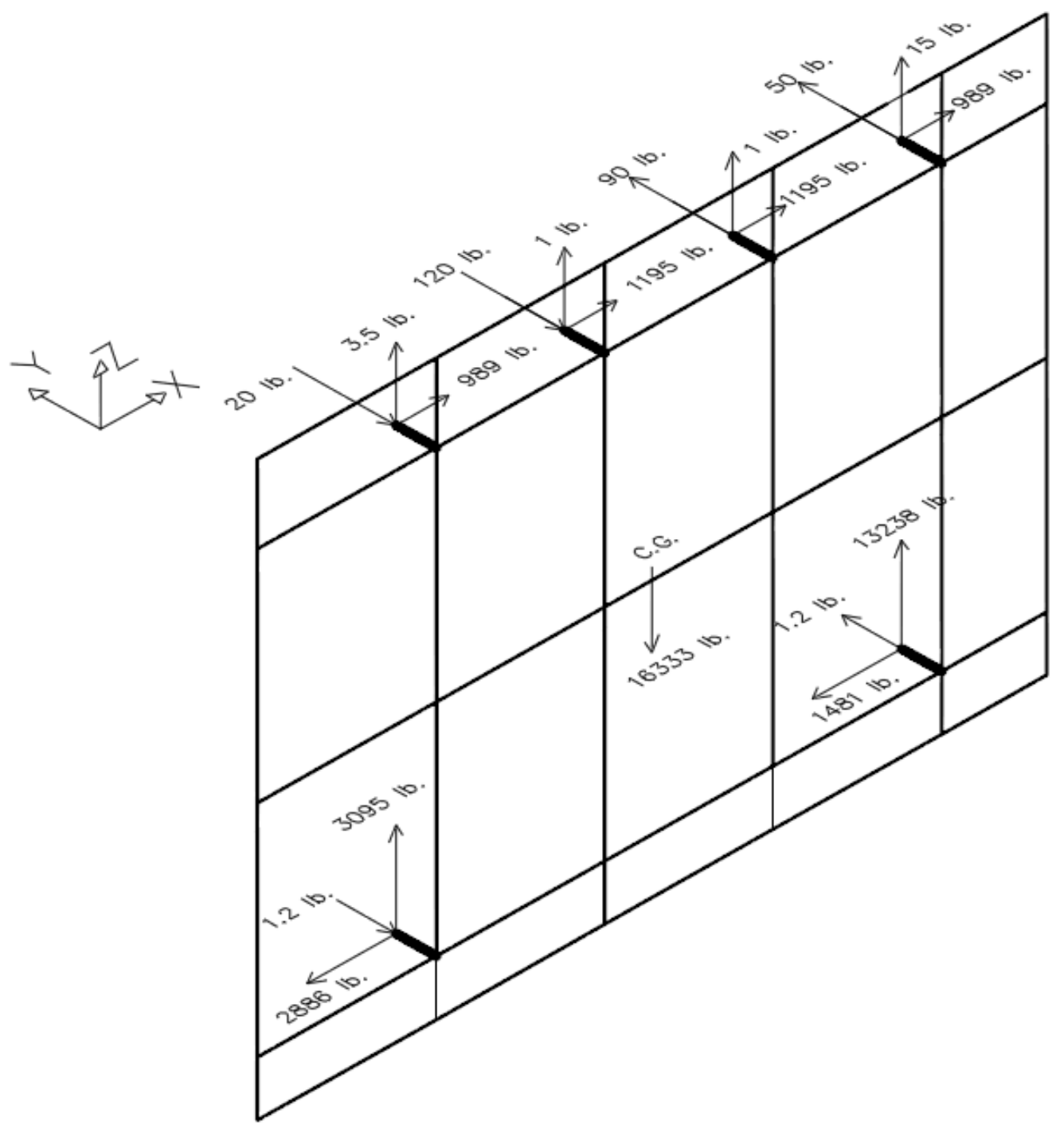

Figure 24. Free body diagram of the precast concrete panel at final step of analysis for loading protocol P1. 
Table 13

Summary of Horizontal Forces for P1 and P2 Loading Protocols

\begin{tabular}{ccccccc}
\hline & \multicolumn{5}{c}{ Horizontal Force (pounds) } \\
\cline { 2 - 7 } Loading & Link 1 & Link 2 & Link 3 & Link 4 & Link 5 & Link 6 \\
\hline P1 & 989 & 1195 & 1195 & 989 & -2886 & -1481 \\
P2 & -989 & -1195 & -1195 & -989 & 2886 & 1481 \\
\hline
\end{tabular}

4.3.6 Top links in-plane direction analysis result for Model MD 2. The

pushover analysis of Model MD 2 was conducted. As the structural frame moves in the $\mathrm{X}$ direction, the precast concrete panel deforms in the same direction as the structural frame, but the displacements of the panel are about $16 \%$ of the structural frame displacement. Therefore, the panel is essentially undeformed. Meanwhile, the links actually deform in the opposite direction to accommodate the relative displacement between the two ends.

Figure 25 defines the global pushover curve for both the positive and negative displacement of the structural frame. It shows the relationship between the absolute value of the summation of the horizontal shear forces developed in the four flexing rod links and the absolute value of the control displacement of the structural frame. The behavior is essentially linear until the displacement nears a magnitude of 1 inch. As the control displacement exceeds the magnitude of $1 \mathrm{inch}$, the relationship remains linear but with a different slope. As shown in Figure 25, the positive and negative curves lie on each other. 


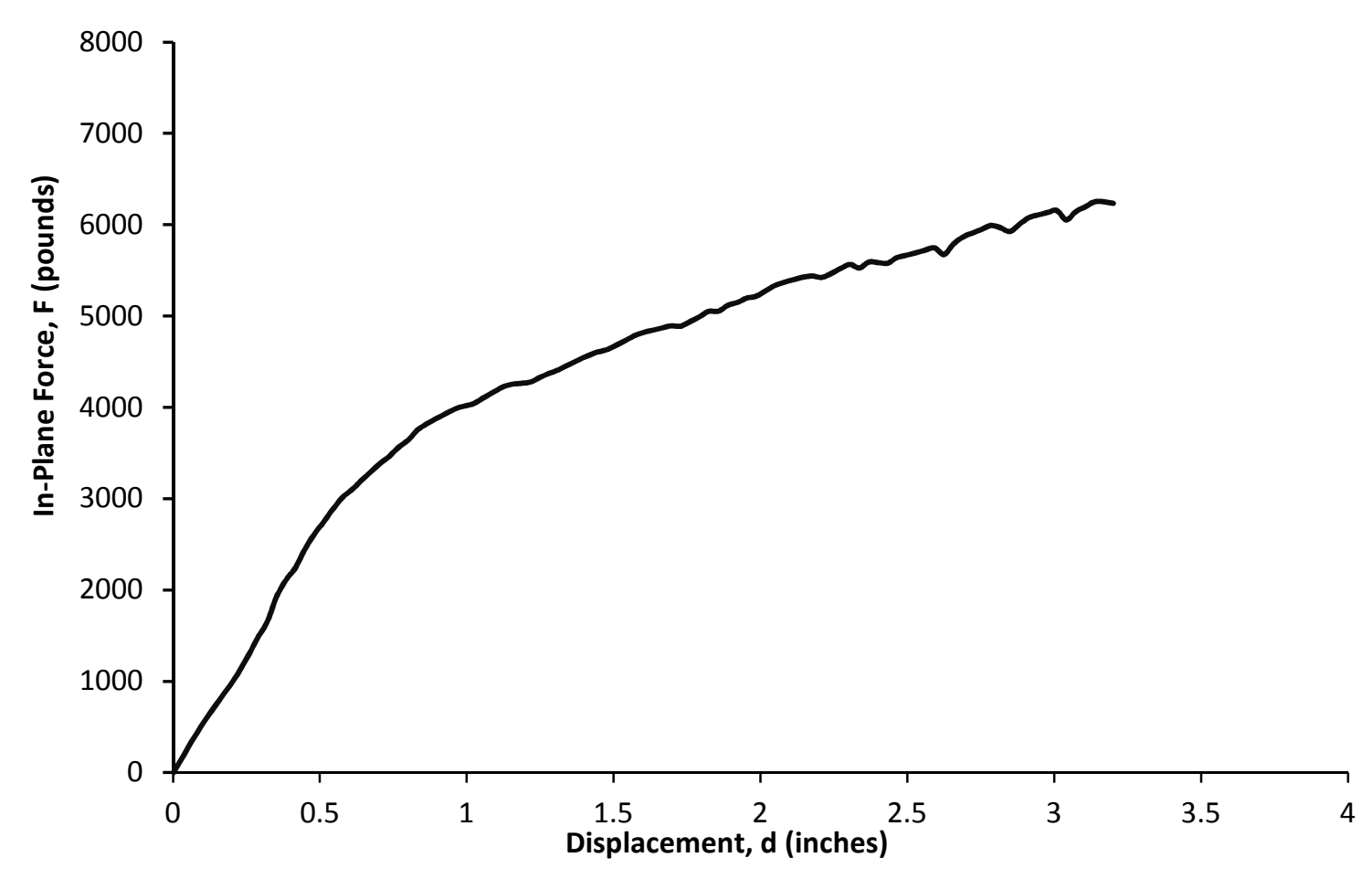

Figure 25. Total force developed in all flexing rod links for loading protocols P1 and P2.

Figure 26 shows the results for Link 1 and Link 4 for both the positive and negative global displacements of the structural frame. It shows the relationship between the force developed in the exterior flexing rod link in the $\mathrm{X}$ direction and the link displacement in the $\mathrm{X}$ direction as the structural frame moves. A linear relationship exists until the displacement nears a magnitude of $1 \mathrm{inch}$. As the control displacement exceeds the magnitude of $1 \mathrm{inch}$, the relationship remains linear but with a different slope. As shown, the positive and negatives curves lie on each other. The force developed in the flexing rod link for the negative displacement of the structural frame was in the opposite direction but with the same magnitude of force developed in the link for the positive displacement of the structural frame. 


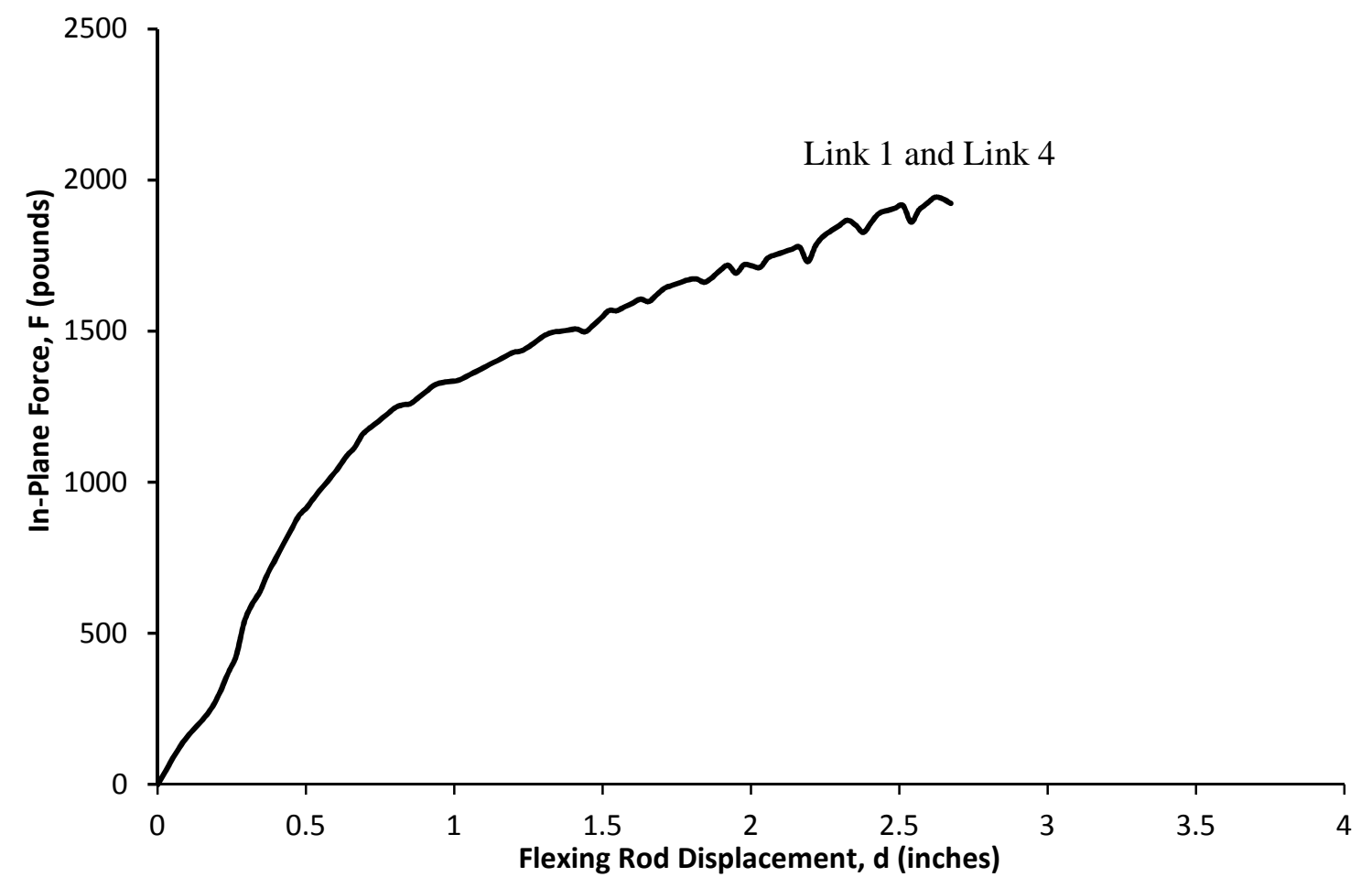

Figure 26. Force developed in the exterior flexing rod in the $\mathrm{X}$ direction versus the link displacement in the $\mathrm{X}$ direction for loading protocols $\mathrm{P} 1$ and $\mathrm{P} 2$.

Figure 27 shows the results for Link 2 and Link 3 for both the positive and negative global displacements of the structural frame. It shows the relationship between the force developed in the interior flexing rod link in the $\mathrm{X}$ direction and the link displacement in the $\mathrm{X}$ direction as the structural frame moves. A linear relationship exists until the displacement nears a magnitude of 0.5 inches. As the link displacement exceeds the magnitude of 0.5 inches, the relationship remains linear but with a different slope. As shown, the positive and negatives curves lie on each other. Similar to the previous graphs, the force developed in the flexing rod link for the negative displacement of the structural frame was in the opposite direction but with the same magnitude of force developed in the link for the positive displacement of the structural frame. 


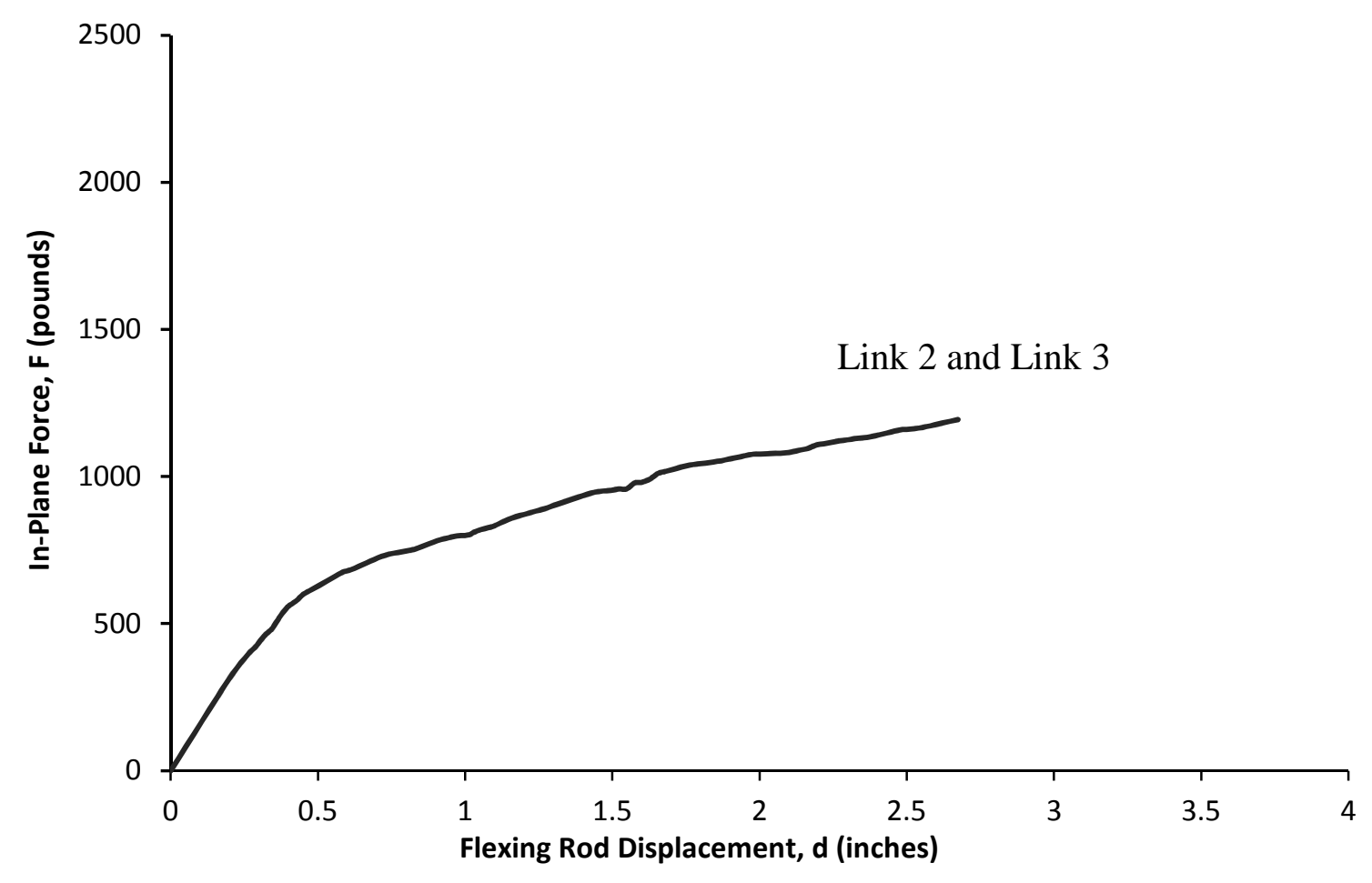

Figure 27. Force developed in the interior flexing rod in the $\mathrm{X}$ direction versus the link displacement in the $\mathrm{X}$ direction for loading protocols $\mathrm{P} 1$ and $\mathrm{P} 2$.

\subsubsection{Bottom links in-plane direction analysis result for Model MD 2. The}

bottom link graphs do not start from the origin because both Link 5 and Link 6 (left and right bottom links) carry part of the weight of the panel.

Figure 28 shows the results for Link 5 (left side, bottom link) for the positive global displacement of the structural frame. It shows the relationship between the force developed in the left bottom link in the $\mathrm{X}$ direction and the link displacement in the $\mathrm{X}$ direction as the structural frame moves. The graph does not start at the origin because Link 5 carries part of the weight of the precast concrete panel due to eccentricity. The relationship is linear throughout the loading, as shown in Figure 28. 


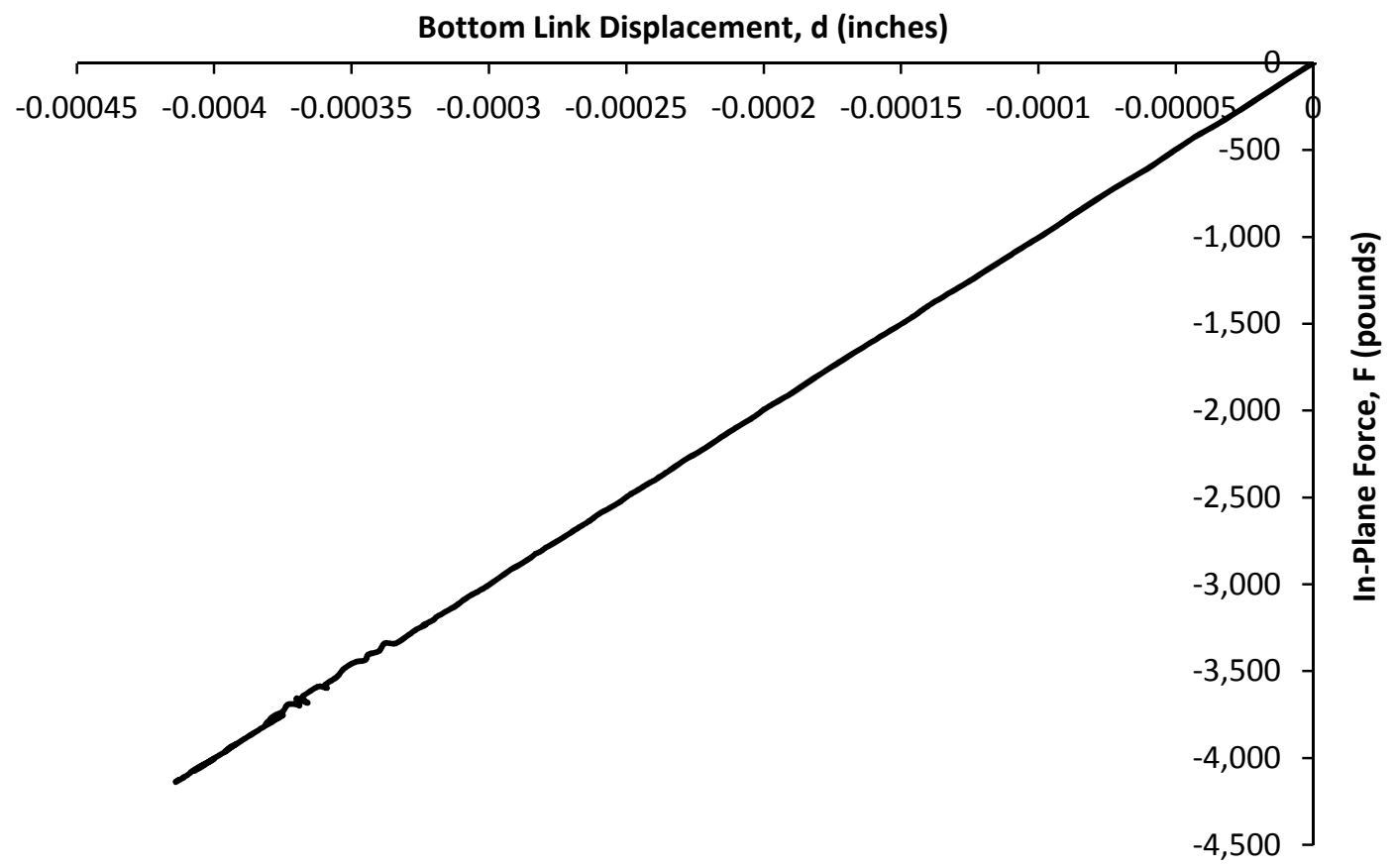

Figure 28. Force developed in Link 5 in the $\mathrm{X}$ direction versus the link displacement in the $\mathrm{X}$ direction for loading protocol $\mathrm{P} 1$.

A similar behavior was observed for the negative global displacement of the structural frame for Link 5. The relationship is linear throughout the loading, as shown in Figure 29. 


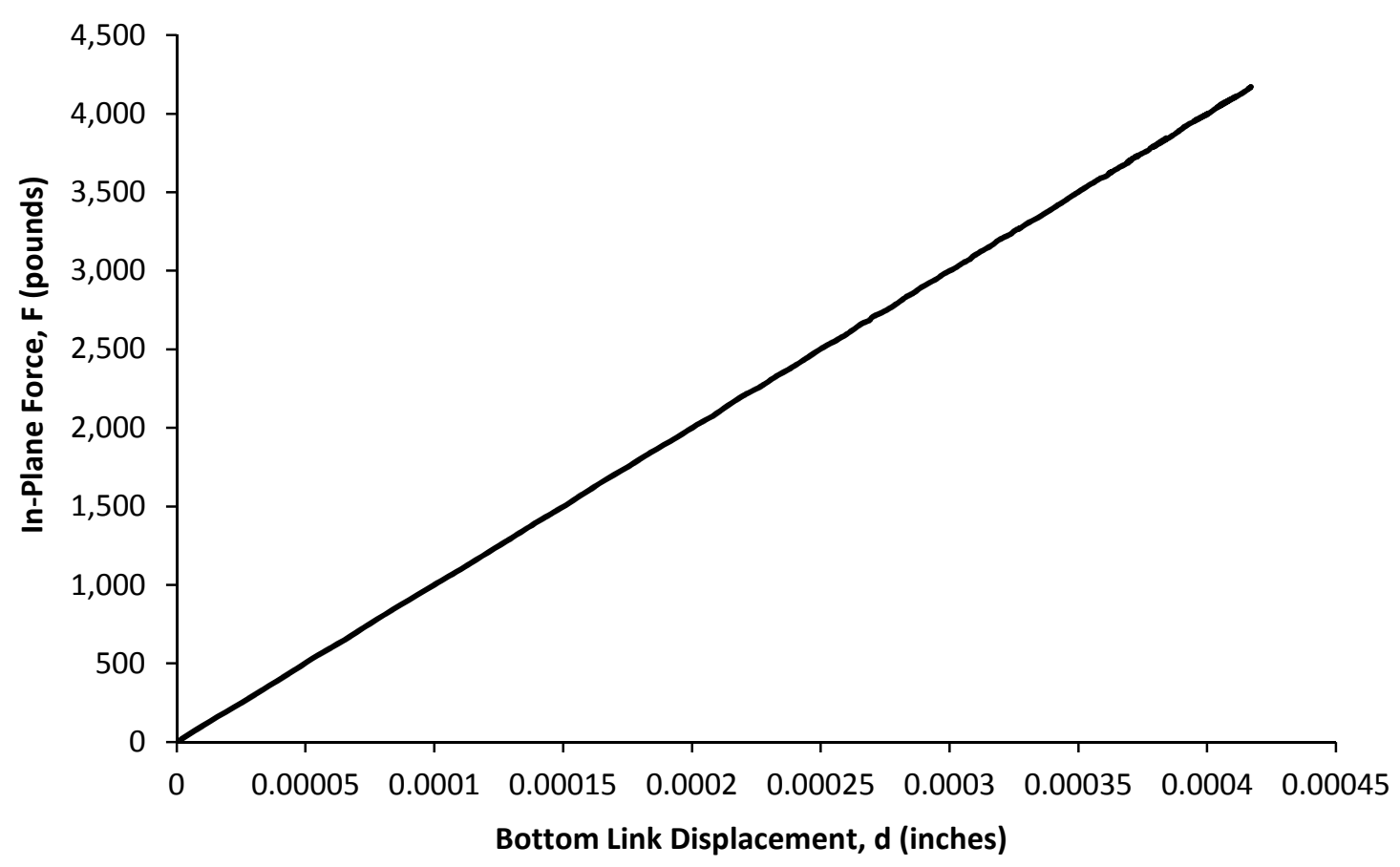

Figure 29. Force developed in Link 5 in the $\mathrm{X}$ direction versus the link displacement in the $\mathrm{X}$ direction for loading protocol $\mathrm{P} 2$.

Figure 30 shows the result for Link 6 (right bottom link) for the positive global displacement of the structural frame. It shows the relationship between the force developed in the right bottom link in the $\mathrm{X}$ direction and the link displacement in the $\mathrm{X}$ direction as the structural frame moves. The graph does not start at the origin because Link 6 carries part of the weight of the precast concrete panel due to eccentricity. A linear relationship exists throughout the loading, as shown in Figure 30. 


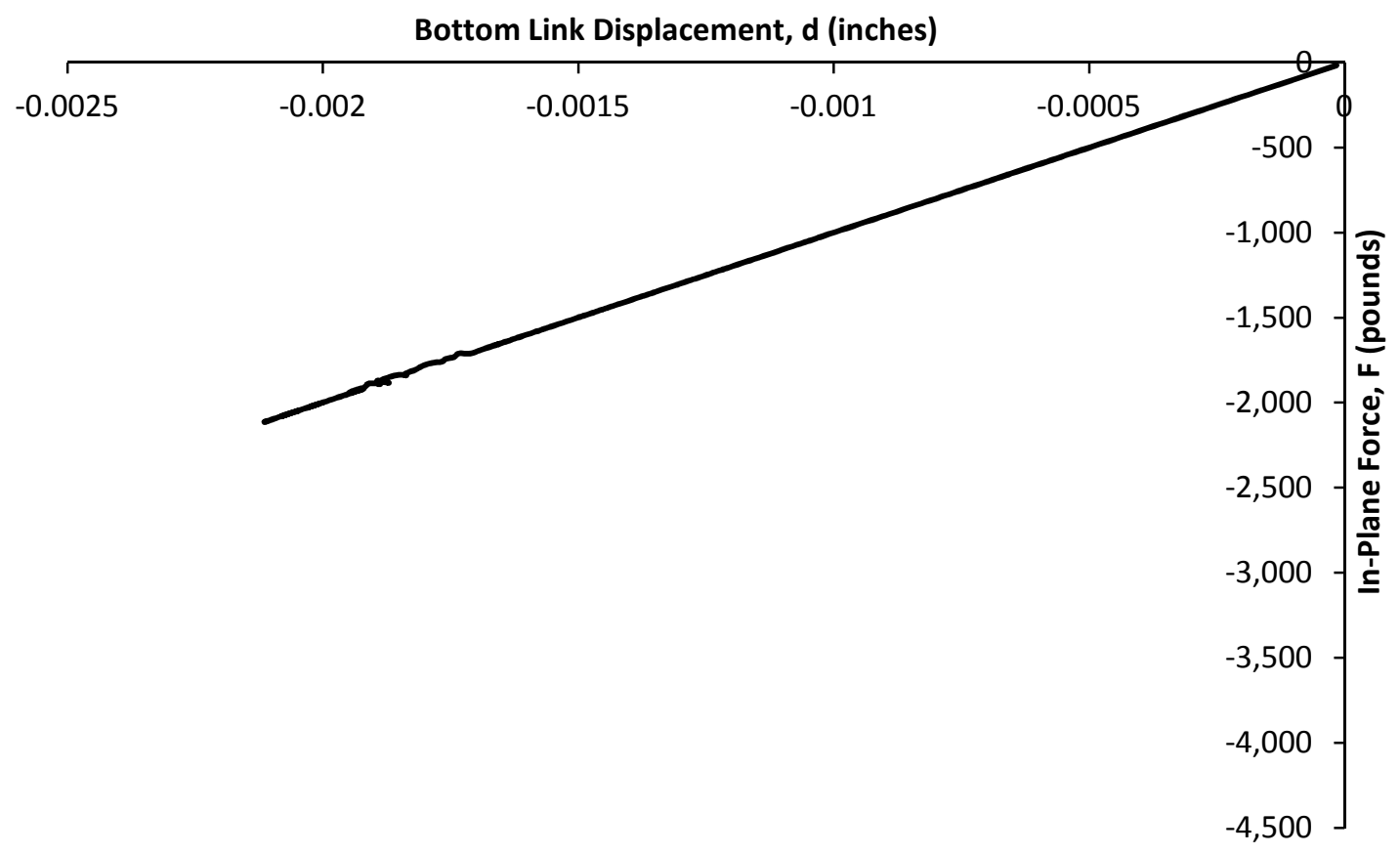

Figure 30. Force developed in Link 6 in the $\mathrm{X}$ direction versus the link displacement in the $\mathrm{X}$ direction for loading protocol $\mathrm{P} 1$.

Similar behavior was observed for the negative global displacement of the structural frame for Link 6. The relationship is linear throughout the loading, as shown in Figure 31. 


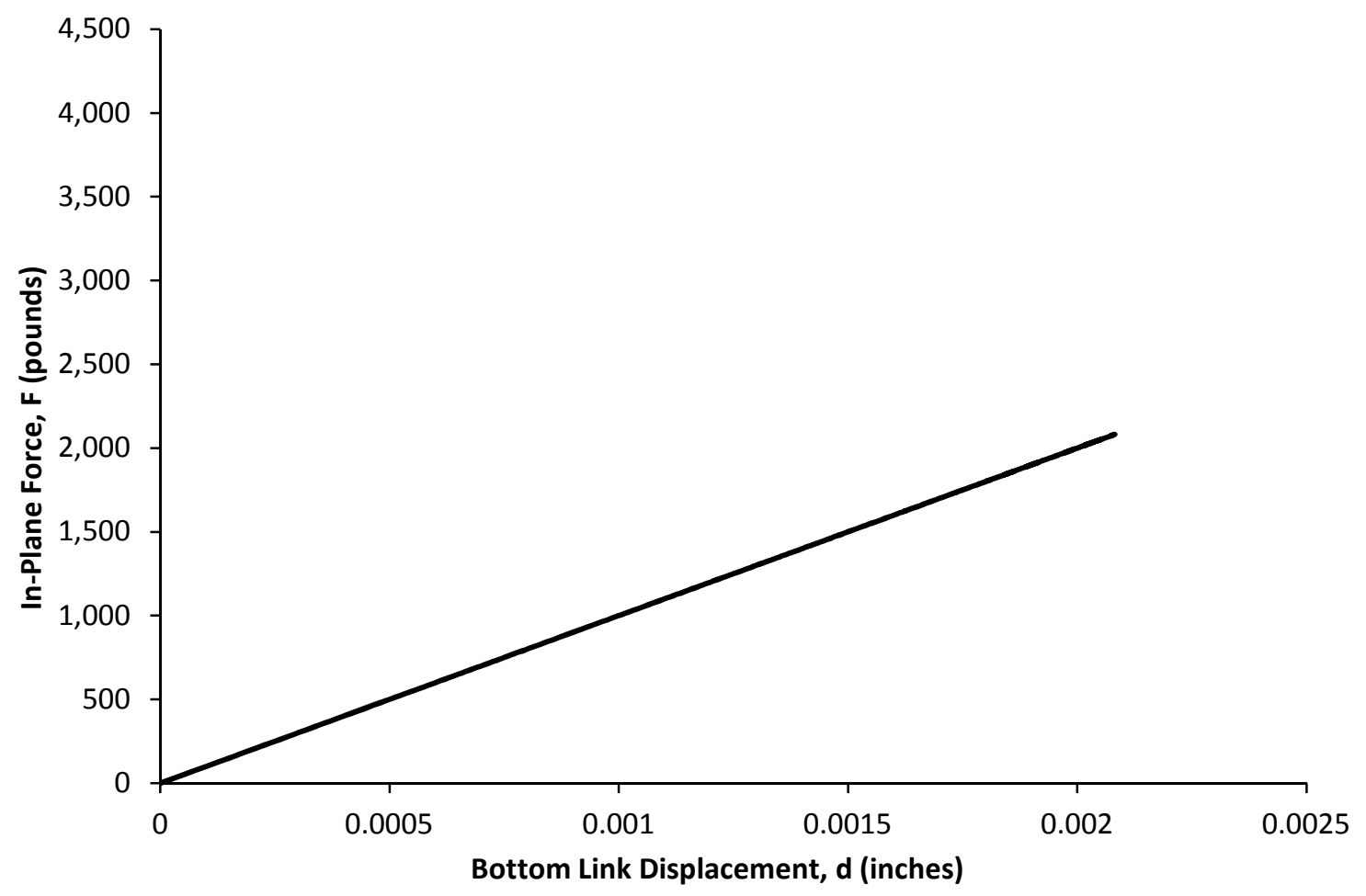

Figure 31. Force developed in Link 6 in the $\mathrm{X}$ direction versus the link displacement in the $\mathrm{X}$ direction for loading protocol $\mathrm{P} 2$.

\subsubsection{Bottom link vertical direction analysis result for Model MD 2. In the}

following plots, the origins of the drawings do not start at the zero axes due to the links carrying the main portion of the weight of the precast concrete panel.

Figure 32 shows the results of Link 5 (left side, bottom link) for the positive and negative global displacements of the structural frame. It shows the relationship between the force developed in the left bottom link in the $\mathrm{Z}$ direction and the link displacement in the $\mathrm{Z}$ direction for loading protocols $\mathrm{P} 1$ and $\mathrm{P} 2$. The relationship is linear throughout the loading, as shown in Figure 32. 


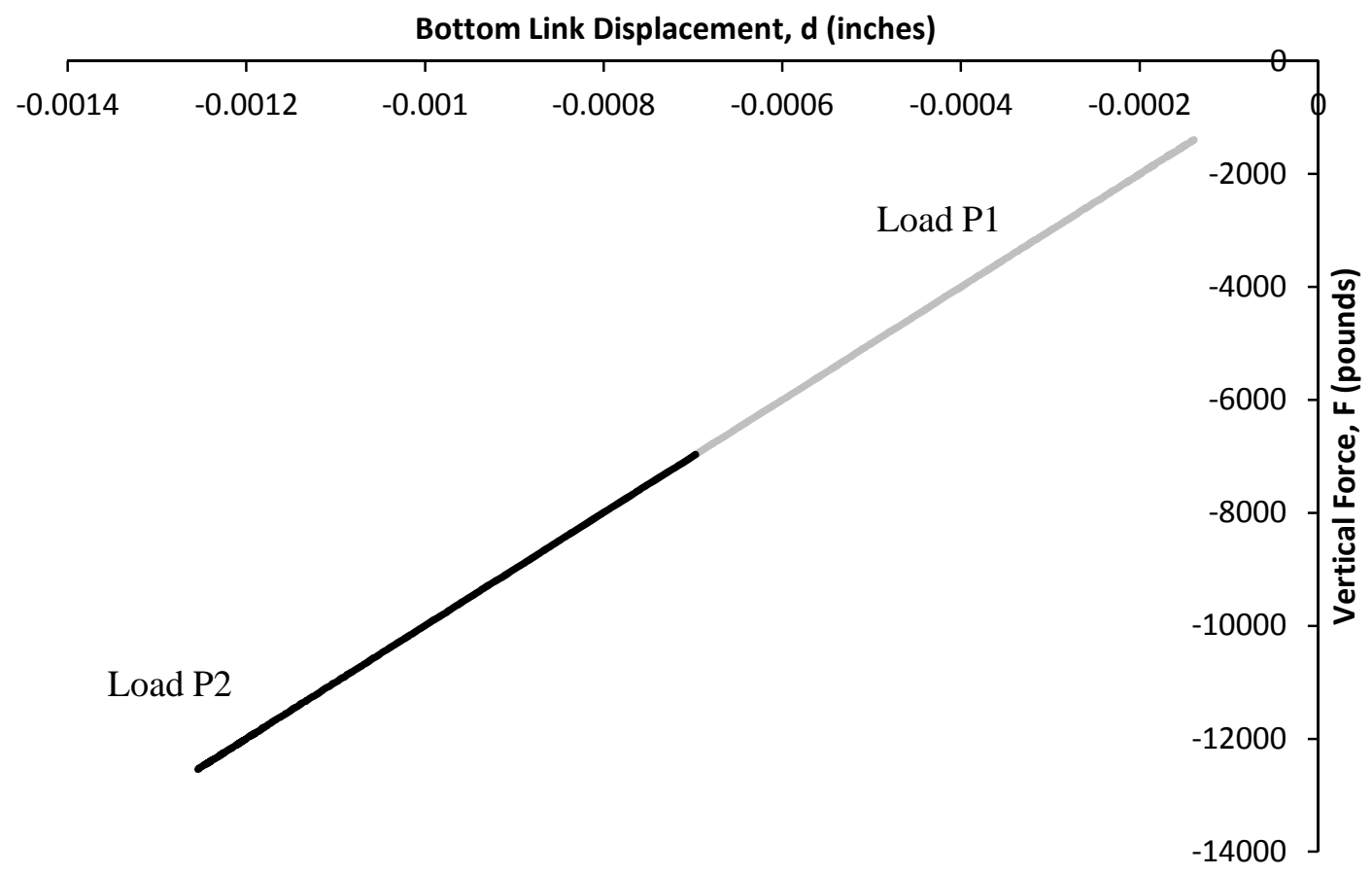

Figure 32. Force developed in Link 5 in the $\mathrm{Z}$ direction versus the link displacement in the $\mathrm{Z}$ direction for loading protocols $\mathrm{P} 1$ and $\mathrm{P} 2$.

Figure 33 shows the results for Link 6 (right bottom link) for the positive and negative global displacements of the structural frame. It shows the relationship between the force developed in the right bottom link in the $\mathrm{Z}$ direction and the link displacement in the $\mathrm{Z}$ direction for loading protocols $\mathrm{P} 1$ and $\mathrm{P} 2$. The relationship is linear throughout the loading, as shown in Figure 33. 


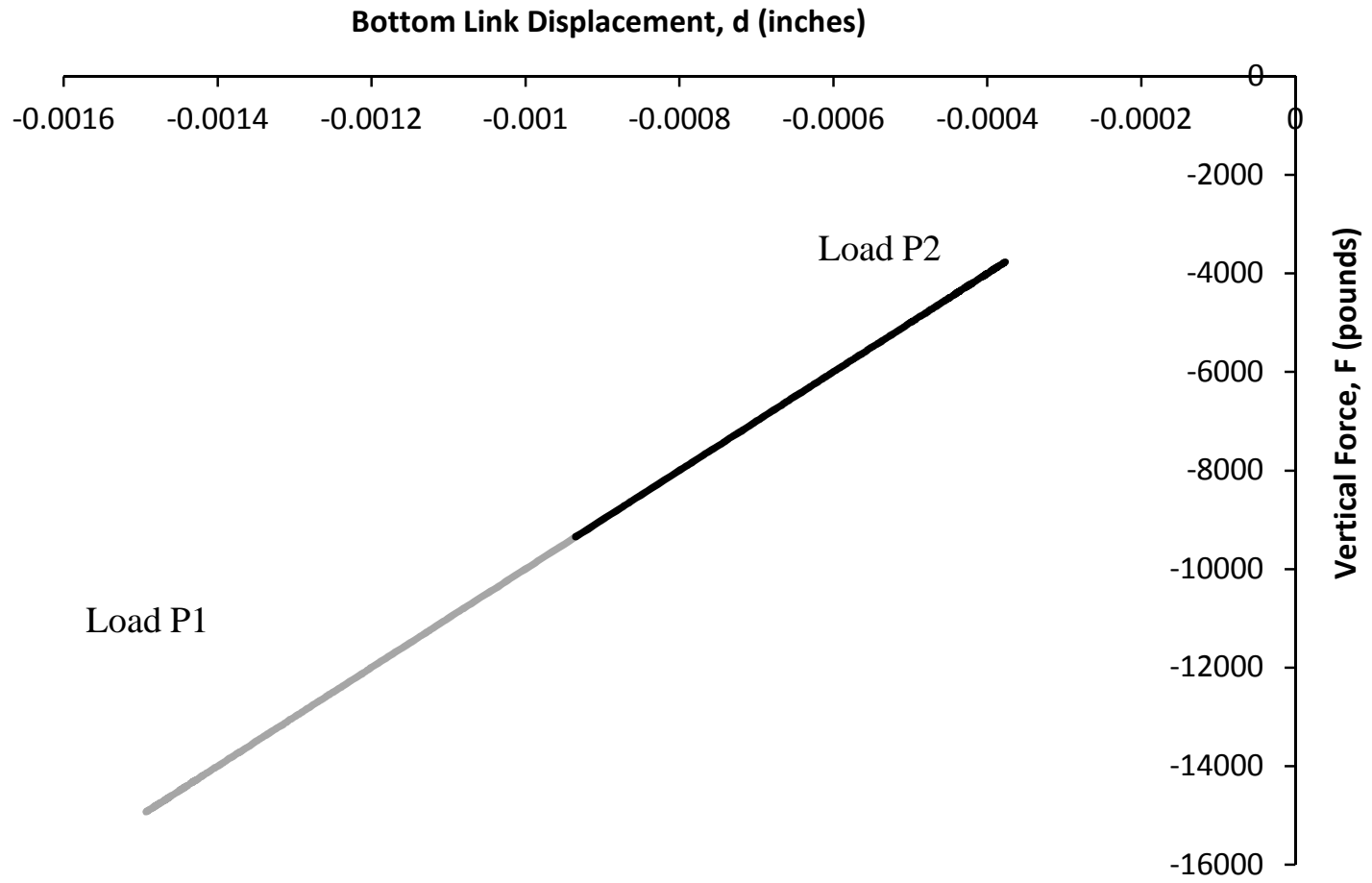

Figure 33. Force developed in Link 6 in the $\mathrm{Z}$ direction versus the link displacement in the $\mathrm{Z}$ direction for loading protocols $\mathrm{P} 1$ and $\mathrm{P} 2$.

4.3.9 Drift ratio for Model MD 2. Panel shear strain and a structural frame drift ratio were calculated. Sample calculations for Model MD 2 are provided here using equations 1 and 2, respectively, for the last step of the positive displacement of the structural frame in the $\mathrm{Z}$ direction (P1 loading protocol).

$$
\begin{array}{lr}
\alpha_{\text {Frame }}=\frac{3.2 \mathrm{in.}-0.517 \mathrm{in} .}{146 \mathrm{in} .}=0.0183 \text { radians } & \text { Equation } 1 \\
\gamma=\frac{0.524 \mathrm{in} .-0.519 \mathrm{in} .}{167 \mathrm{in} .}=2.818 \times 10^{-5} \text { radians } & \text { Equation 2 }
\end{array}
$$

Figure 34 shows the shear strain developed in the precast concrete panel versus the drift ratio of the structural frame for the positive global displacements of the structural frame. A linear relationship exists until a structural frame drift ratio of 0.005 is reached. 
As the drift ratio of the structural frame exceeds 0.005 , the relationship remains linear but with a different slope. The same results were observed for the negative displacement of the structural frame.

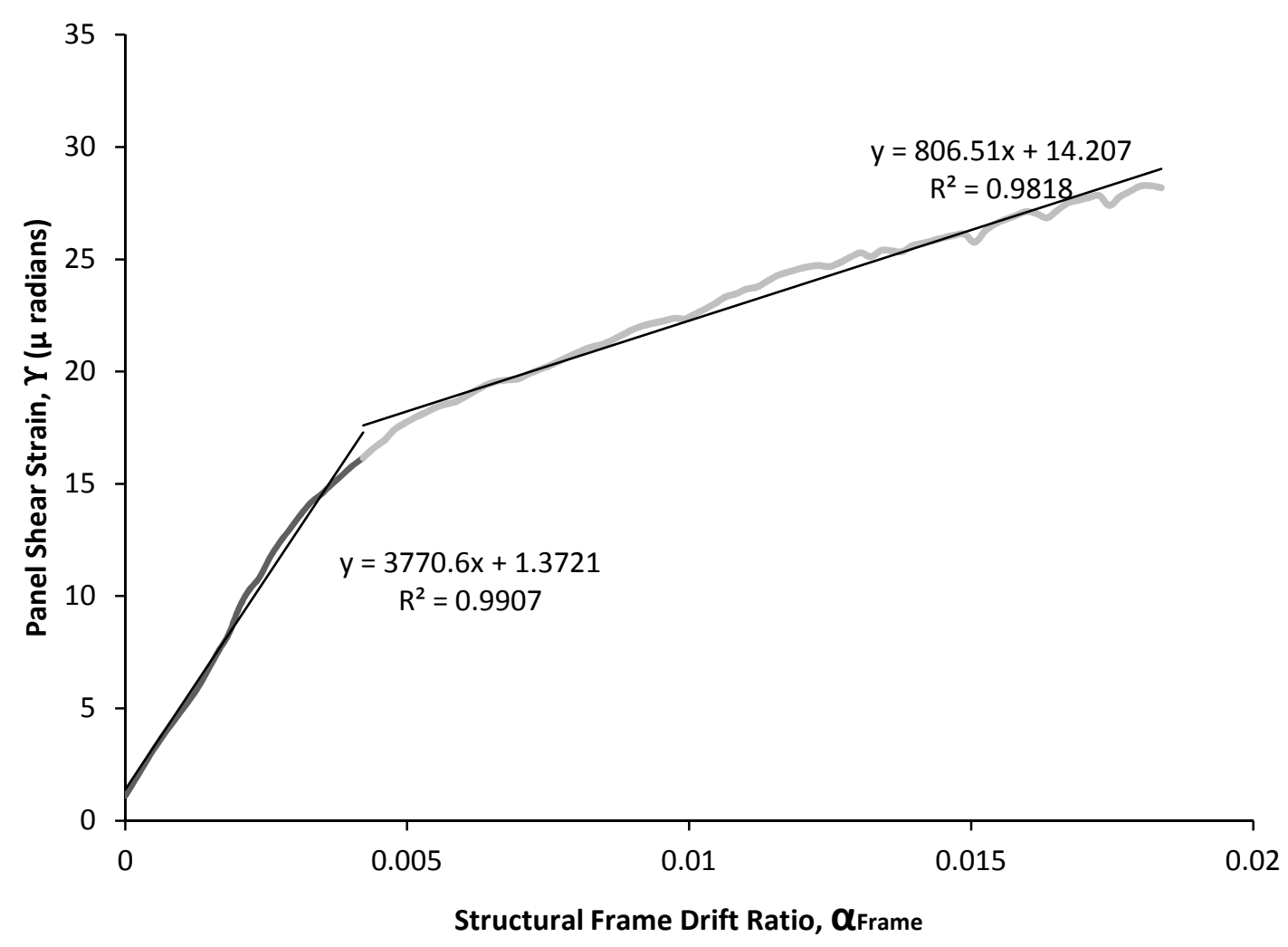

Figure 34. Shear strain of the precast concrete panel versus drift ratio of the structural frame.

4.3.10 Summary of analysis for Model MD 2. Table 14 shows the summary of the maximum displacement recorded for each link in the $\mathrm{X}$ direction divided by maximum control displacement of the structural frame as described previously in Equation 3.

The table shows that the displacements do not vary based on their locations along the length of the panel. 
Table 14

Summary Table of Displacement Ratios With Respect to Control Displacement of the Structural Frame for Model MD 2 in the X Direction

\begin{tabular}{lllll}
\hline Pushover Analysis & Link 1 & Link 2 & Link 3 & Link 4 \\
\hline $\begin{array}{l}\text { Positive X Direction, } \\
\text { Displacement 3.2 in. }\end{array}$ & 0.835 & 0.835 & 0.835 & 0.835 \\
$\begin{array}{l}\text { Negative X Direction, } \\
\text { Displacement 3.2 in. }\end{array}$ & 0.835 & 0.835 & 0.0 .835 & 0.835 \\
\hline
\end{tabular}

Figure 35 shows the free body diagram of the precast concrete panel at the final point of analysis for the P1 loading protocol. The same magnitudes of forces were observed in the links for the P2 loading protocol, but the forces were in the opposite direction. The forces in the flexing rods with the same size are equal, and bearing connections resist much higher horizontal forces compared to the flexing rod links, as shown in Figure 35. Table 15 shows horizontal forces developed in the last step of P1 and P2 loading protocols. 


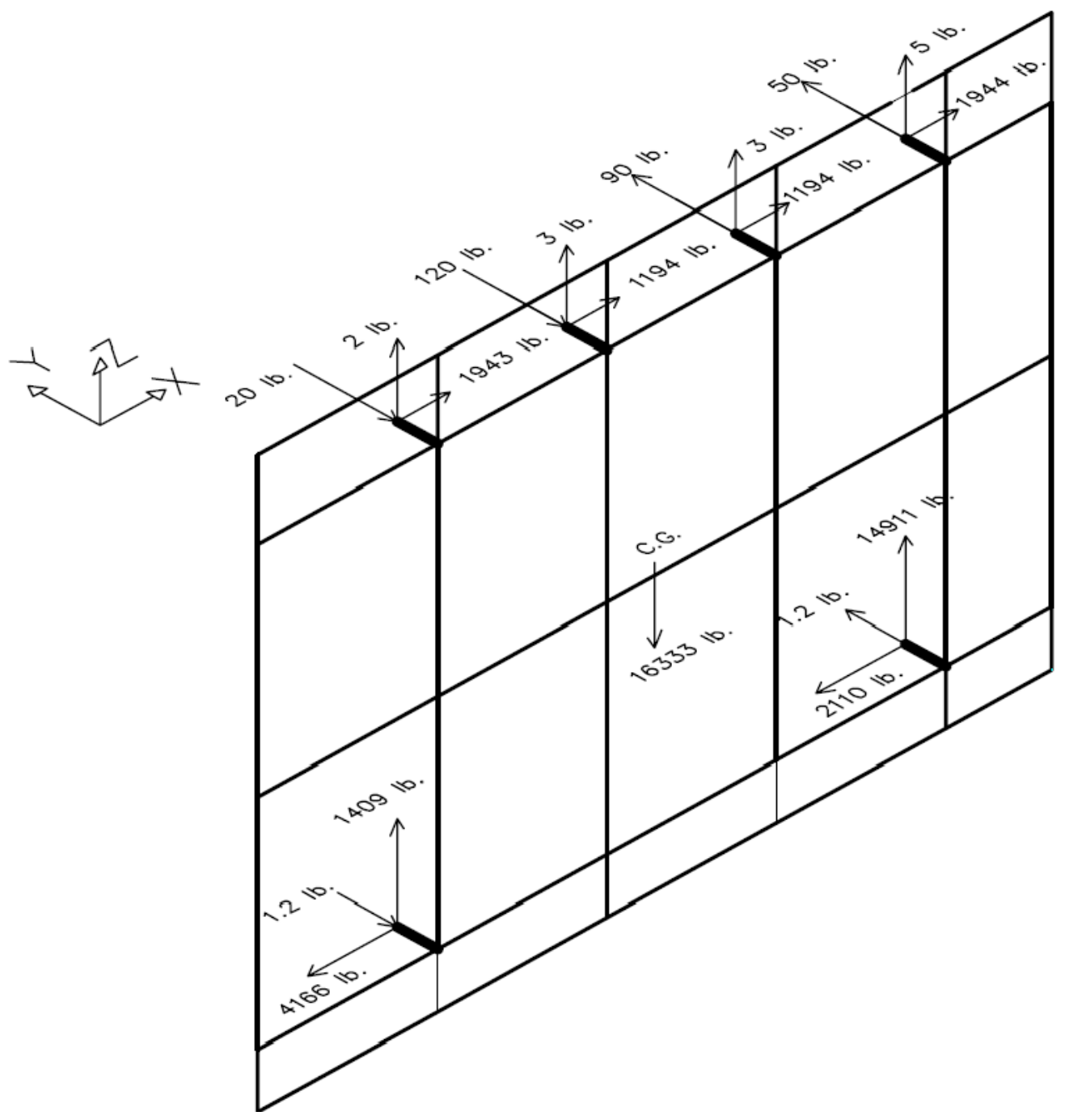

Figure 35. Free body diagram of the precast concrete panel at final step of analysis for loading protocol P1.

Table 15

Summary of Horizontal Forces for P1 and P2 Loading Protocols

\begin{tabular}{ccccccc}
\hline & \multicolumn{6}{c}{ Horizontal Force (pounds) } \\
\cline { 2 - 7 } Loading & Link 1 & Link 2 & Link 3 & Link 4 & Link 5 & Link 6 \\
\hline P1 & 1943 & 1194 & 1194 & 1944 & -4166 & -2109 \\
P2 & -1943 & -1194 & -1194 & -1944 & -4165 & -2110 \\
\hline
\end{tabular}




\section{Displacement-Controlled Time History Analysis Results}

\subsection{Modal Analysis}

Modal analysis was conducted to identify the dynamic characteristics of the precast concrete panel system, including the mass participation ratios. Two separate conditions for the structural frame were studied and compared for each of the two models to determine the mass participation ratio of the precast concrete panel and the structural frame. First, the mass of the structural frame was set to zero; and mode shapes, periods of vibration, and mass participations ratios were determined. Second, the mode shapes, periods of vibration, and mass participation ratios for both models, including the mass of

the structural frame, were determined. Based on the results, the discrepancy between the two conditions for the mass of the structural frame was negligible and did not make a difference in mode shapes, periods of vibration, or mass participation. It was also concluded that the significant vibration characteristics of the precast concrete facade occurred in the first five modes of vibration.

The results of the analysis for both Models MD1 and MD2 are presented in Tables 16 and 17 for the first five modes of vibration. As shown in the following tables, significant coupling of translation and rotation occurs in most modes. 
Table 16

Modal Participation Mass Ratio for Model MD 1

\begin{tabular}{cccccccc}
\hline & Period & $\begin{array}{c}\text { Translation } \\
\text { in X }\end{array}$ & $\begin{array}{c}\text { Translation } \\
\text { in Y }\end{array}$ & $\begin{array}{c}\text { Translation } \\
\text { in Z }\end{array}$ & $\begin{array}{c}\text { Rotation } \\
\text { in X }\end{array}$ & $\begin{array}{c}\text { Rotation } \\
\text { in Y }\end{array}$ & $\begin{array}{c}\text { Rotation } \\
\text { in Z }\end{array}$ \\
\cline { 2 - 8 } Modes & (Sec.) & (Unitless) & (Unitless) & (Unitless) & (Unitless) & (Unitless) & (Unitless) \\
\hline 1 & 0.5989 & 0.3853 & 0.0000 & 0.0000 & 0.0000 & 0.2911 & 0.0031 \\
2 & 0.3231 & 0.0006 & 0.7530 & 0.0048 & 0.8924 & 0.0003 & 0.5491 \\
3 & 0.2742 & 0.2659 & 0.0009 & 0.0006 & 0.0013 & 0.2413 & 0.0497 \\
4 & 0.2383 & 0.0596 & 0.0057 & 0.0000 & 0.0050 & 0.0478 & 0.0934 \\
5 & 0.2173 & 0.0013 & 0.0823 & 0.0053 & 0.0623 & 0.0001 & 0.1068 \\
\hline
\end{tabular}

Table 17

Modal Participation Mass Ratio for Model MD 2

\begin{tabular}{cccccccc}
\hline & Period & $\begin{array}{c}\text { Translation } \\
\text { in X }\end{array}$ & $\begin{array}{c}\text { Translation } \\
\text { in Y }\end{array}$ & $\begin{array}{c}\text { Translation } \\
\text { in Z }\end{array}$ & $\begin{array}{c}\text { Rotation } \\
\text { in X }\end{array}$ & $\begin{array}{c}\text { Rotation } \\
\text { in Y }\end{array}$ & $\begin{array}{c}\text { Rotation } \\
\text { in Z }\end{array}$ \\
\cline { 2 - 8 } Modes & (Sec.) & (Unitless) & (Unitless) & (Unitless) & (Unitless) & (Unitless) & (Unitless) \\
\hline 1 & 0.598 & 0.5543 & 0.0000 & 0.0000 & 0.0000 & 0.3599 & 0.0035 \\
2 & 0.3231 & 0.0006 & 0.7527 & 0.0048 & 0.8921 & 0.0004 & 0.5488 \\
3 & 0.2814 & 0.2328 & 0.0013 & 0.0005 & 0.0019 & 0.1914 & 0.0349 \\
4 & 0.2399 & 0.0335 & 0.0049 & 0.0000 & 0.0041 & 0.0215 & 0.1093 \\
5 & 0.2174 & 0.0007 & 0.0829 & 0.0051 & 0.0629 & 0.0004 & 0.1058 \\
\hline
\end{tabular}




\subsection{Analysis Result for Model MD 1}

5.2.1 Top links force-time relationship for Model MD 1. Three nonlinear dynamic analyses using displacement-controlled time history were used to evaluate the dynamic characteristics of the flexing rod links, the bottom links, and the precast concrete panel. Figures 36 and 37 show the relationship between forces developed in each of the flexural links with respect to the time for loading for a period of 100 s. Figures 38 and 39 show the same relationship for loading for a period of $1 \mathrm{~s}$. Figures 40 and 41 show the same relationship for loading for a period of $0.32 \mathrm{~s}$. In all cases, Link 3 has a graph identical to that of Link 2, and Link 4 has a graph identical to that of Link 1.

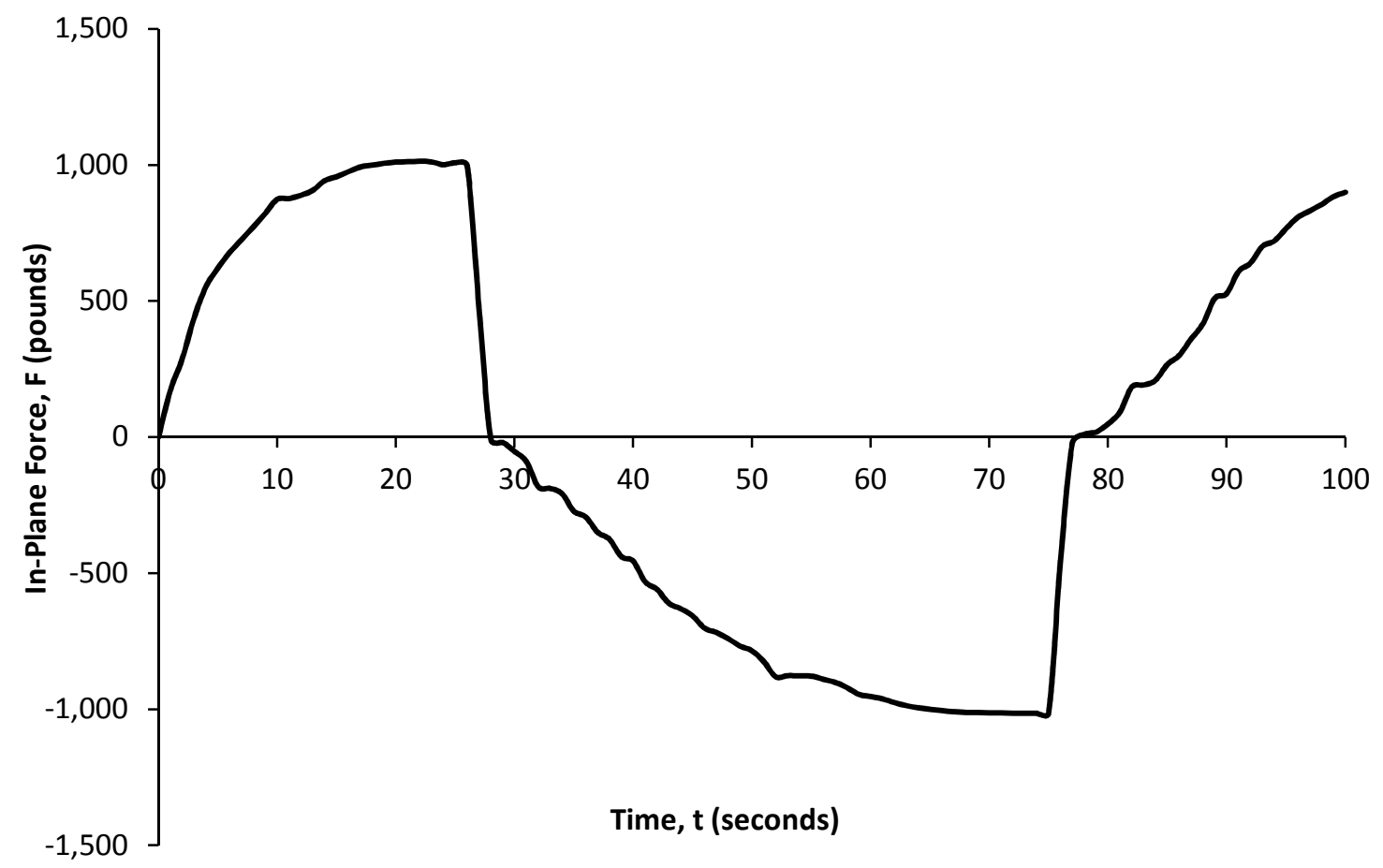

Figure 36. Force developed in the exterior flexing rod versus time for $\mathrm{T}=100$ seconds. 


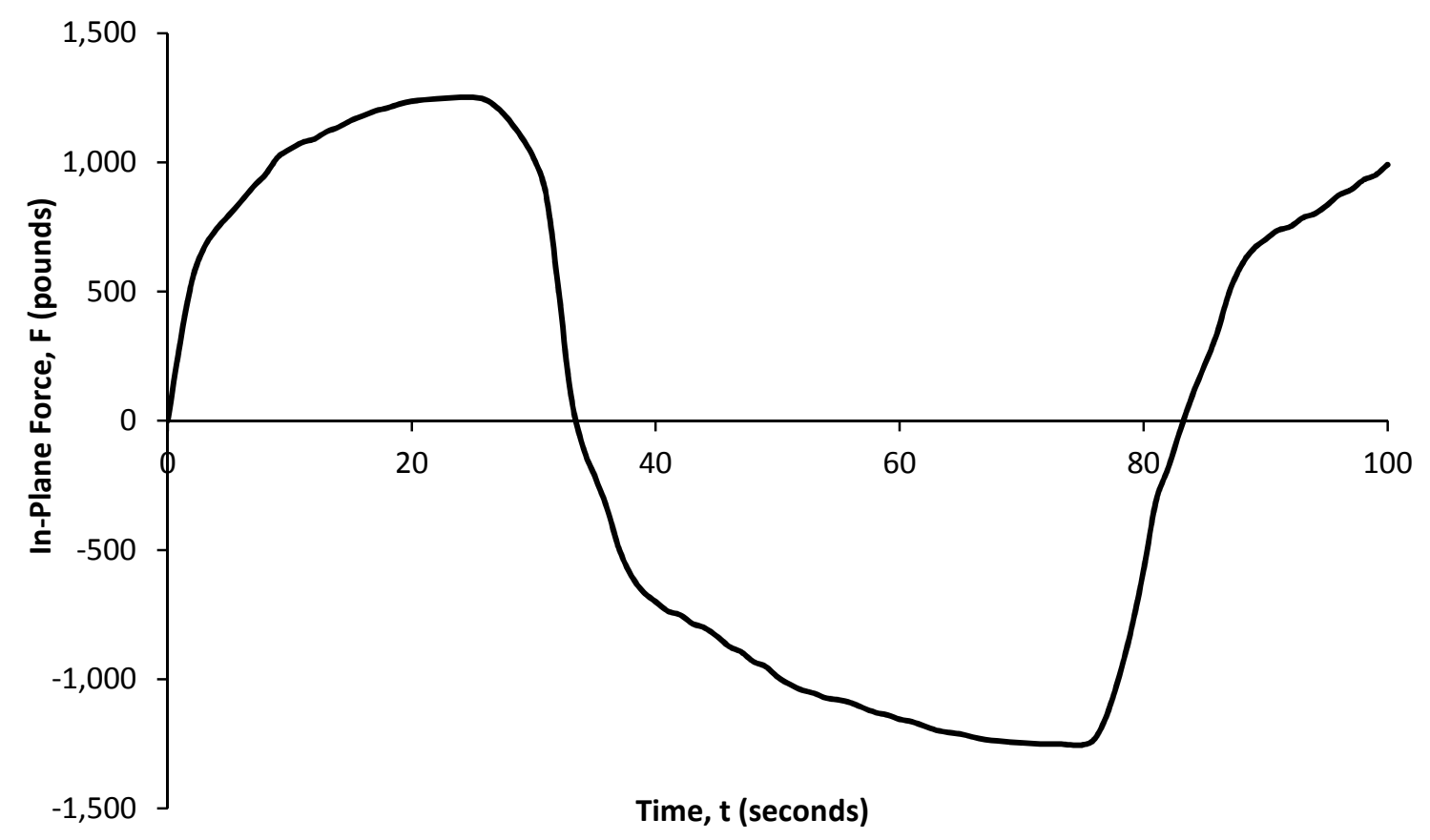

Figure 37. Force developed in the interior flexing rod versus time for $\mathrm{T}=100$ seconds.

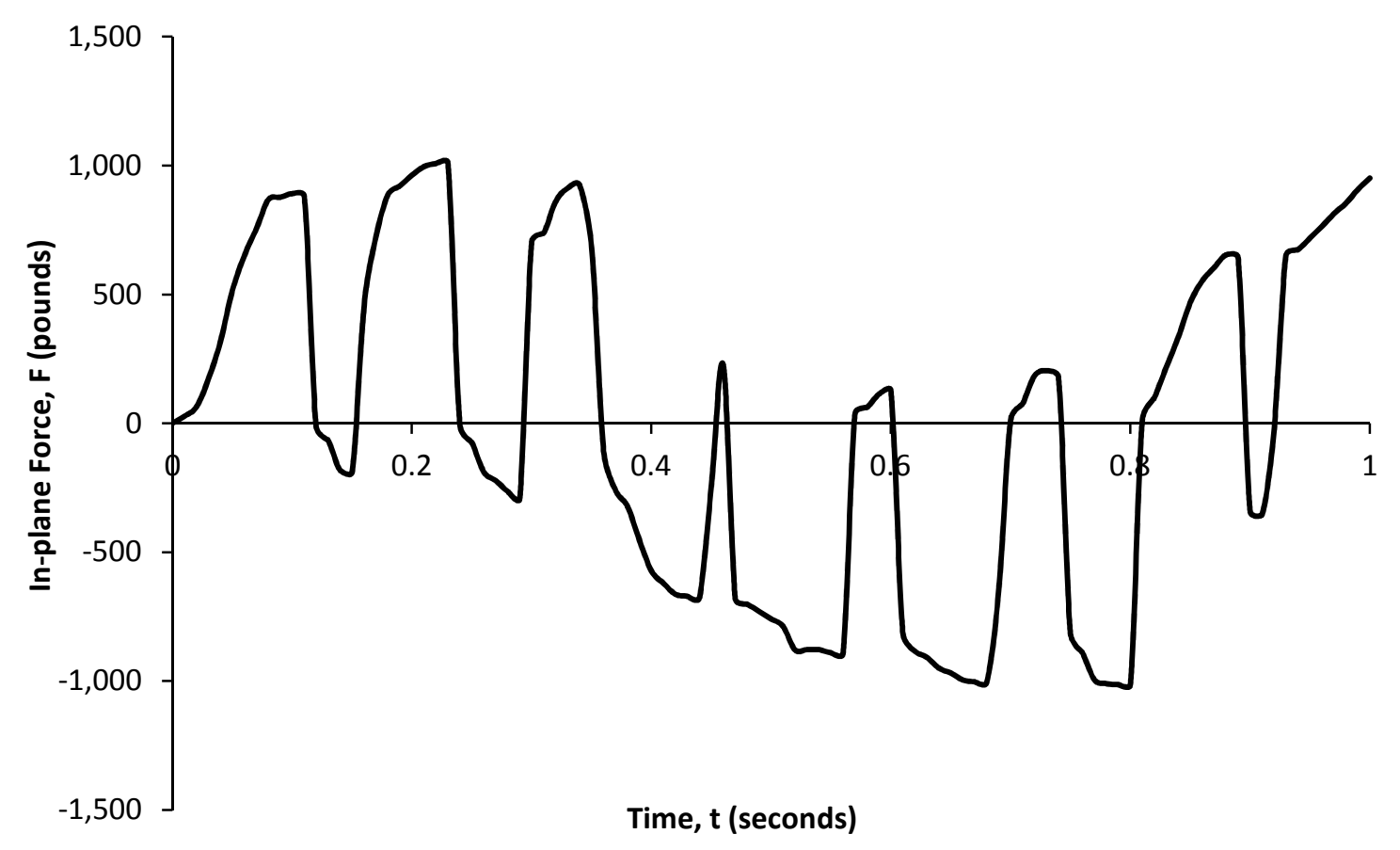

Figure 38. Force developed in the exterior flexing rod versus time for $\mathrm{T}=1 \mathrm{~second}$. 


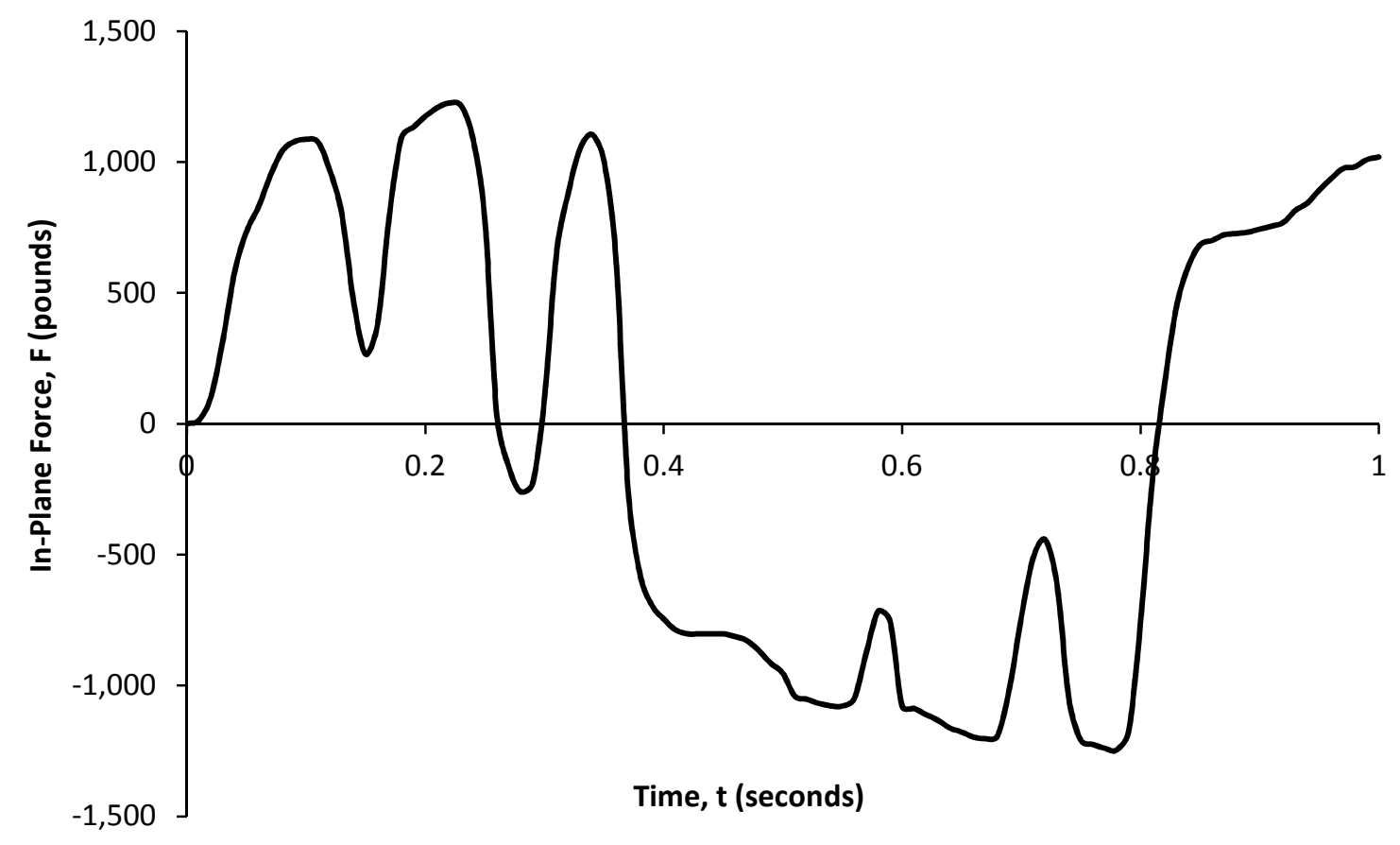

Figure 39. Force developed in the interior flexing rod versus time for $\mathrm{T}=1$ second.

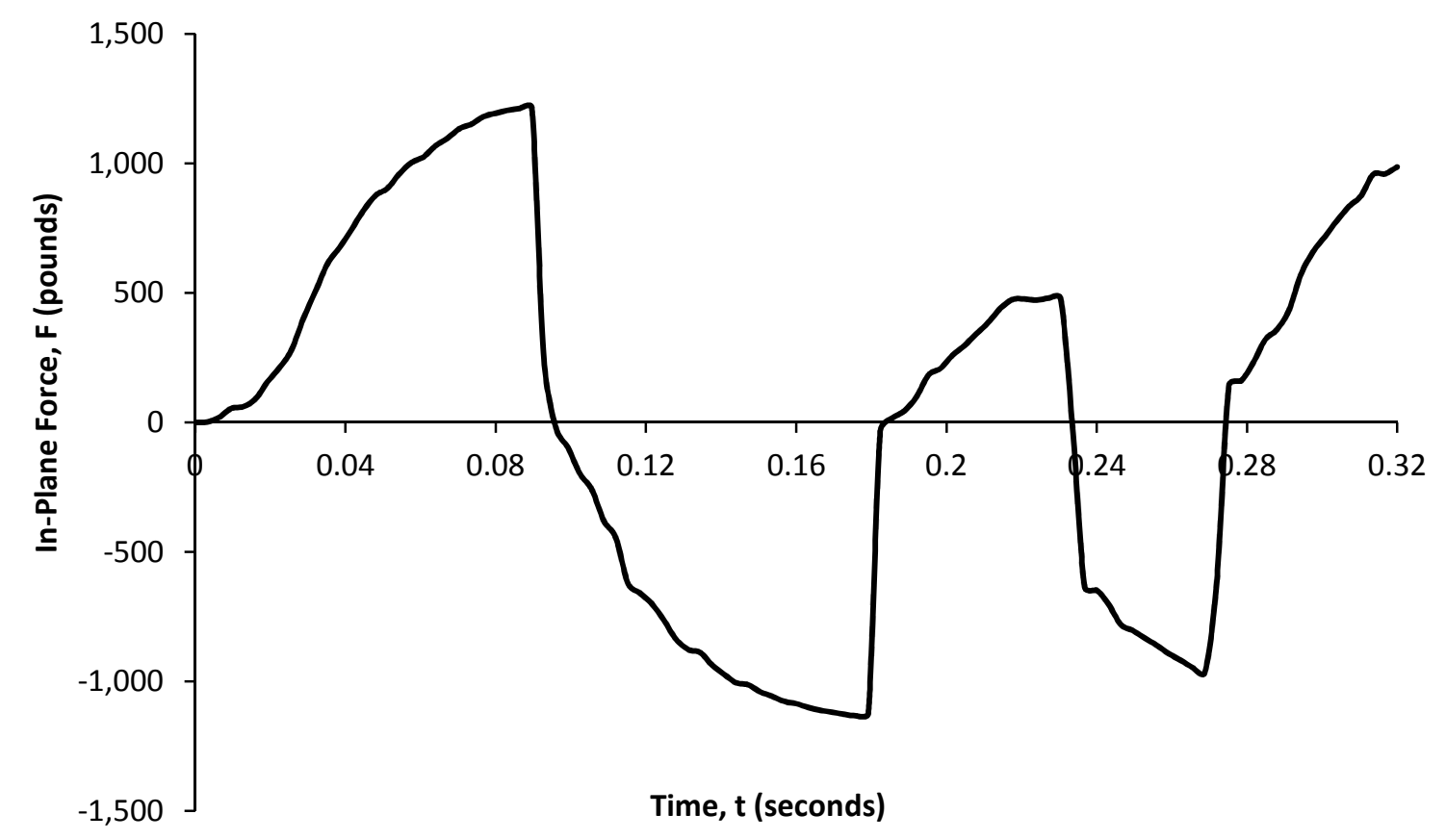

Figure 40. Force developed in the exterior flexing rod versus time for $\mathrm{T}=0.32$ seconds. 


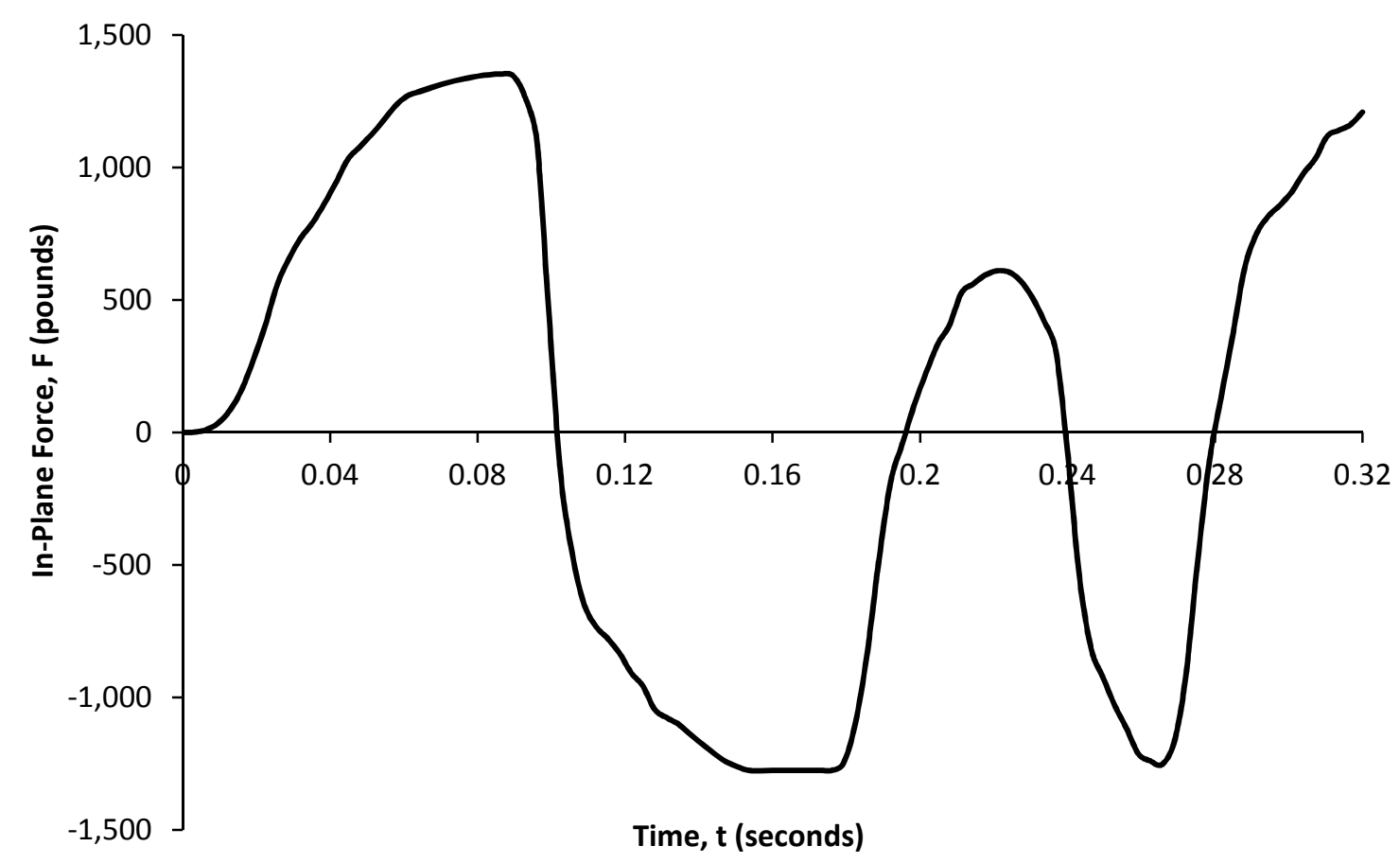

Figure 41. Force developed in the exterior flexing rod versus time for $\mathrm{T}=0.32$ seconds.

\subsubsection{Top links analysis result for Model MD 1 under dynamic load for a}

period of 100 seconds in the in-plane direction. Figure 42 shows the relationship

between the summation of forces developed in the flexing rod links in the $\mathrm{X}$ direction and the control displacement of the structural frame. A hysteretic behavior exists for forces developed in all flexing rods as the structural frame undergoes one cycle of displacement loading between +3.2 and -3.2 inches. 


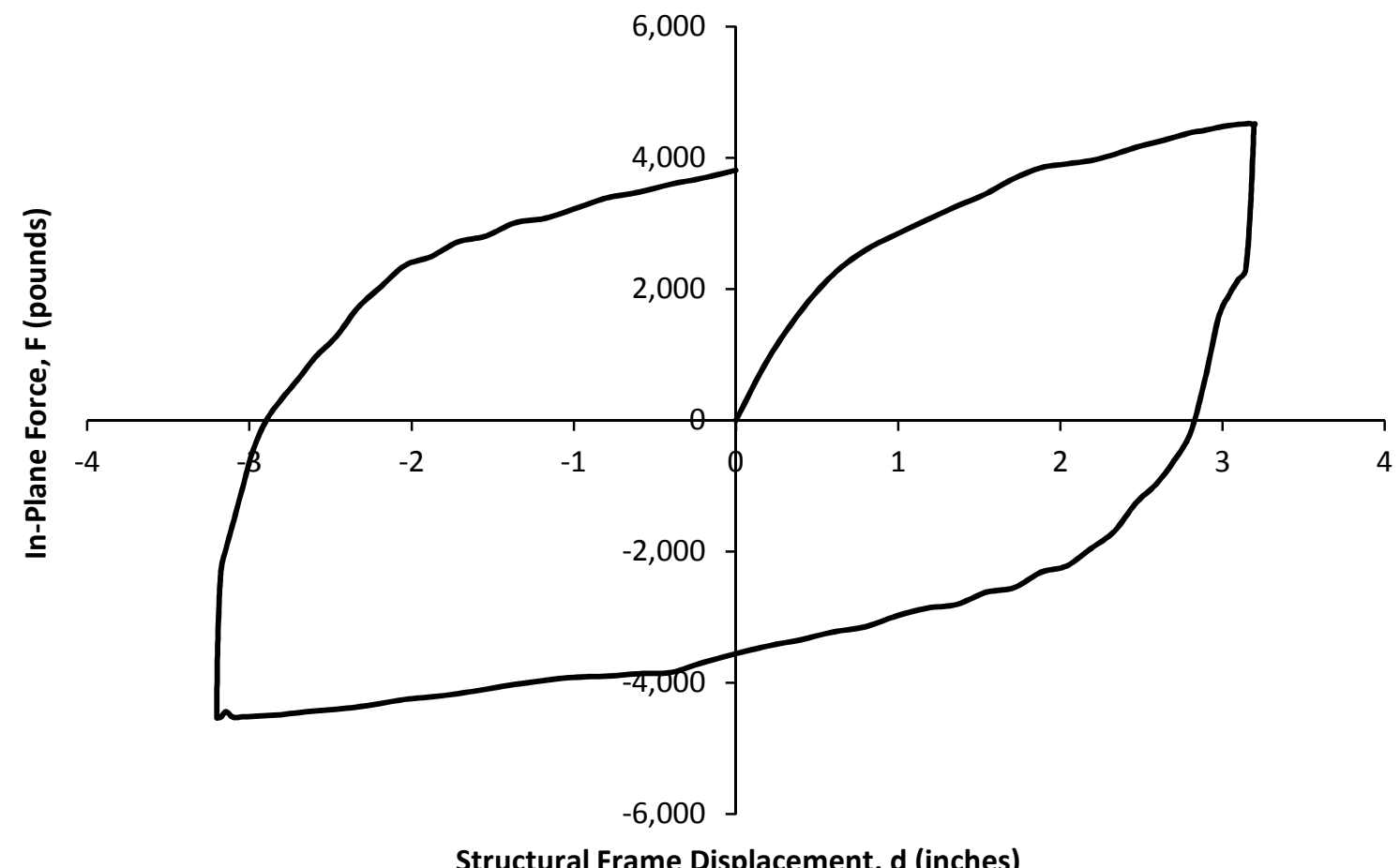

Figure 42. Forces developed in all flexing rod links versus the structural frame displacement.

Figures 43 and 44 show the force-deformation relationship for the top links.

Figure 43 is for Link 1, and Figure 44 is for Link 2. In both graphs, a hysteretic behavior exists as the structural frame undergoes one cycle of displacement loading. Link 4 has a graph identical to that of Link 1, and Link 3 has a graph identical to that of Link 2. 


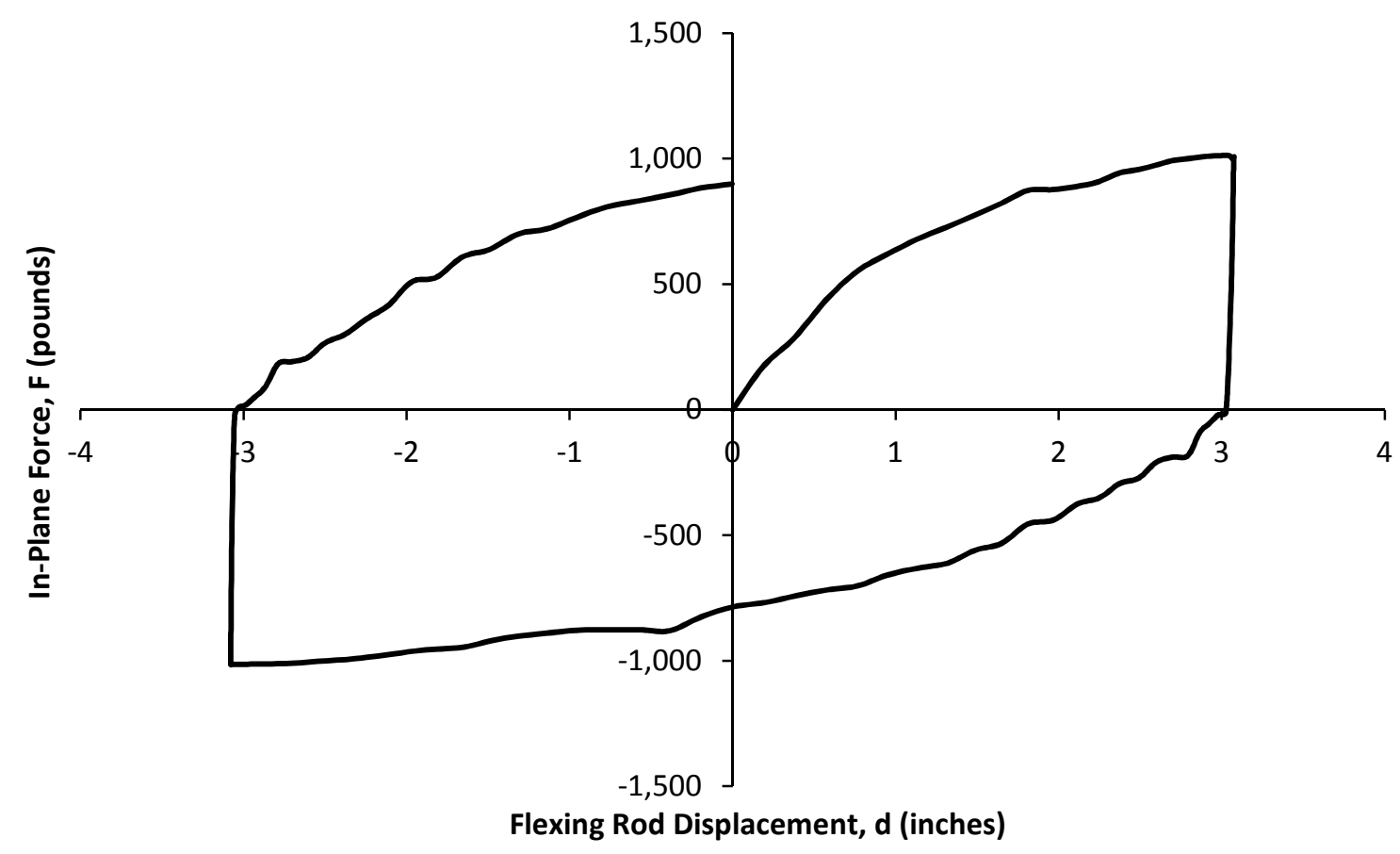

Figure 43. Force developed in the exterior flexing rod versus the exterior link displacement.

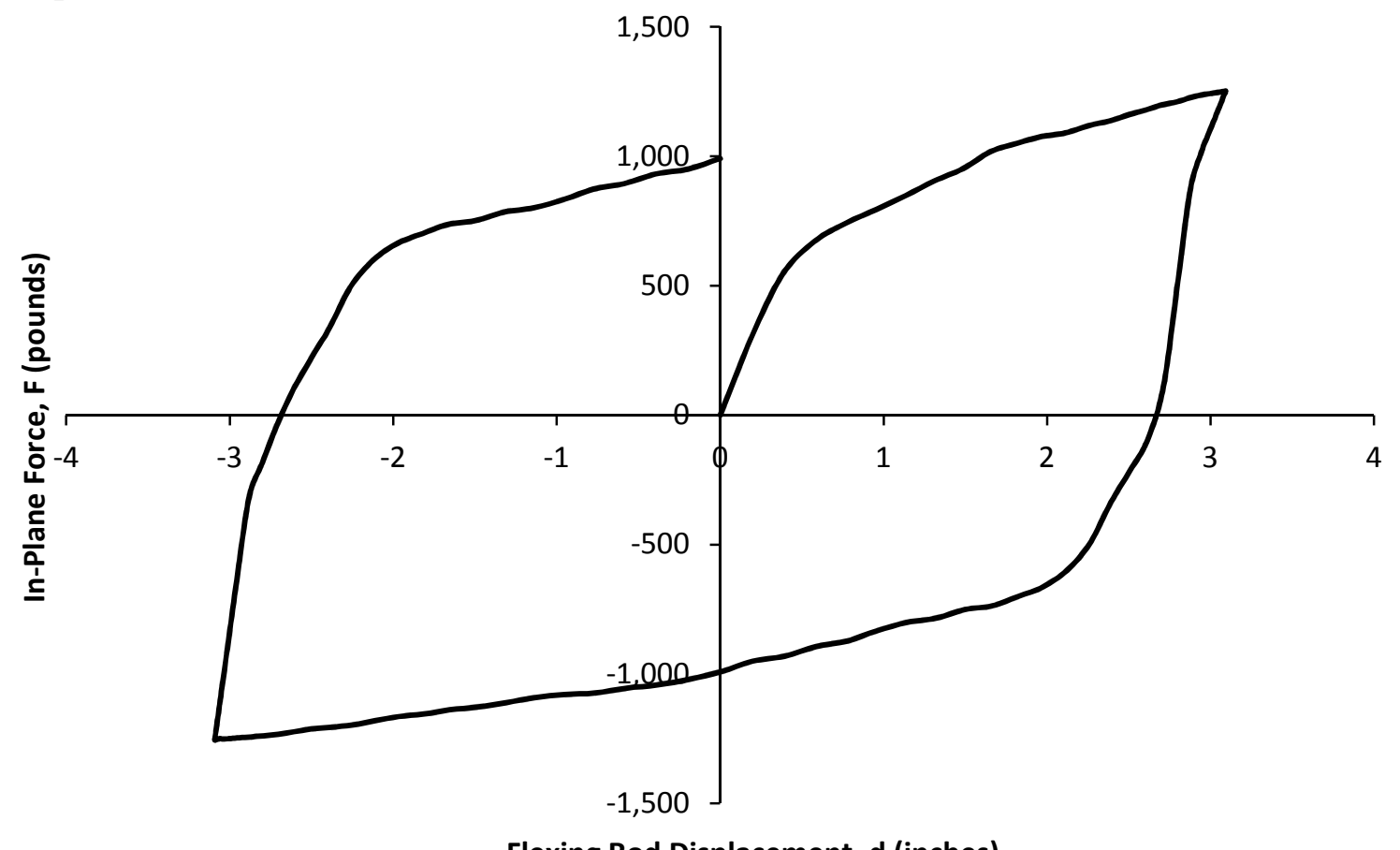

Flexing Rod Displacement, $d$ (inches)

Figure 44. Force developed in the interior flexing rod versus the interior link displacement. 
The force-deformation relationship for the two bottom links is linear. Table 18 shows the relationship type and its domain for each of the bottom links.

Table 18

Force-Deformation Relationships for Bottom Links in the X Direction

\begin{tabular}{llll}
\hline Link No. & $\begin{array}{l}\text { Relationship } \\
\text { Type }\end{array}$ & $\begin{array}{l}\text { Displacement Domain } \\
\text { (inches) }\end{array}$ & $\begin{array}{l}\text { Slope } \\
\text { (kips/in) }\end{array}$ \\
\hline Link 5 & Linear & {$[-0.0128,0.0 .128]$} & 10000 \\
Link 6 & Linear & {$[-0.124,0.123]$} & 1000 \\
\hline
\end{tabular}

5.2.3 Bottom links analysis result for Model MD 1 under dynamic load for a period of 100 seconds in the vertical direction. A force-deformation relationship in the $\mathrm{Z}$ direction for the two bottom links is also linear. Table 19 shows the relationship type and its domain for each of the bottom links.

Table 19

Force-Deformation Relationships for Bottom Links in the Z Direction

\begin{tabular}{llll}
\hline Link No. & $\begin{array}{l}\text { Relationship } \\
\text { Type }\end{array}$ & $\begin{array}{l}\text { Displacement Domain } \\
\text { (inches) }\end{array}$ & $\begin{array}{l}\text { Slope } \\
\text { (kip/in) }\end{array}$ \\
\hline Link 5 & Linear & {$[-0.00054,0.00054]$} & 10000 \\
Link 6 & Linear & {$[-0.0004,0.0004]$} & 10000 \\
\hline
\end{tabular}

\subsubsection{Acceleration and displacement result for Model MD 1 under dynamic}

load for a period of 100 seconds. To determine the acceleration in the $\mathrm{X}$ direction of the precast concrete panel, four points were selected at the middle of each edge of the precast concrete panel, and the absolute value of the average of the accelerations was then 
calculated. The maximum value of the average was then normalized with respect to the acceleration of gravity. The maximum acceleration of the panel in the $\mathrm{X}$ direction was $0.81 \mathrm{in} / \mathrm{sec}^{2}$, or $0.002 \mathrm{~g}$. For the structural frame, the maximum acceleration recorded was $0.0039 \mathrm{in} / \mathrm{sec}^{2}$. Based on Equation 4, the amplification ratio was calculated. Figure 45 shows the precast concrete panel acceleration time history.

$$
\begin{aligned}
& \boldsymbol{A P}=\frac{\left[\boldsymbol{a}_{\text {Panel }}\right]_{\max }}{\left[\boldsymbol{a}_{\text {frame }}\right]_{\text {Max }}} \\
& A P=\frac{0.81 \mathrm{in} . / \mathrm{sec}^{2}}{0.0039}=207
\end{aligned}
$$

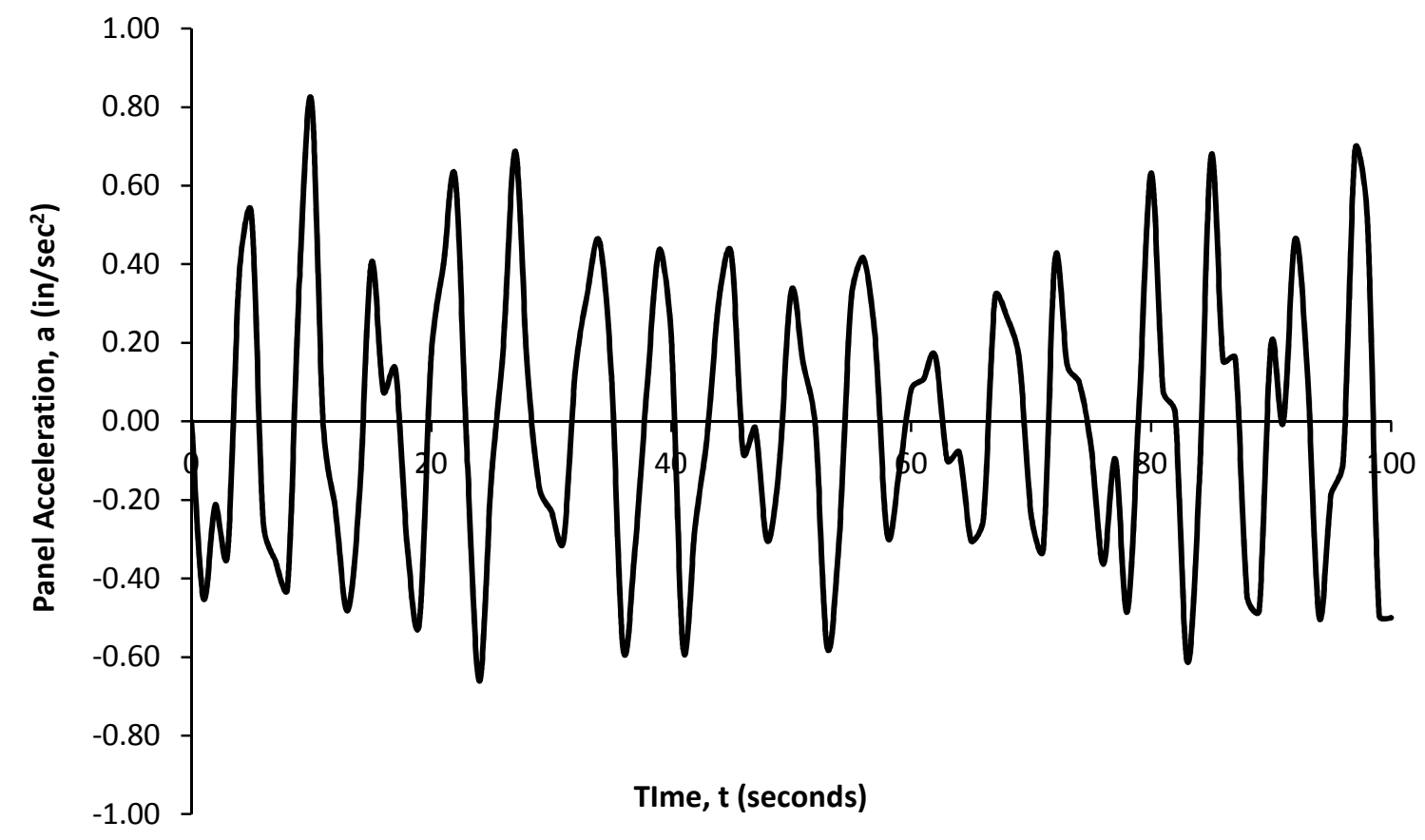

Figure 45. Precast concrete panel acceleration in the $\mathrm{X}$ direction versus time.

Figures 46 and 47 show the displacement of the precast concrete panel with respect to the time of analysis. The displacement of the precast concrete in the $\mathrm{X}$ 
direction is sinusoidal with an amplitude of 0.56 inches, whereas the displacement in the $\mathrm{Z}$ direction is sinusoidal with two distinctive vibration components: steady-state response and transient response.

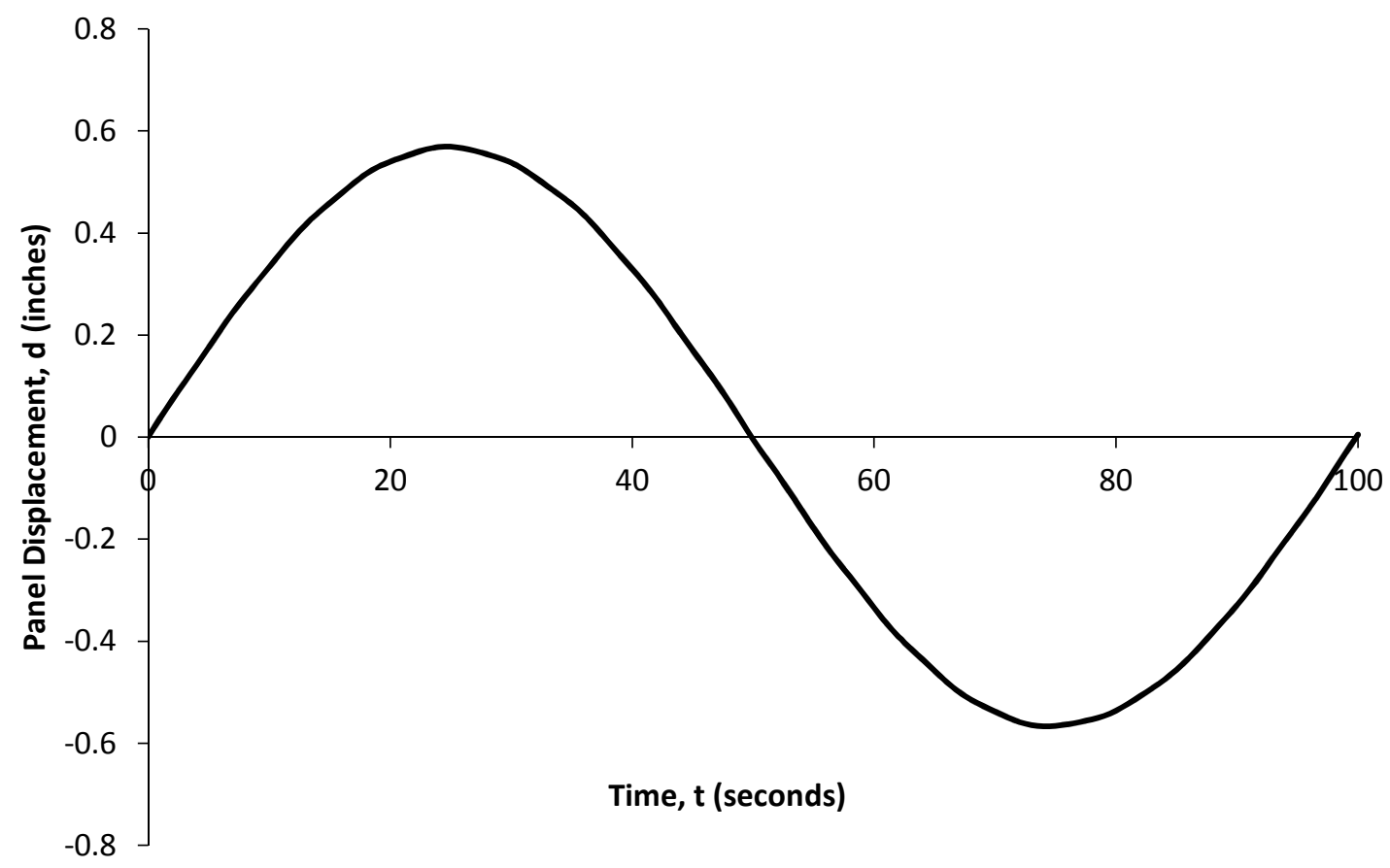

Figure 46. Precast concrete panel displacement in the $\mathrm{X}$ direction versus time. 


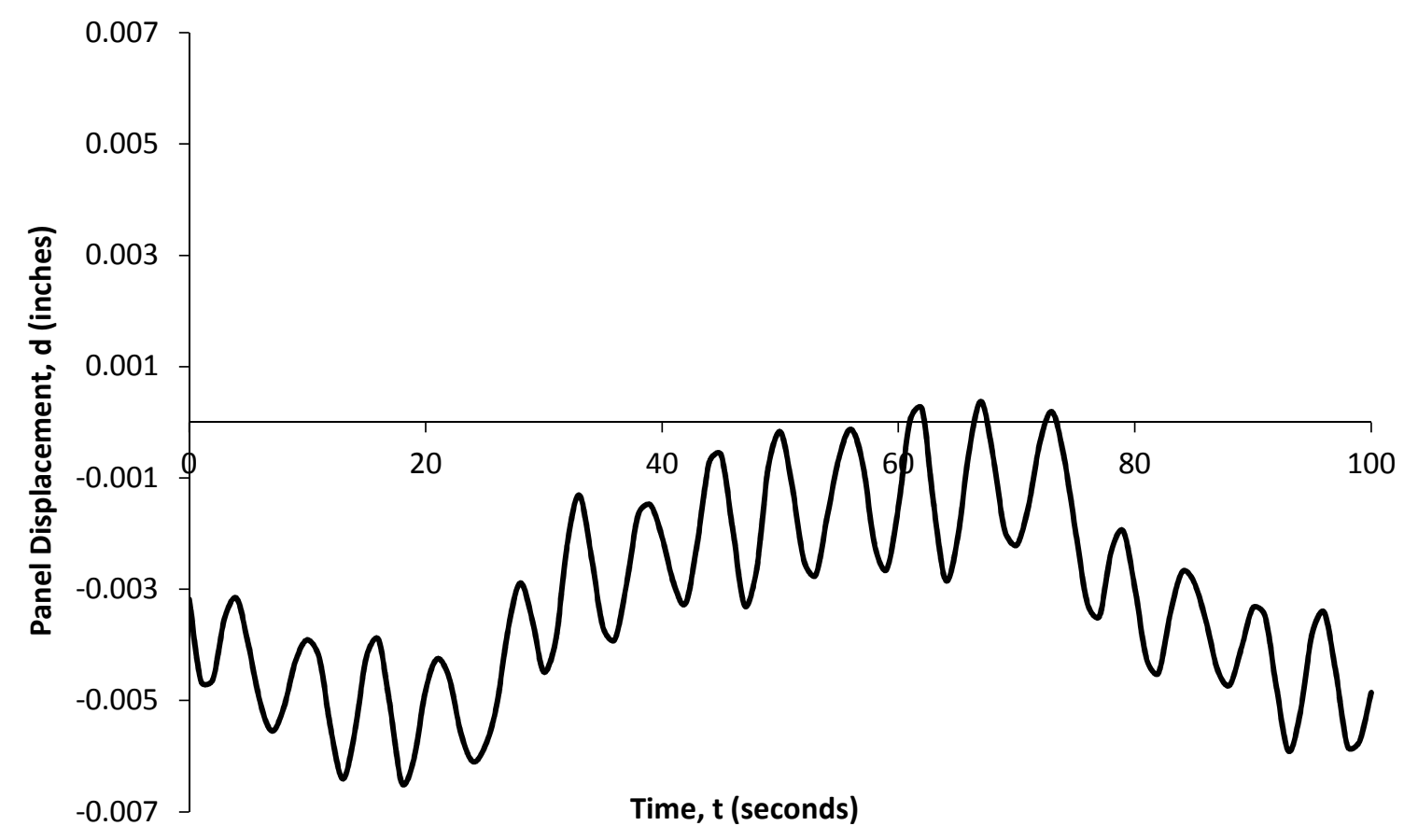

Figure 47. Precast concrete panel displacement in the $\mathrm{Z}$ direction versus time.

\subsubsection{Top links analysis result for Model MD 1 under dynamic load for a}

period of 1 second in the in-plane direction. Figures 48 and 49 show the force-

deformation relationship for the top links. Figure 48 is for Link 1, and Figure 49 is for

Link 2. In both graphs, a hysteretic behavior exists as the structural frame undergoes one cycle of displacement loading. The graph for Link 4 is identical to that of Link 1.

Similarly, the graph for Link 3 is identical to that of Link 2. An unloading and reloading cycle of the flexing rod link exists at six separate displacements for Links 1 and 4 . A separate unloading and reloading cycle exists for Link 2. 


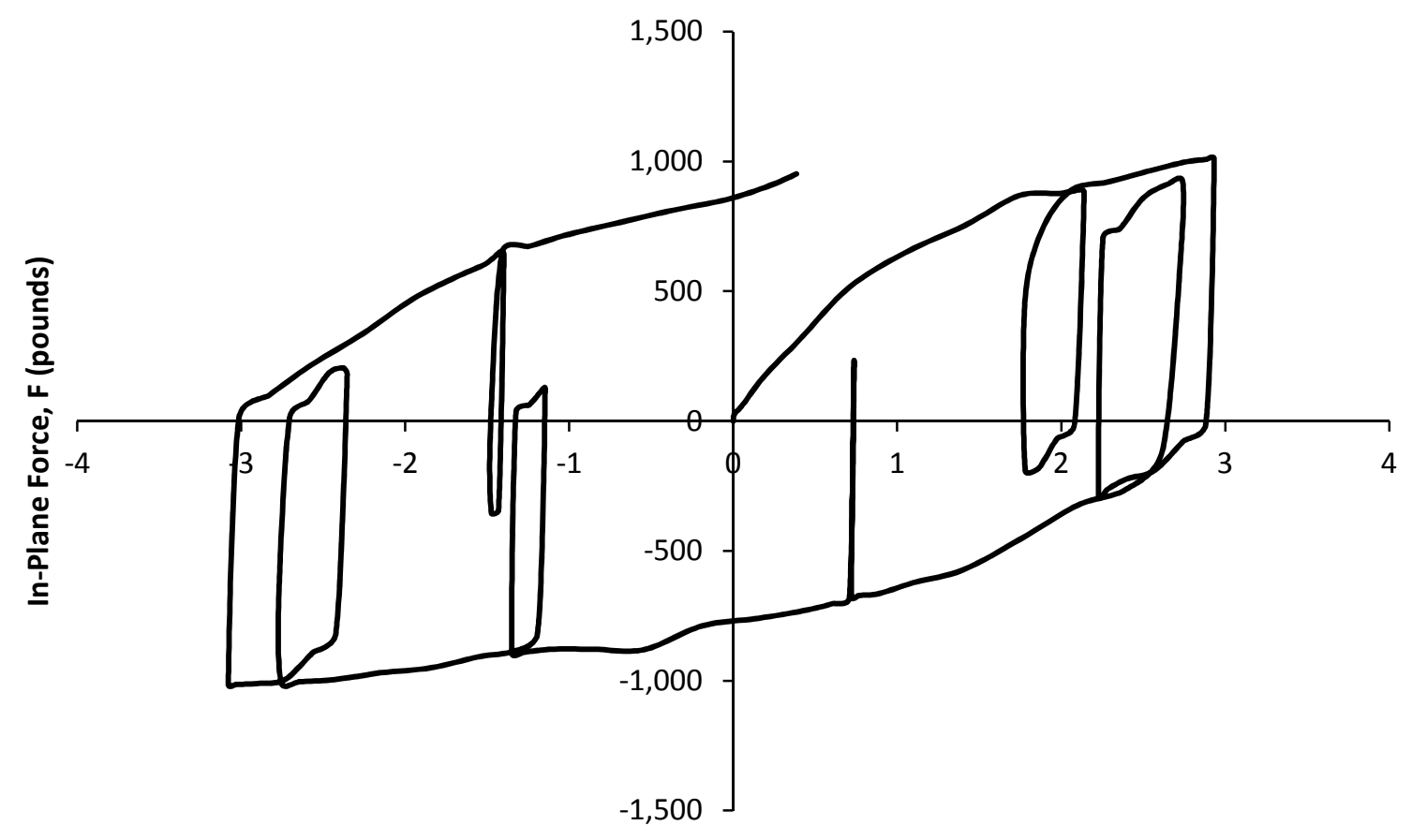

Flexing Rod Displacement, d (inches)

Figure 48. Force developed in the exterior flexing rod versus the exterior link displacement.

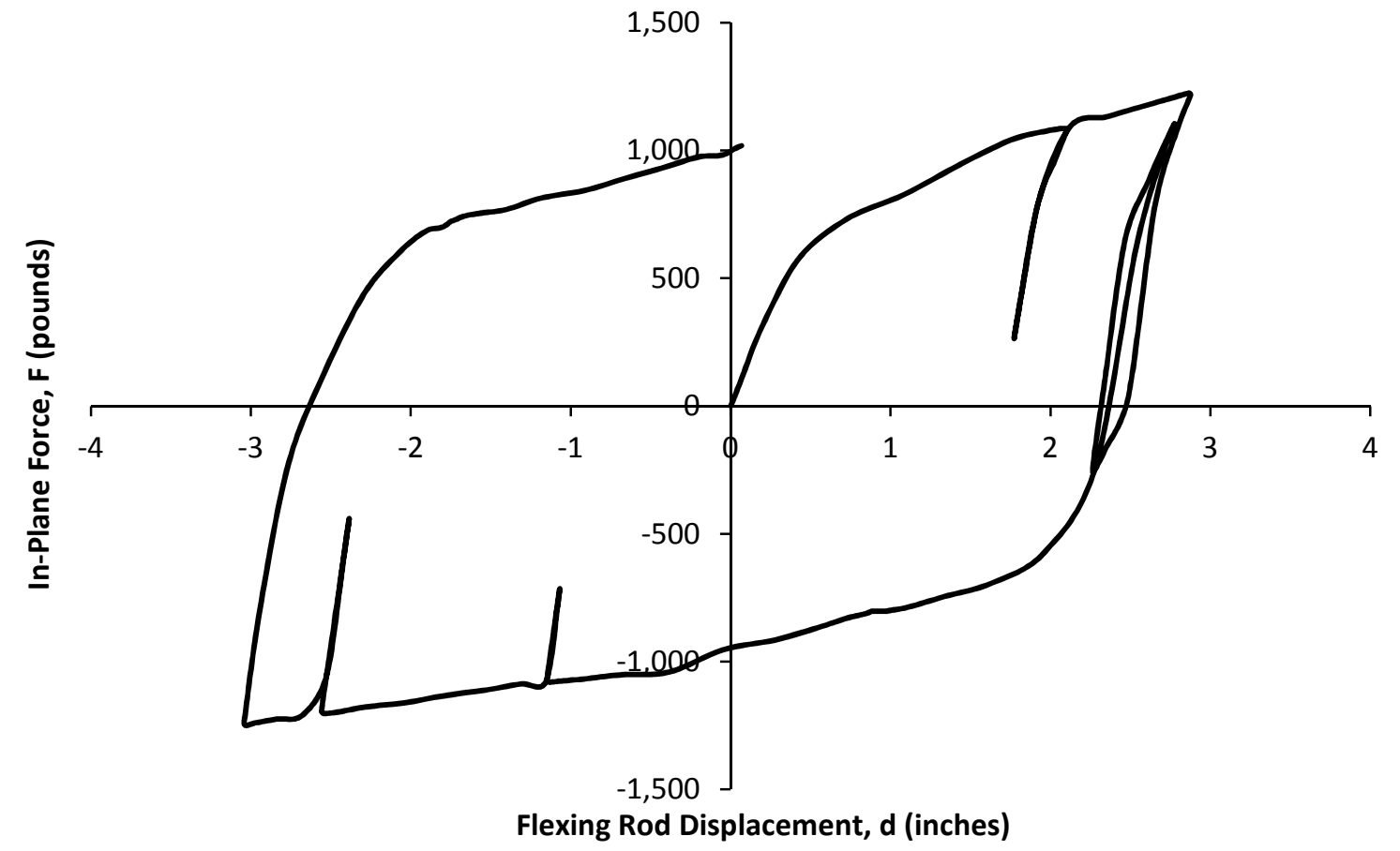

Figure 49. Force developed in the interior flexing rod versus the interior link displacement. 
The force-deformation relationship for the two bottom links is linear. Table 20 shows the relationship type and domain for each of the bottom links.

Table 20

Force-Deformation Relationships for Bottom Links in the X Direction

\begin{tabular}{llll}
\hline Link No. & $\begin{array}{l}\text { Relationship } \\
\text { Type }\end{array}$ & $\begin{array}{l}\text { Displacement Domain } \\
\text { (inches) }\end{array}$ & $\begin{array}{l}\text { Slope } \\
\text { (kip/in) }\end{array}$ \\
\hline Link 5 & Linear & {$[-0.02679,0.02357]$} & 10000 \\
Link 6 & Linear & {$[-0.07661,0.06442]$} & 1000 \\
\hline
\end{tabular}

5.2.6 Bottom links analysis result for Model MD 1 under dynamic load for a period of 1 second in the vertical direction. The force deformation relationship in the $\mathrm{Z}$ direction for the two bottom links is linear. Table 21 shows the relationship type and the domain for each of the bottom links.

Table 21

Force-Deformation Relationships for Bottom Links in the Z Direction

\begin{tabular}{llll}
\hline Link No. & $\begin{array}{l}\text { Relationship } \\
\text { Type }\end{array}$ & $\begin{array}{l}\text { Displacement Domain } \\
\text { (inches) }\end{array}$ & $\begin{array}{l}\text { Slope } \\
\text { (kip/in) }\end{array}$ \\
\hline Link 5 & Linear & {$[-0.02128,0.01875]$} & 10000 \\
Link 6 & Linear & {$[-0.022471,0.02709]$} & 10000 \\
\hline
\end{tabular}

\subsubsection{Acceleration and displacement result for Model MD1 under dynamic}

load for a period of 1 second. To determine the acceleration in the $\mathrm{X}$ direction for the precast concrete panel, four points were selected on the middle of each edge of the 
precast concrete panel, and an average of absolute values of acceleration was then calculated. The maximum value of the average was then normalized with respect to the acceleration of gravity. The maximum acceleration of the panel in the $\mathrm{X}$ direction was $106.5 \mathrm{in} / \mathrm{sec}^{2}$, or $0.27 \mathrm{~g}$. For the structural frame, the maximum acceleration recorded was $39.4 \mathrm{in} / \mathrm{sec}^{2}$. Therefore, the amplification ratio was 2.7 . Figure 50 shows the acceleration time history for the precast concrete panel time history.

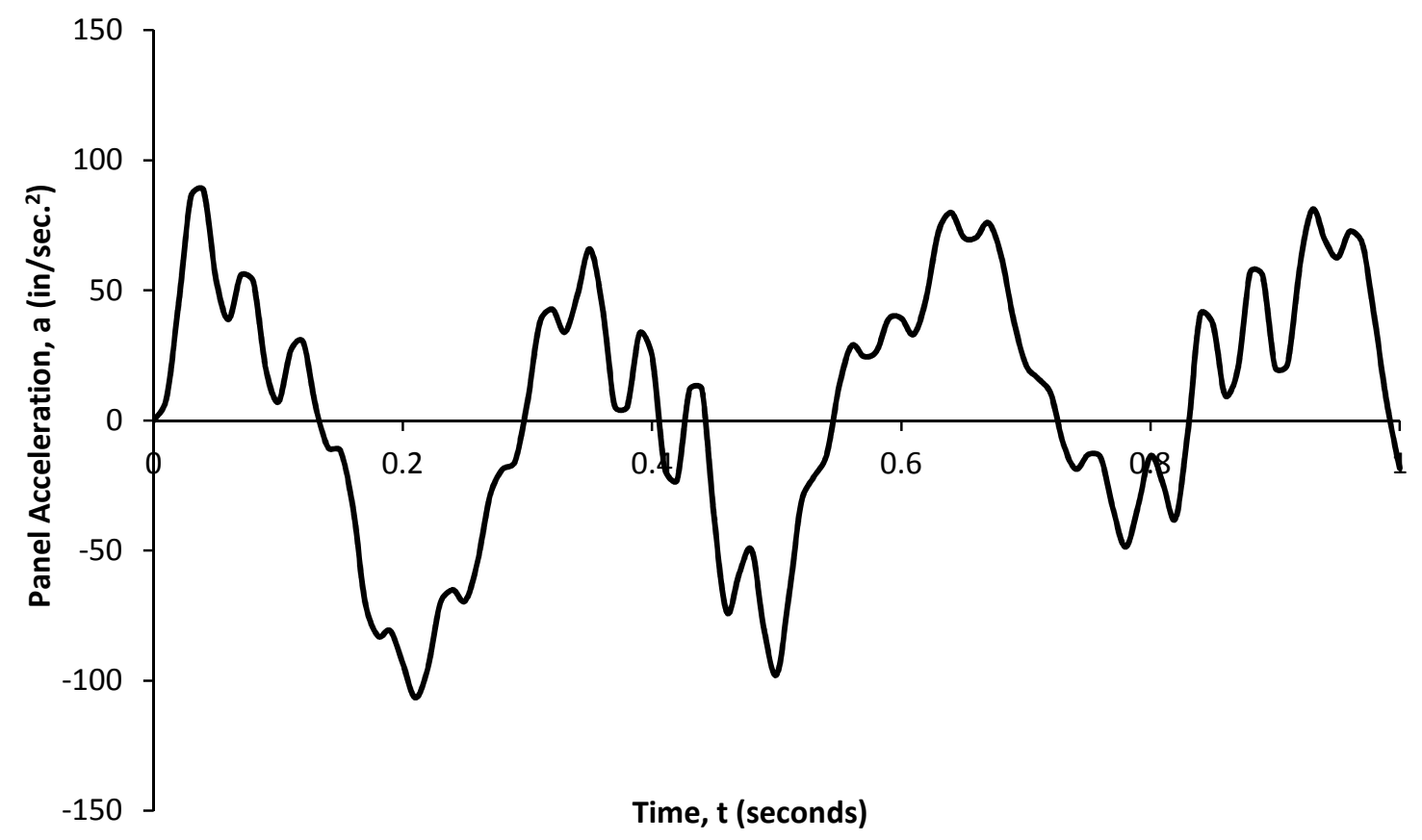

Figure 50. Acceleration of the precast concrete panel in the $\mathrm{X}$ direction versus time.

Figures 51 and 52 show the displacement of the precast concrete panel with respect to the time of analysis. The displacement of the precast concrete panel in the $\mathrm{X}$ direction is sinusoidal with two distinct vibration components: steady-state response and transient response. The transient response had a period of 0.32 seconds, which is the 
period of the maximum mass participation ratio of the precast concrete panel. The displacement in the $\mathrm{Z}$ direction is sinusoidal with two distinct vibration components: steady-state response and transient response.

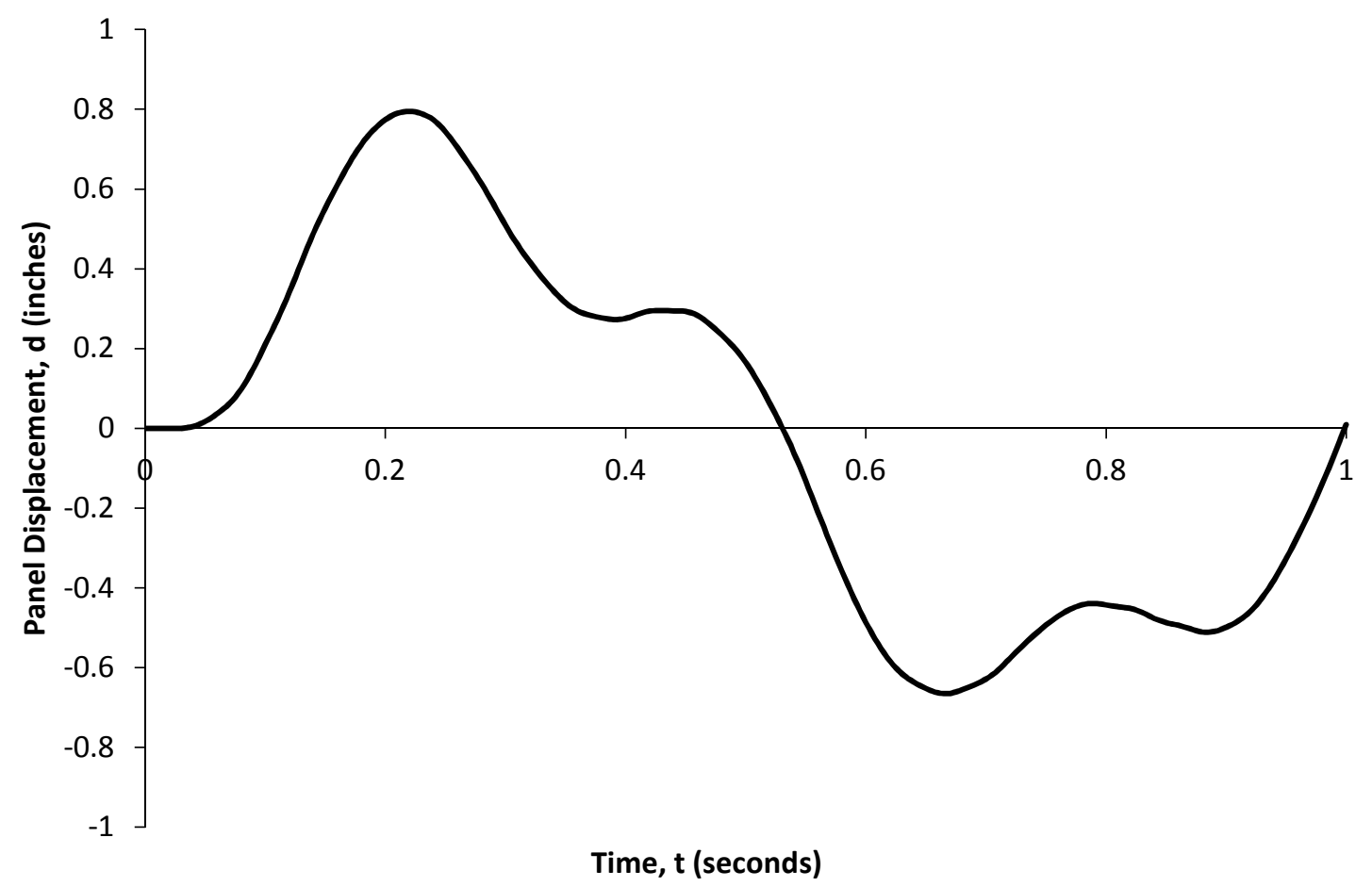

Figure 51. Precast concrete panel displacement in the $\mathrm{X}$ direction versus time. 


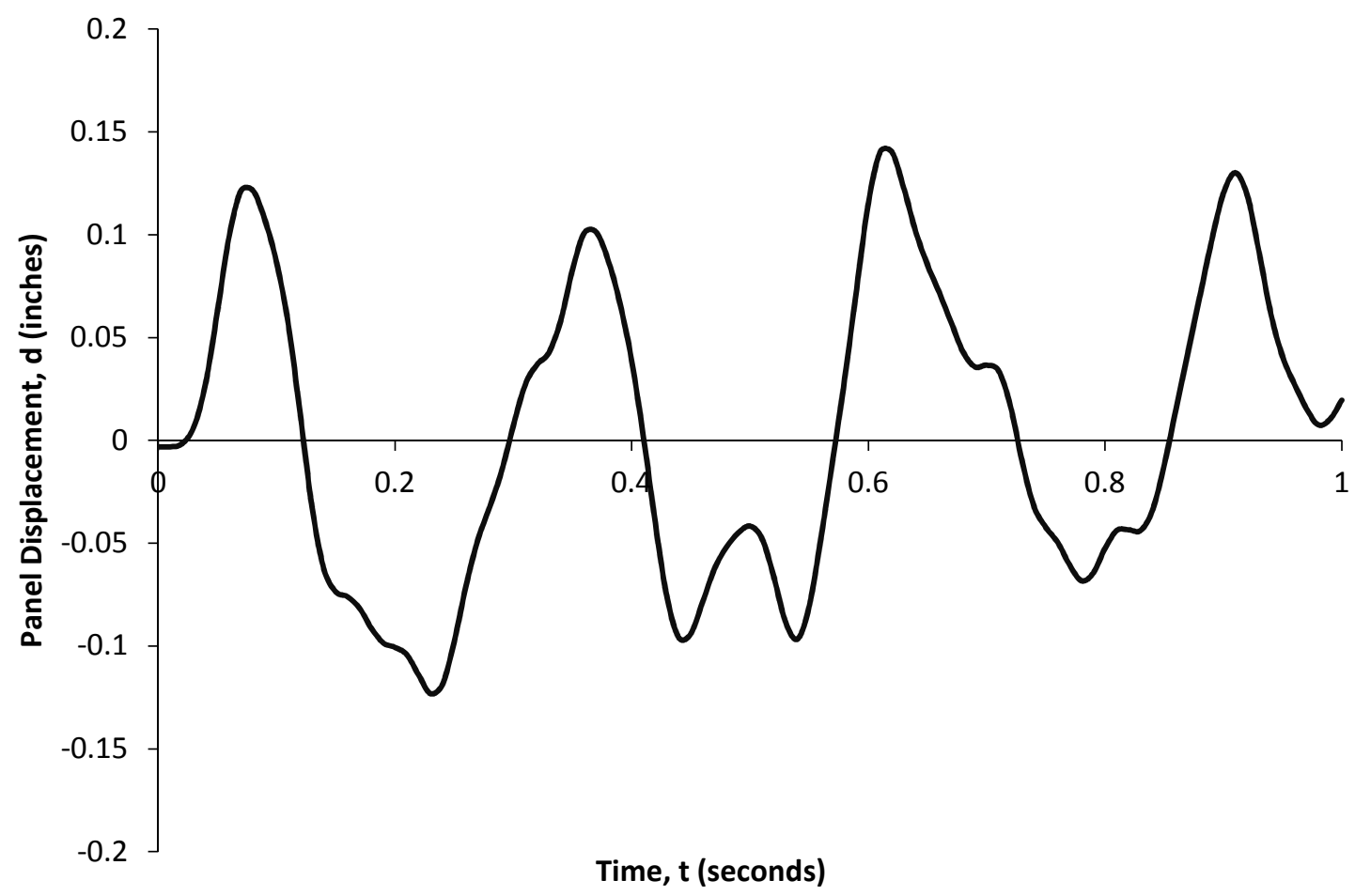

Figure 52. Precast concrete panel displacement in the $\mathrm{Z}$ direction versus time.

\subsubsection{Top links analysis result for Model MD 1 under dynamic load for a} period of 0.32 seconds in the in-plane direction. Figures 53 and 54 show the forcedeformation relationship for the top links. Figure 53 is for Link 1, and Figure 54 is for Link 2. In both graphs a hysteretic behavior exists as the structural frame undergoes one cycle of displacement loading. Link 4 has an identical graph to that of Link 1, and Link 3 has an identical graph to that of Link 2. One loading and unloading cycle exists in the force-deformation graphs of Link 1 and Link 2. 


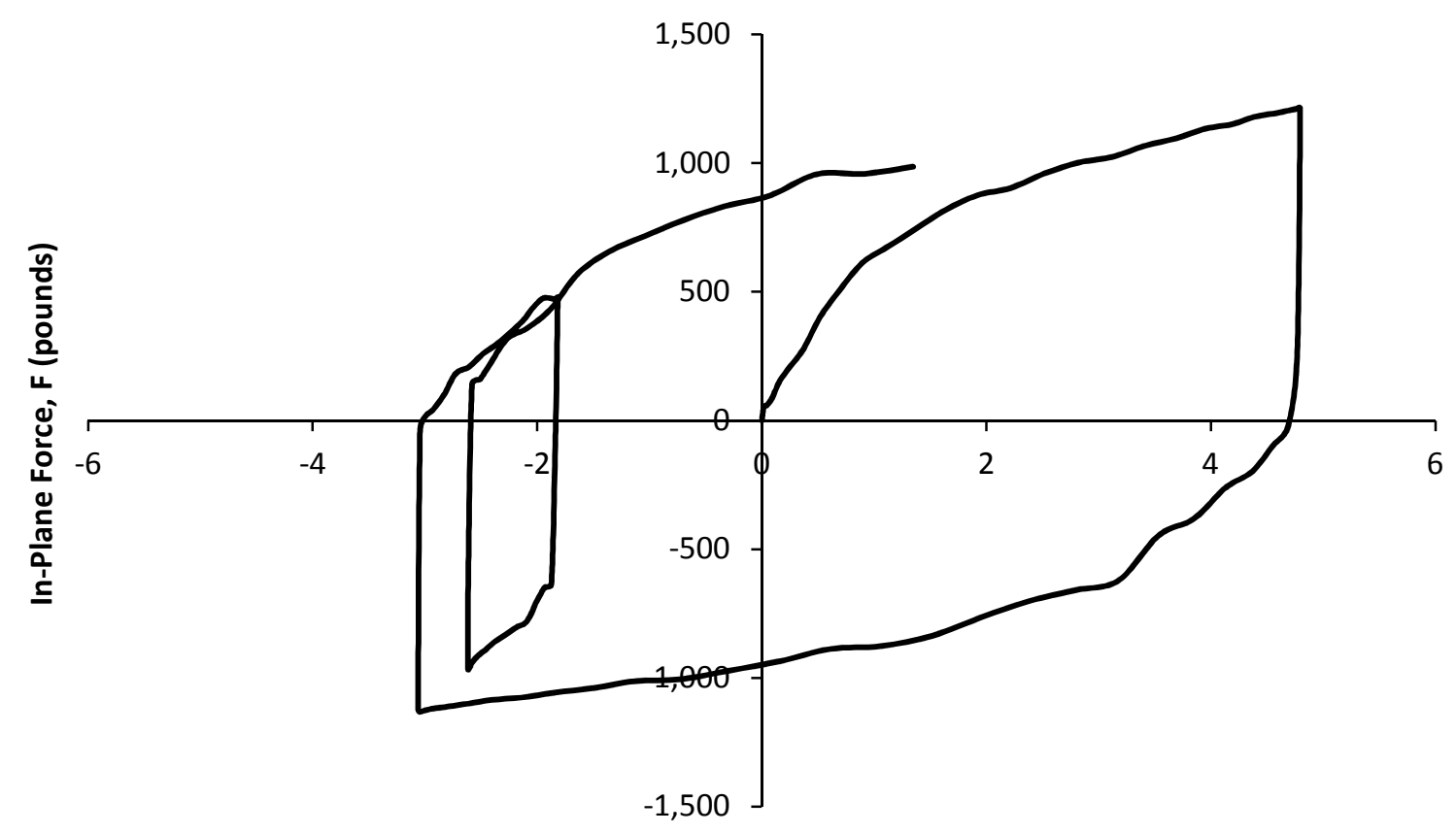

Flexing Rod Displacement, $d$ (inches)

Figure 53. Force developed in the exterior flexing rod versus the exterior link displacement.

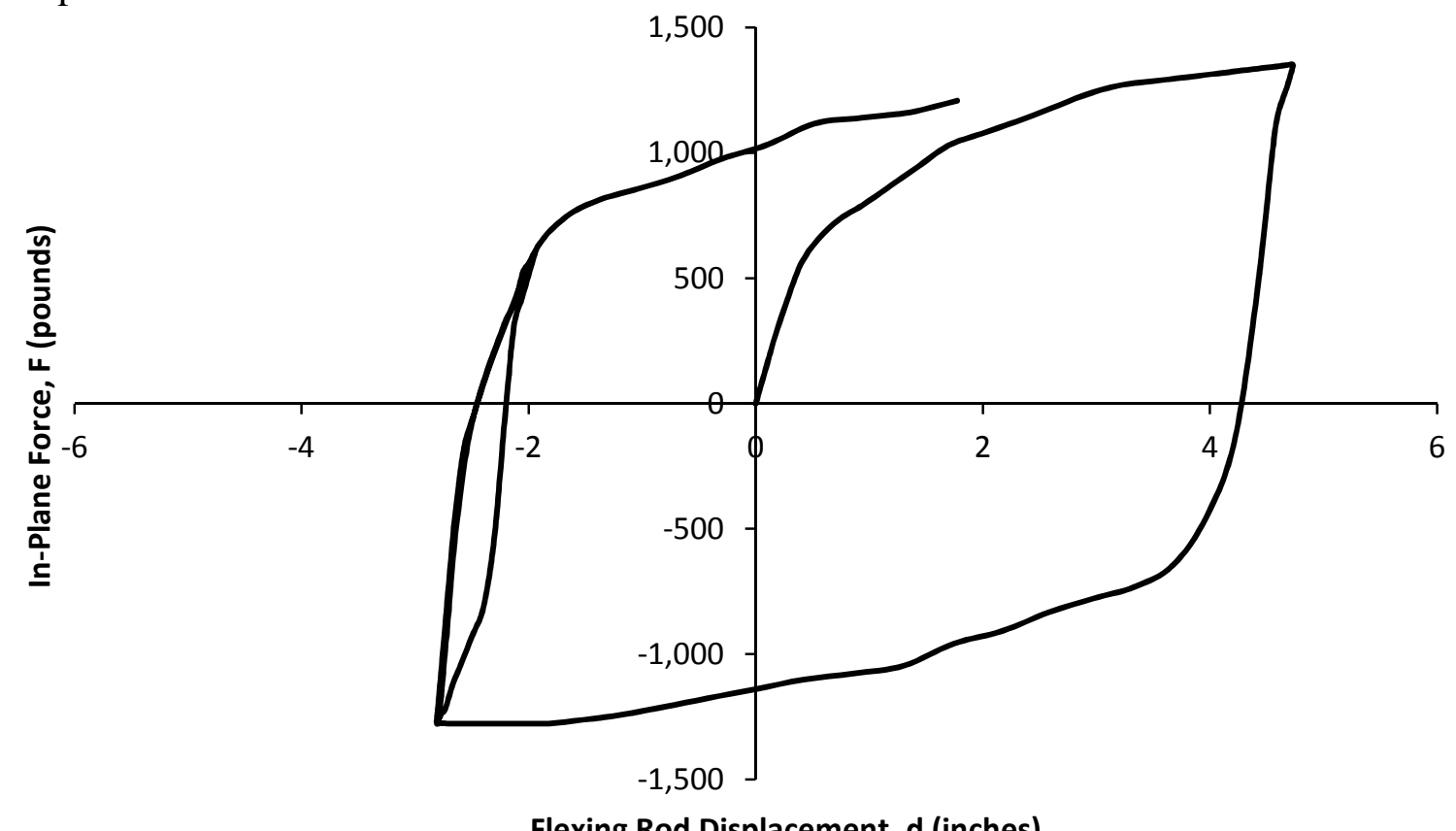

Flexing Rod Displacement, $d$ (inches)

Figure 54. Force developed in the interior flexing rod versus the interior link displacement. 
The force-deformation relationship for the left bottom link and right bottom link is linear as the structural frame undergoes one cycle of displacement. Table 22 shows the relationship type and domain for each of the bottom links.

Table 22

Force-Deformation Relationships for Bottom Links in the X Direction

\begin{tabular}{llll}
\hline Link No. & $\begin{array}{l}\text { Relationship } \\
\text { Type }\end{array}$ & $\begin{array}{l}\text { Displacement Domain } \\
\text { (inches) }\end{array}$ & $\begin{array}{l}\text { Slope } \\
\text { (kip/in) }\end{array}$ \\
\hline Link 5 & Linear & {$[-0.08630,0.14618]$} & 10000 \\
Link 6 & Linear & {$[-0.23264,0.37131]$} & 1000 \\
\hline
\end{tabular}

\subsubsection{Bottom links analysis result for Model MD 1 under dynamic load for a}

period of 0.32 seconds in the in-plane direction. The force-deformation relationship in the $\mathrm{Z}$ direction for the two bottom links is linear. Table 23 shows the relationship type and domain for each of the bottom links.

Table 23

Force-Deformation Relationships for Bottom Links in the Z Direction

\begin{tabular}{llll}
\hline Link No. & $\begin{array}{l}\text { Relationship } \\
\text { Type }\end{array}$ & $\begin{array}{l}\text { Displacement Domain } \\
\text { (inches) }\end{array}$ & $\begin{array}{l}\text { Slope } \\
\text { (kip/in) }\end{array}$ \\
\hline Link 5 & Linear & {$[-0.17339,0.11015]$} & 10000 \\
Link 6 & Linear & {$[-0.09702,0.16017]$} & 10000 \\
\hline
\end{tabular}

\subsubsection{Acceleration and displacement result for Model MD 1 under dynamic} load for a period of $\mathbf{0 . 3 2}$ seconds. To determine the acceleration in the $\mathrm{X}$ direction for 
the precast concrete panel, four points were selected on the middle of each edge of the precast concrete panel, and an average of absolute values of acceleration was then calculated. The maximum value of the average was then normalized with respect to the acceleration of gravity. The maximum acceleration of the panel in the $\mathrm{X}$ direction was $723.5 \mathrm{in} / \mathrm{sec}^{2}$, or $1.8 \mathrm{~g}$. For the structural frame the maximum acceleration recorded was $385.15 \mathrm{in} / \mathrm{sec}^{2}$. Therefore, the amplification ratio was 1.87 . Figure 55 shows the acceleration time history for the precast concrete panel time history.

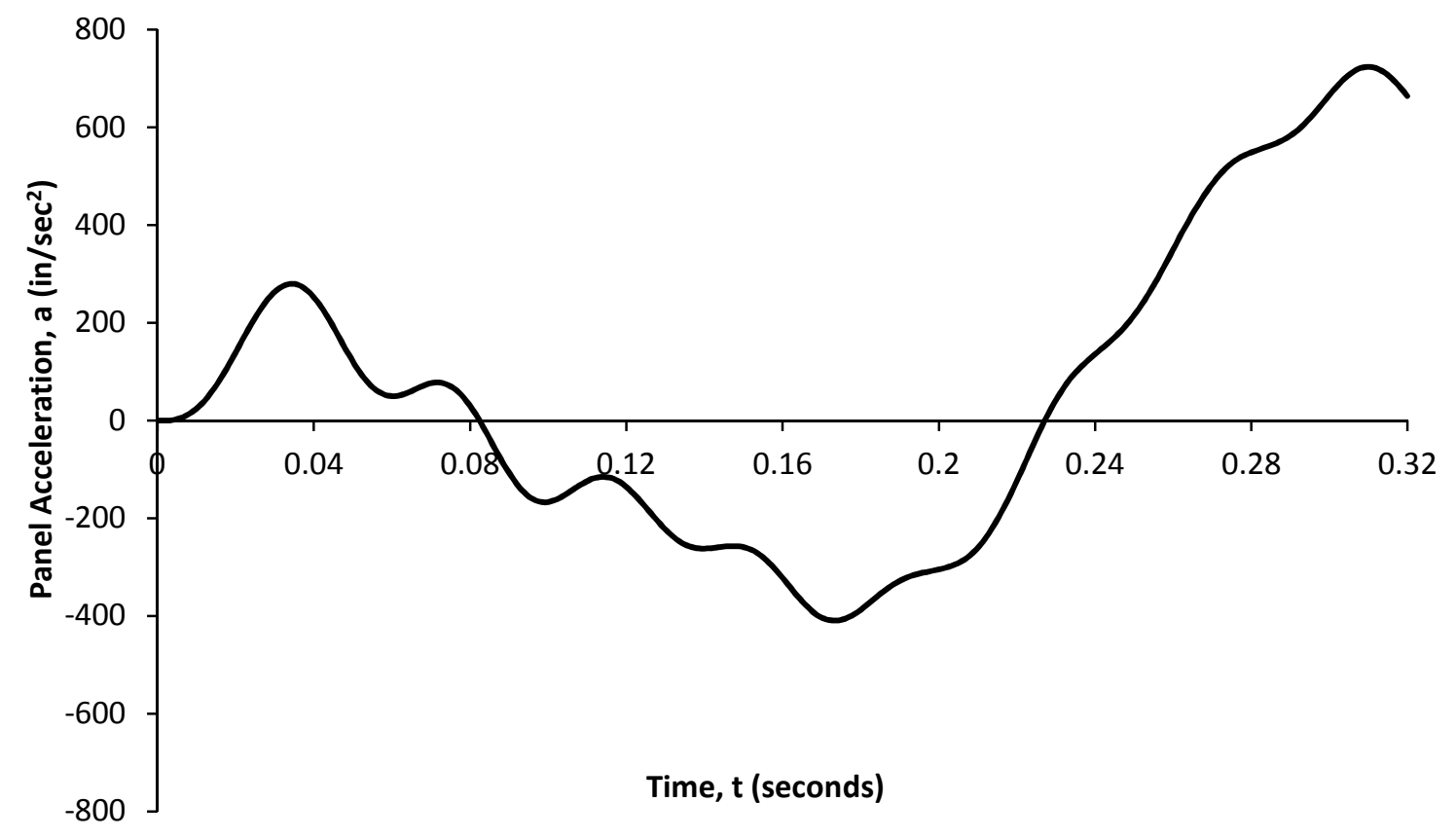

Figure 55. Acceleration of the precast concrete panel in the $\mathrm{X}$ direction versus time.

Figures 56 and 57 show the displacement of the precast concrete panel with respect to the time of analysis. The displacement of the precast concrete in the $\mathrm{X}$ direction is sinusoidal, and the amplitude of the displacement increases for each time 
increment. The displacement in the $\mathrm{Z}$ direction is sinusoidal with two distinct vibration components with similar frequency: steady-state response and transient response.

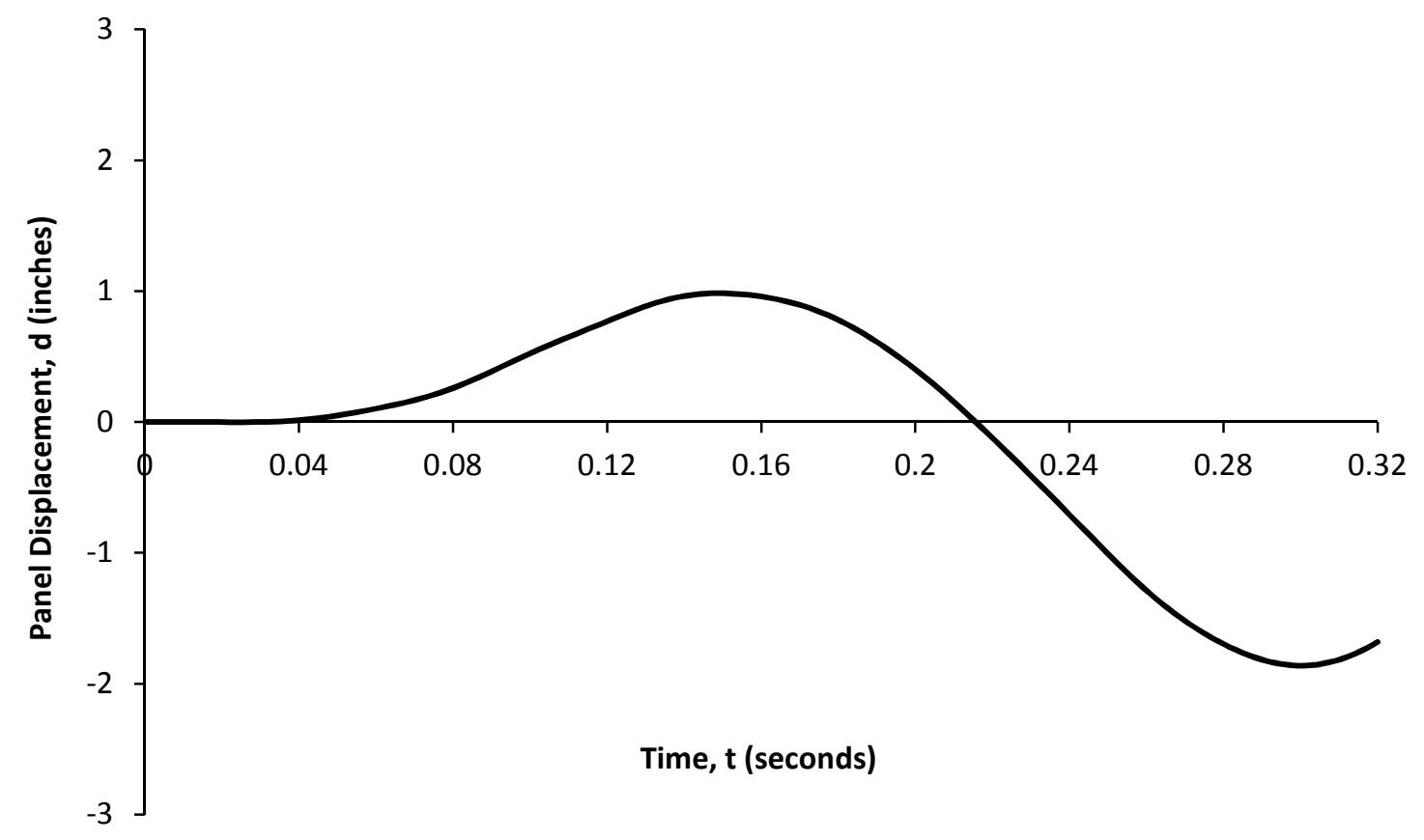

Figure 56. Precast concrete panel displacement in the $\mathrm{X}$ direction versus time. 


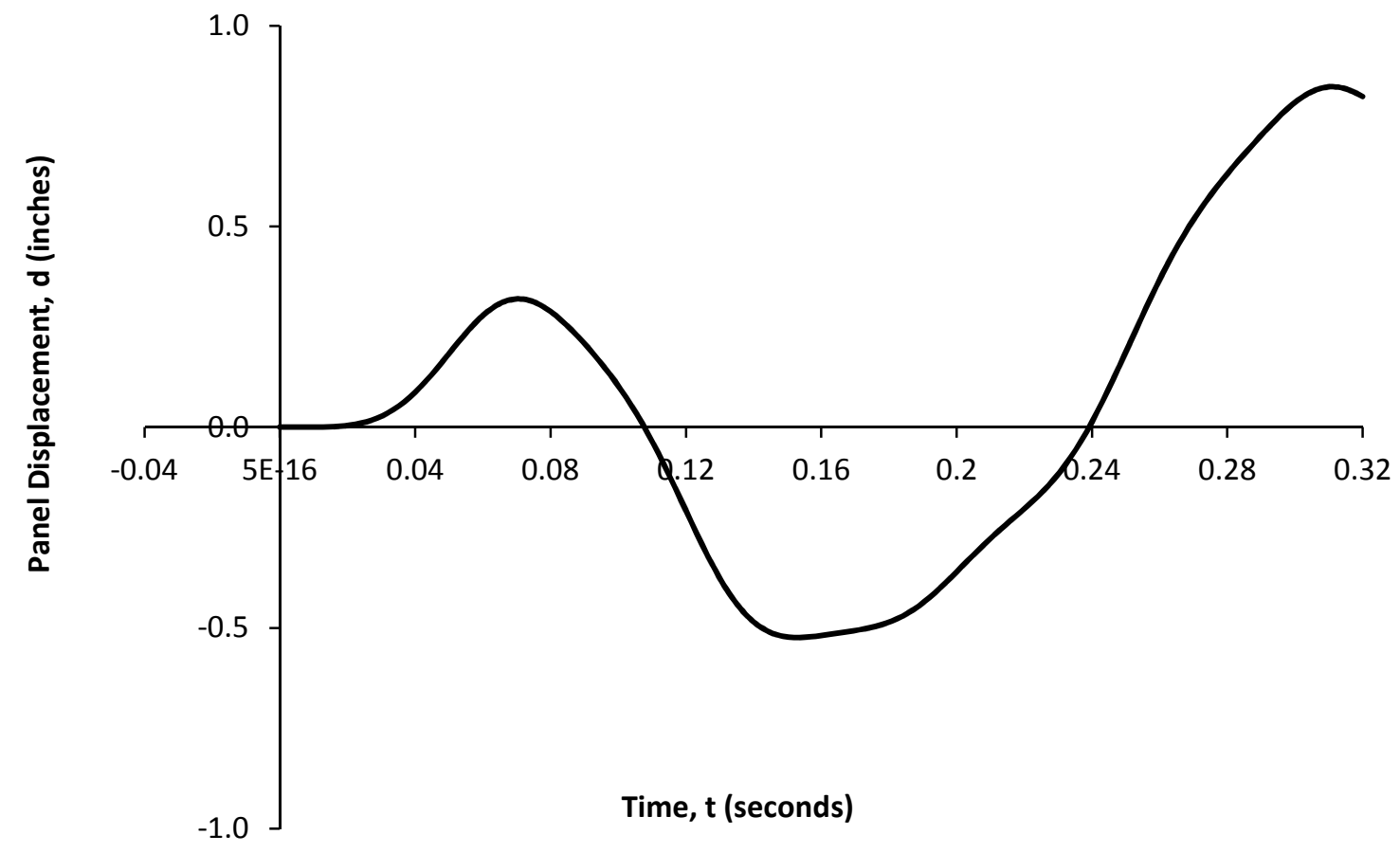

Figure 57. Precast concrete panel displacement in the $\mathrm{X}$ direction versus time. 


\subsection{Analysis Result for Model MD 2}

5.3.1 Top links force-time relationship for Model MD 2. Three nonlinear dynamic analyses using displacement-controlled time history were used to evaluate the dynamic characteristics of the flexing rod links, the bottom links, and the precast concrete panel. Figures 58 and 59 show the relationship between forces developed in the each of the flexural links with respect to the time of loading for a period of 100 seconds. Figures 60 and 61 show the same relationship for loading for a period of 1 second. Figures 62 and 63 show the same relationship for loading for a period of 0.32 seconds. In all cases Link 3 has an identical graph to that of Link 2, and Link 4 has an identical graph to that of Link 1.

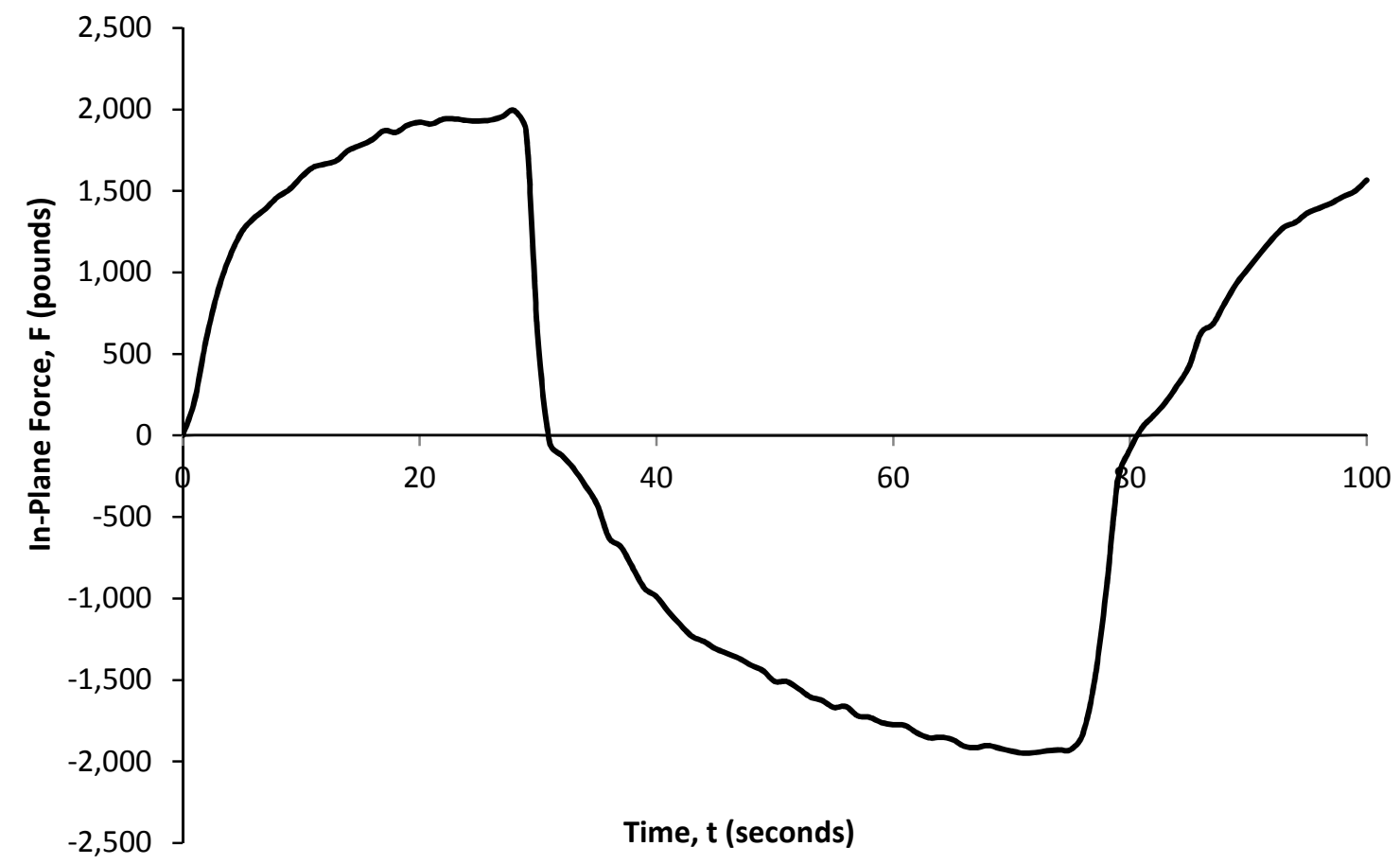

Figure 58. Force developed in the exterior flexing rod versus time for $\mathrm{T}=100$ seconds. 


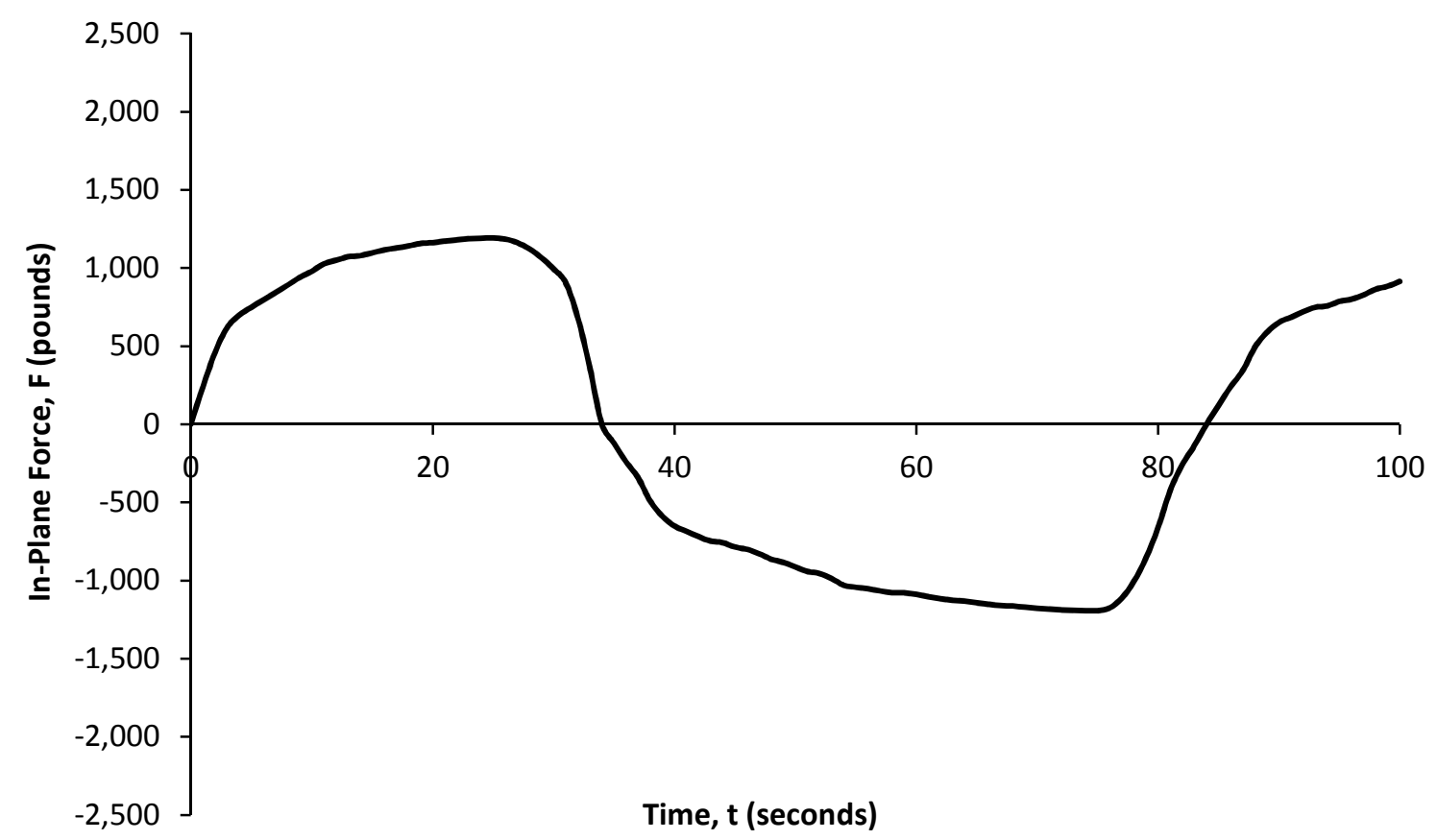

Figure 59. Force developed in the interior flexing rod versus time for $\mathrm{T}=100$ seconds.

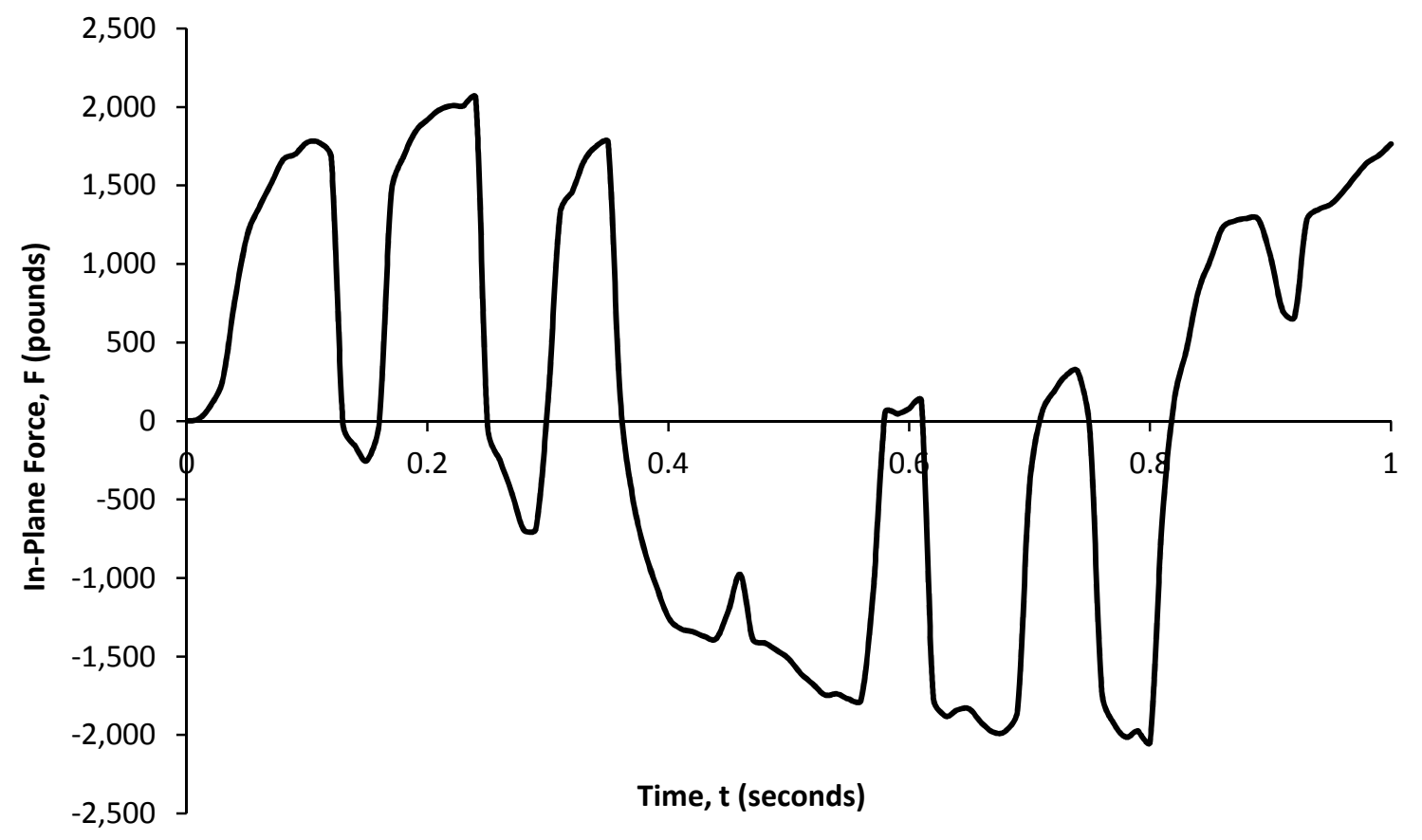

Figure 60. Force developed in the exterior flexing rod versus time for $\mathrm{T}=1 \mathrm{~second}$. 


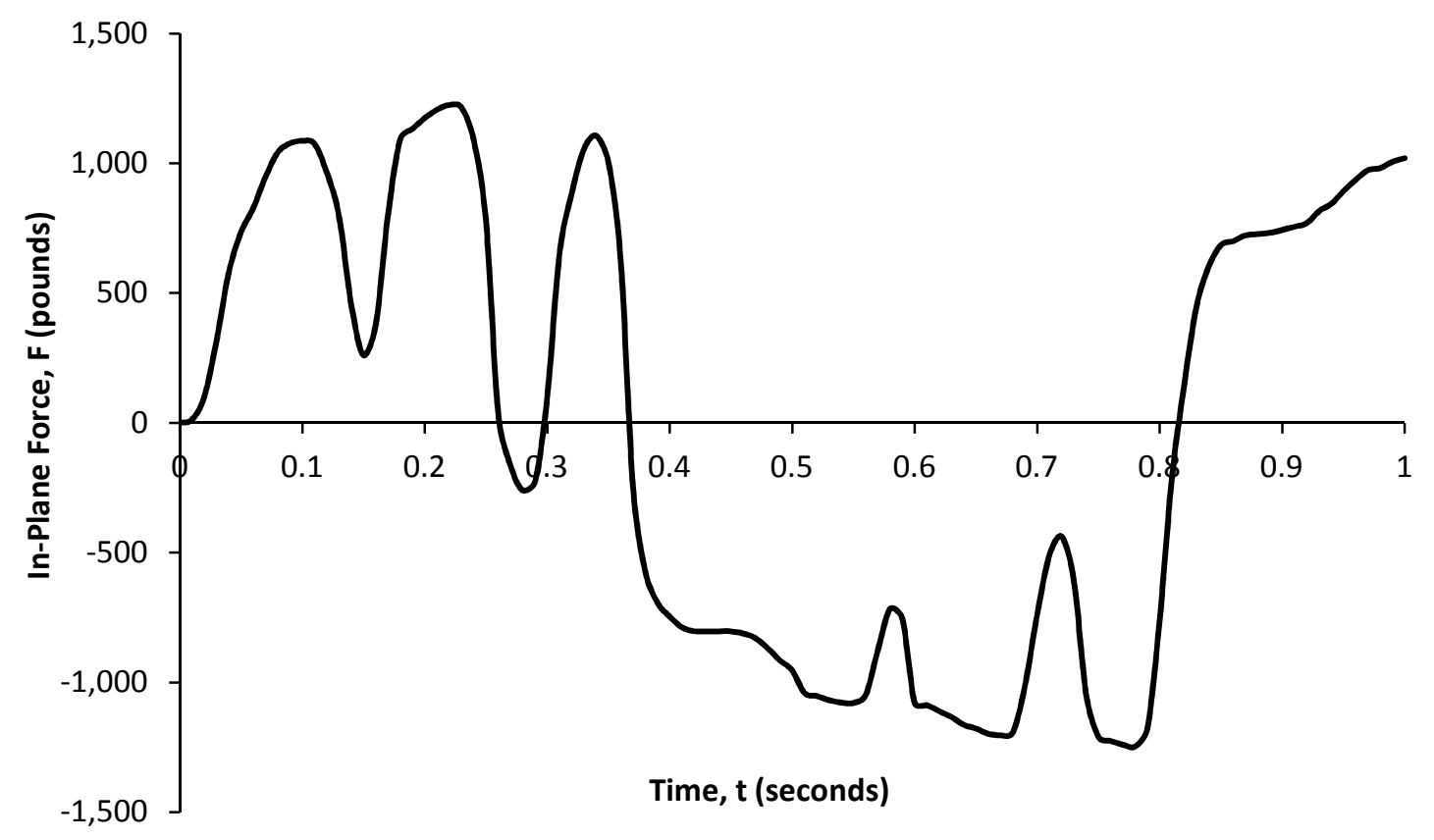

Figure 61. Force developed in the interior flexing rod for $\mathrm{T}=1$ second.

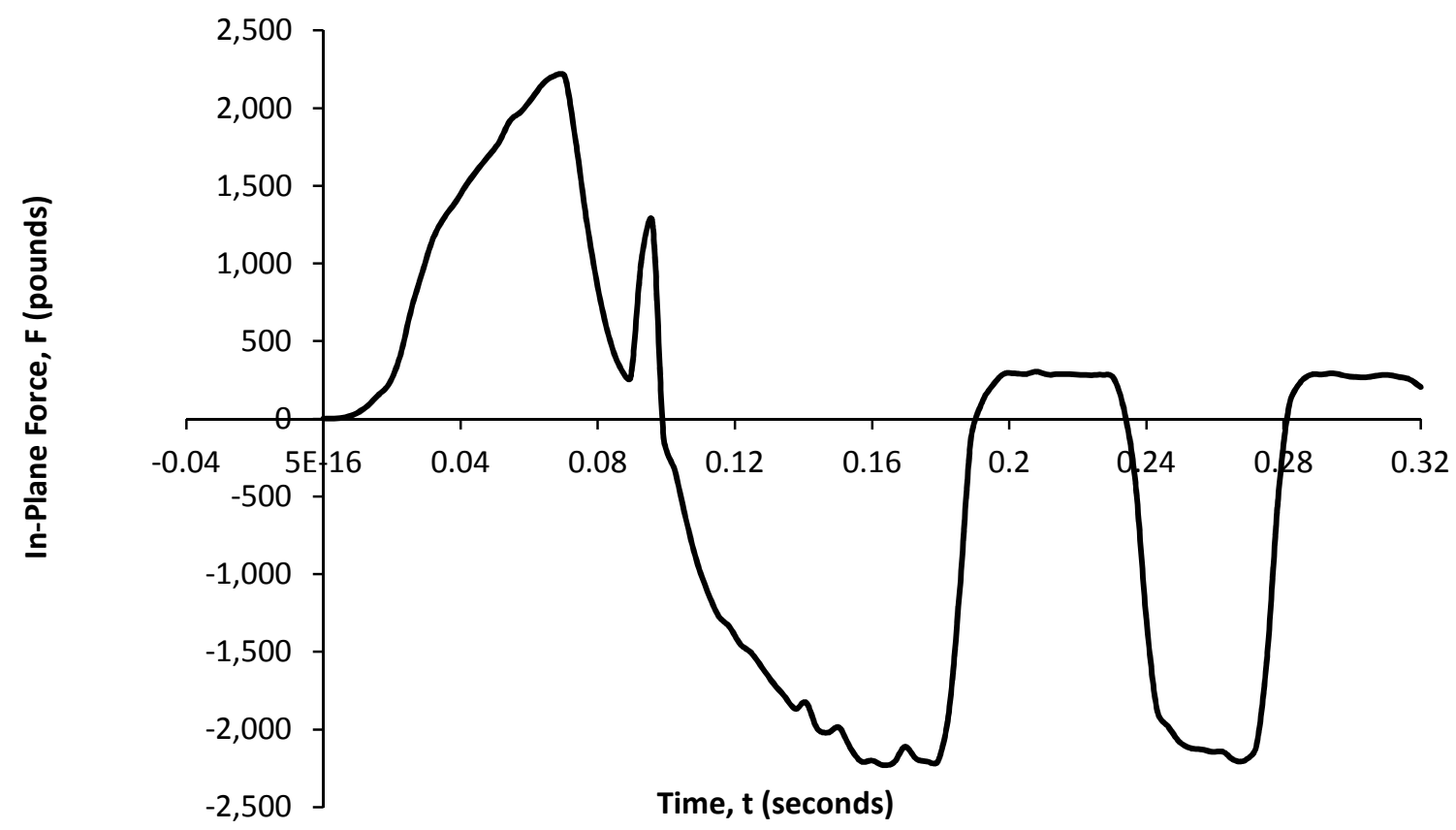

Figure 62. Force developed in the exterior flexing rod versus time for $\mathrm{T}=0.32$ seconds. 


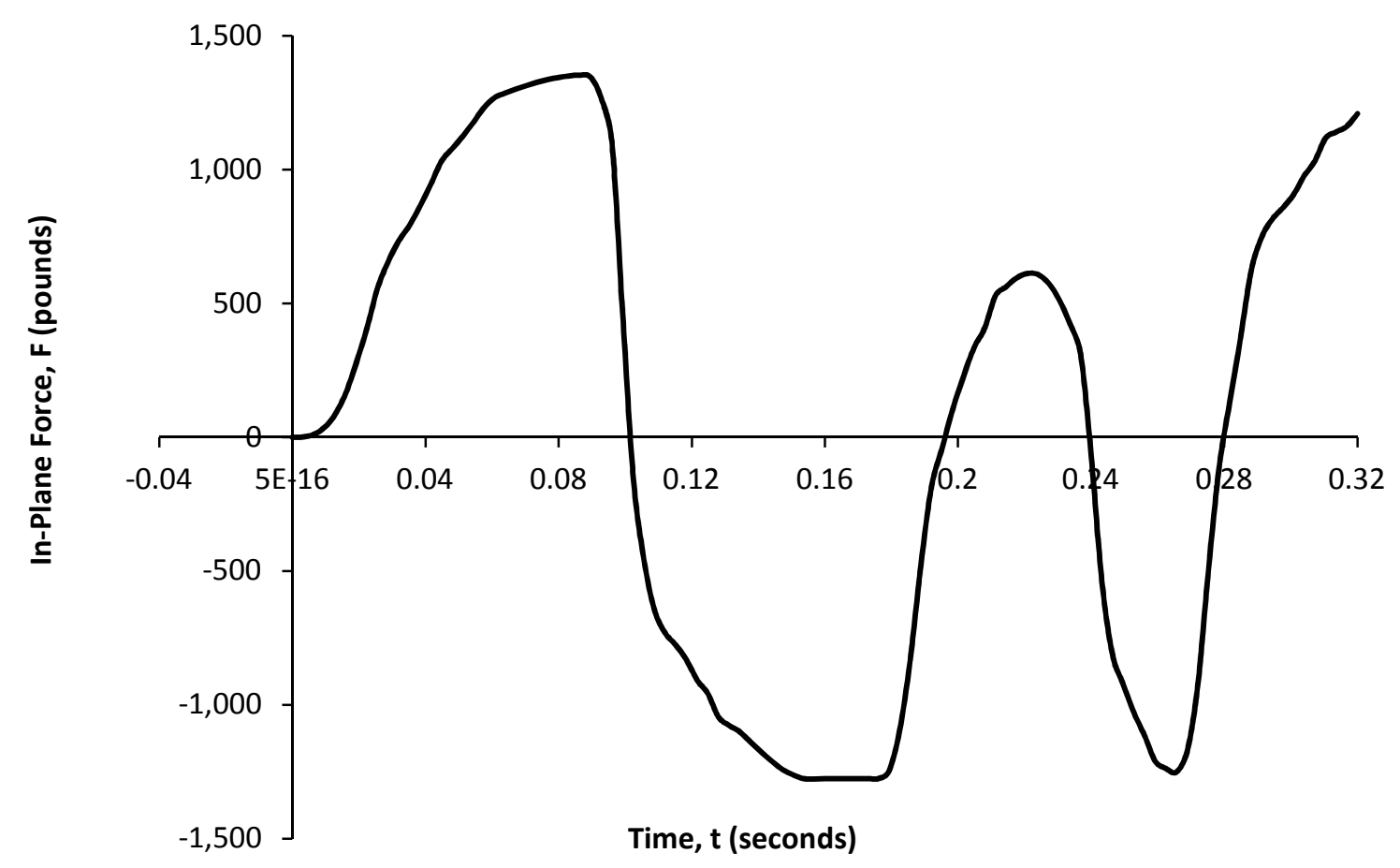

Figure 63. Force developed in the interior flexing rod versus time for $\mathrm{T}=0.32$ seconds.

\subsubsection{Top links analysis result for Model MD 2 under dynamic load for a}

period of 100 seconds in the in-plane direction. Figure 64 shows the relationship between the summation of forces developed in the flexing rod links in the $\mathrm{X}$ direction and the control displacement of the structural frame. A hysteretic behavior exists for forces developed in all flexing rods as the structural frame undergoes one cycle of displacement loading between +3.2 and -3.2 inches. 


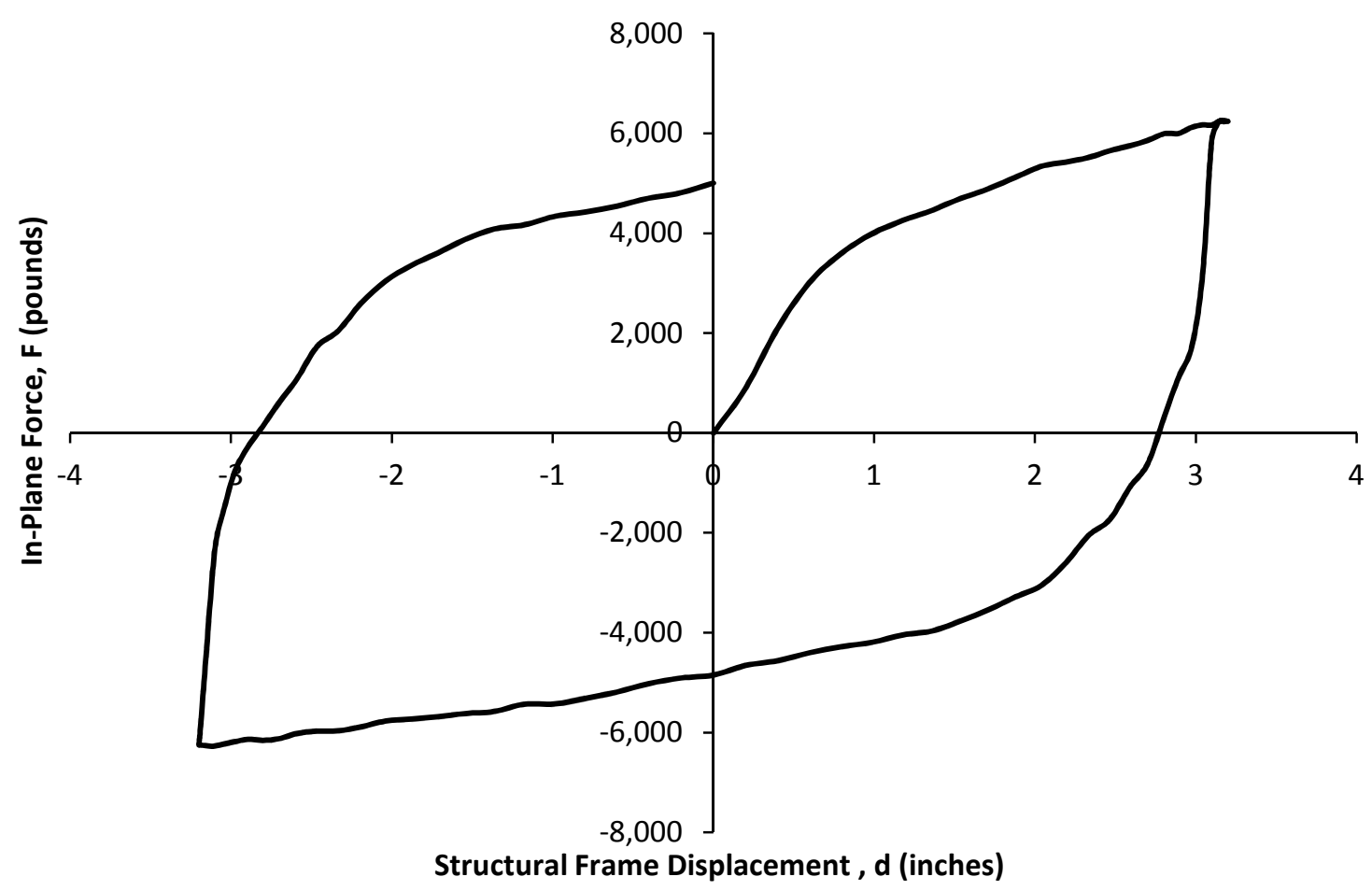

Figure 64. Forces developed in all flexing rod links versus the structural frame displacement.

Figures 65 and 66 show the force-deformation relationship for the top links.

Figure 65 is for Link 1, and Figure 66 is for Link 2. In both graphs, a hysteretic behavior exists as the structural frame undergoes one cycle of displacement loading. Link 4 has an identical graph to that of Link 1, and Link 3 has an identical graph to that of Link 2. 


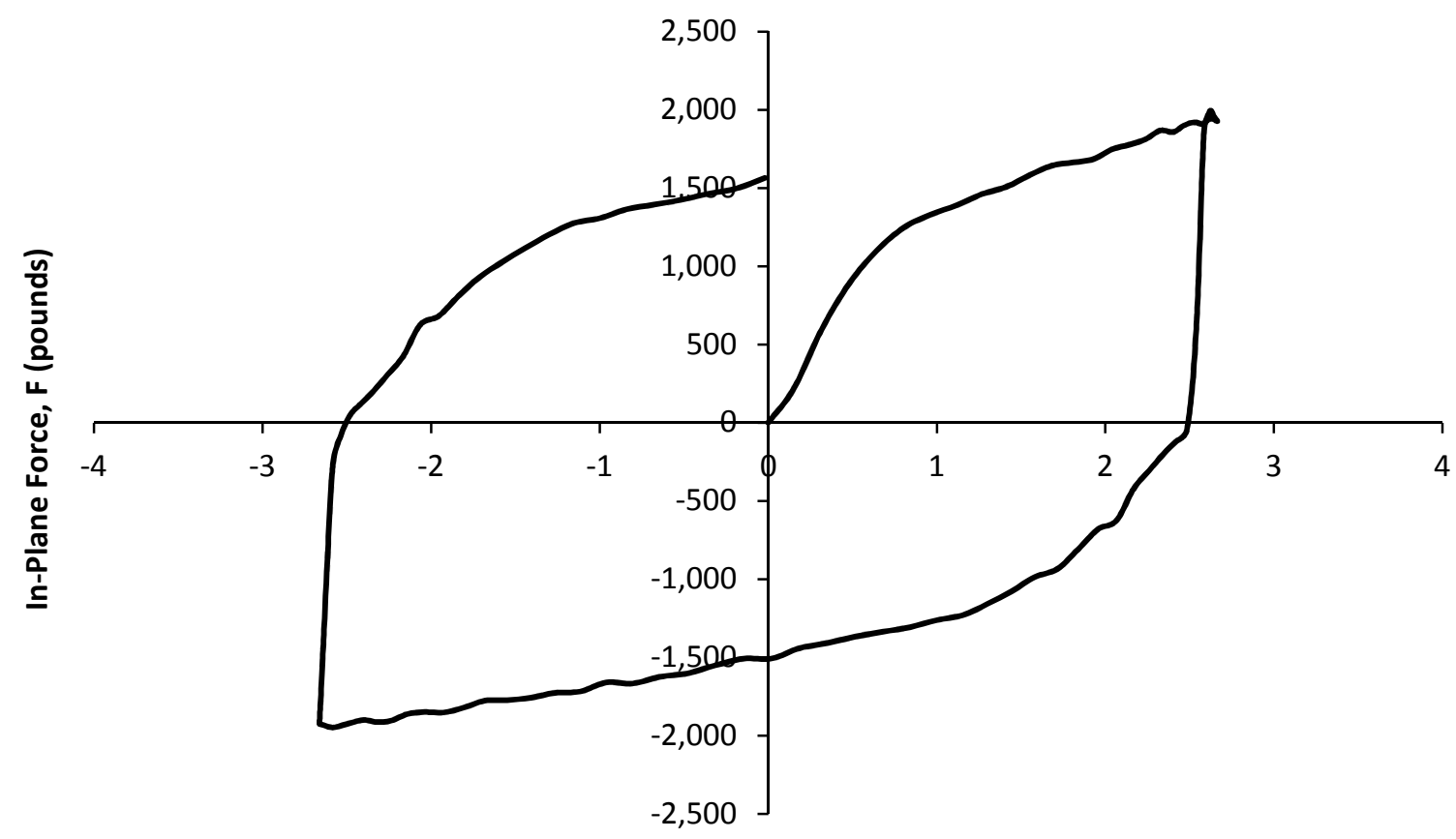

Flexing Rod Displacement, $d$ (inches)

Figure 65. Force developed in the exterior flexing rod versus the exterior link displacement.

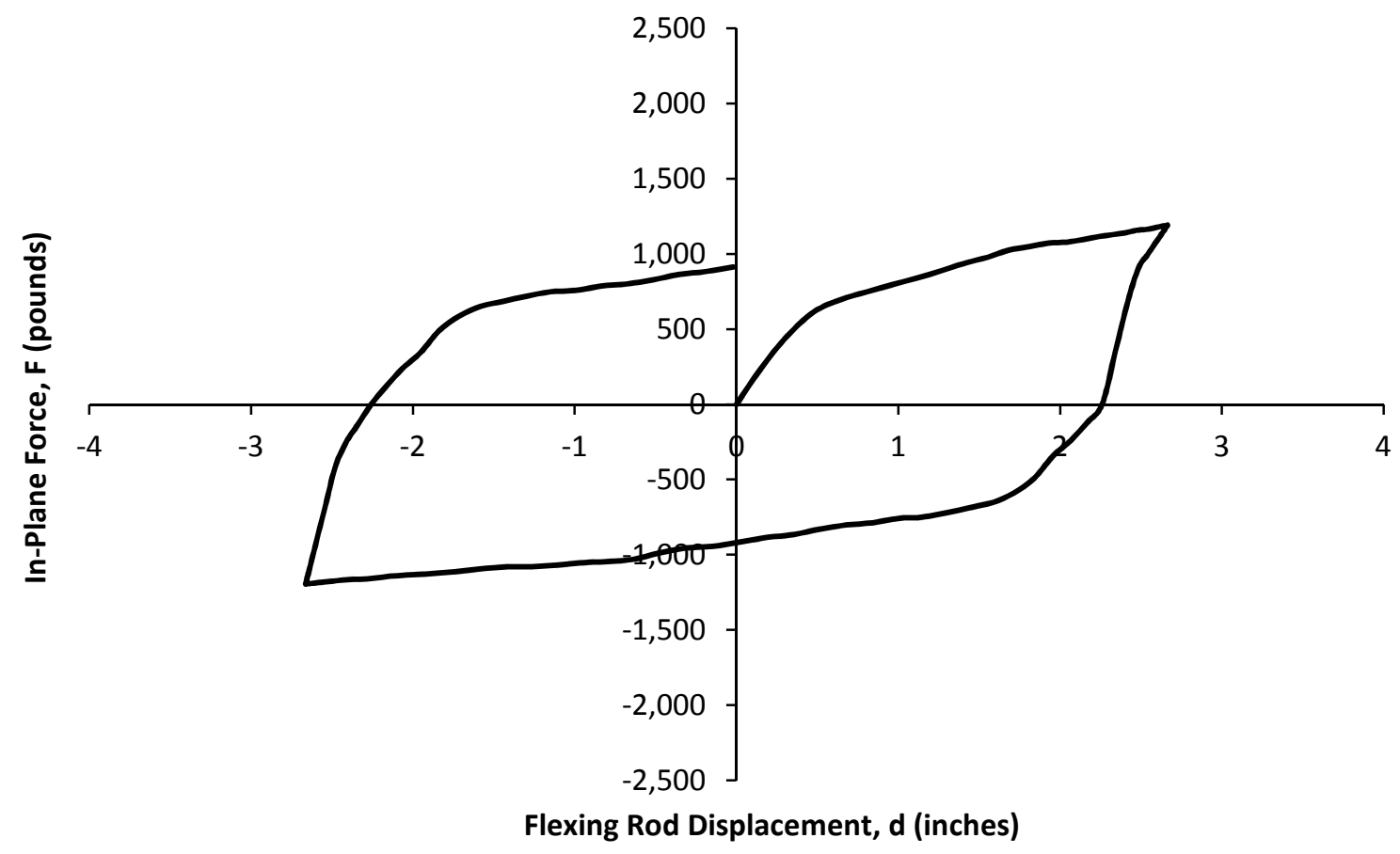

Figure 66. Force developed in the interior flexing rod versus the interior link displacement. 
The force-deformation relationship for the two bottom links is linear. Table 24 shows the relationship type and domain for each of the bottom links.

Table 24

Force-Deformation Relationships for Bottom Links in the X Direction

\begin{tabular}{llll}
\hline Link No. & $\begin{array}{l}\text { Relationship } \\
\text { Type }\end{array}$ & $\begin{array}{l}\text { Displacement Domain } \\
\text { (inches) }\end{array}$ & $\begin{array}{l}\text { Slope } \\
\text { (kips/in) }\end{array}$ \\
\hline Link 5 & Linear & {$[-0.0011,0.0014]$} & 10000 \\
Link 6 & Linear & {$[-0.0029,0.0034]$} & 1000 \\
\hline
\end{tabular}

5.3.3 Bottom links analysis result for Model MD 2 under dynamic load for a period of 100 seconds in the vertical direction. The force-deformation relationship in the $\mathrm{Z}$ direction for the two bottom links is also linear. Table 25 shows the relationship type and domain for each of the bottom links.

Table 25

Force-Deformation Relationships for Bottom Links in the Z Direction

\begin{tabular}{llll}
\hline Link No. & $\begin{array}{l}\text { Relationship } \\
\text { Type }\end{array}$ & $\begin{array}{l}\text { Displacement Domain } \\
\text { (inches) }\end{array}$ & $\begin{array}{l}\text { Slope } \\
\text { (kips/in) }\end{array}$ \\
\hline Link 5 & Linear & {$[-0.0023,0.00065]$} & 10000 \\
Link 6 & Linear & {$[-0.0022,0.00067]$} & 10000 \\
\hline
\end{tabular}

\subsubsection{Acceleration and displacement result for Model MD 2 under dynamic}

load for a period of $\mathbf{1 0 0}$ seconds. To determine the acceleration in the $\mathrm{X}$ direction for the precast concrete panel, a similar procedure for Model MD 1 was conducted. The 
maximum acceleration of the panel in the $\mathrm{X}$ direction is $0.33 \mathrm{in} / \mathrm{sec}^{2}$, or $\mathrm{g}$. For the structural frame, the maximum acceleration recorded was $0.0039 \mathrm{in} / \mathrm{sec}^{2}$. Based on Equation 4 presented in section 5.2.4, the AP was calculated. Figure 67 shows precast concrete panel acceleration time history in the $\mathrm{X}$ direction.

$A P=\frac{0.33}{0.0039}=84.61$

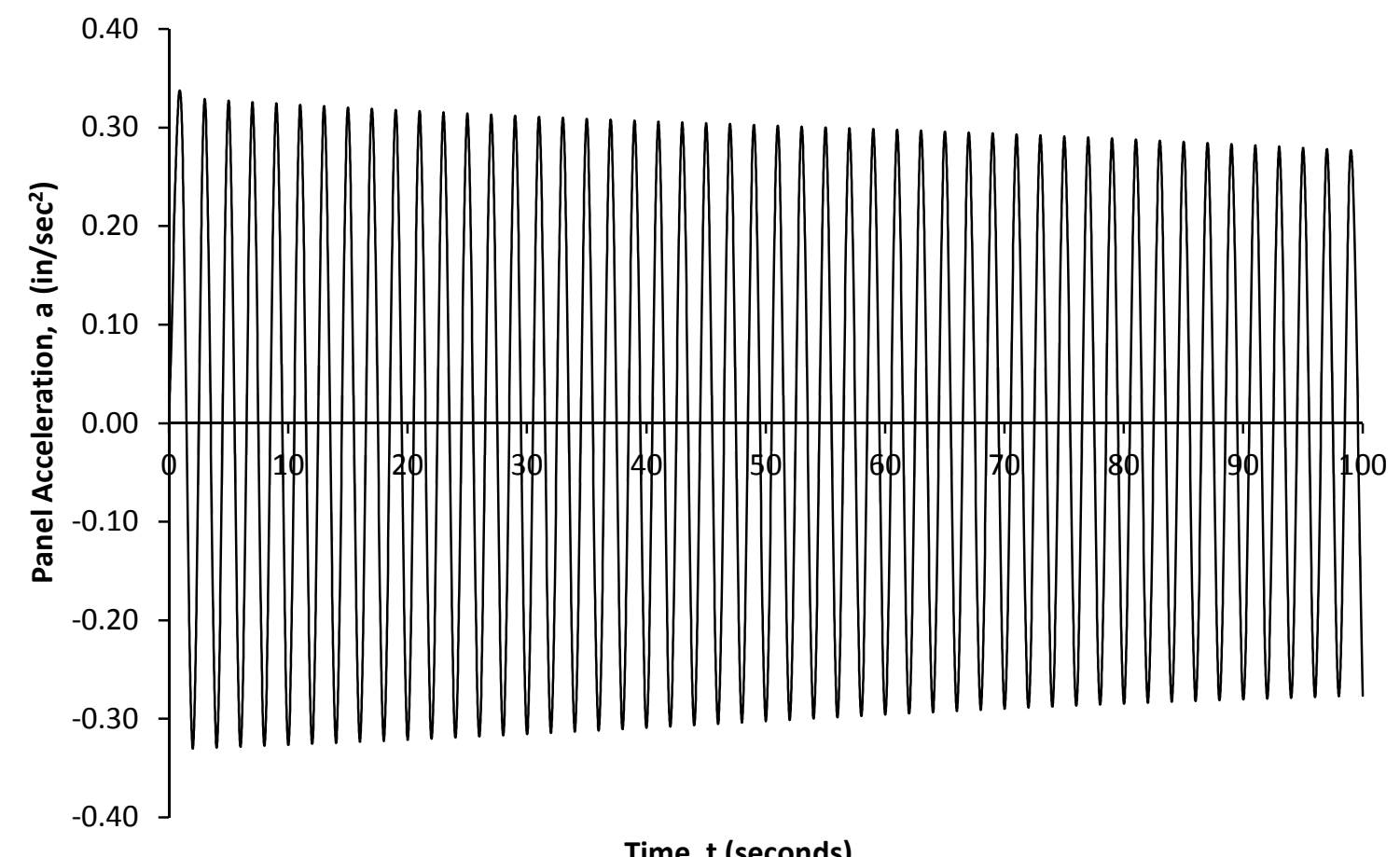

Figure 67. Acceleration of the precast concrete panel in the $\mathrm{X}$ direction versus time.

Figures 68 and 69 show the displacement of the precast concrete panel with respect to time of analysis. The displacement of the precast concrete in the $\mathrm{X}$ direction is sinusoidal with an amplitude of 0.529 inches, whereas the displacement in the $\mathrm{Z}$ direction is sinusoidal with an amplitude of 0.0054 inches. 


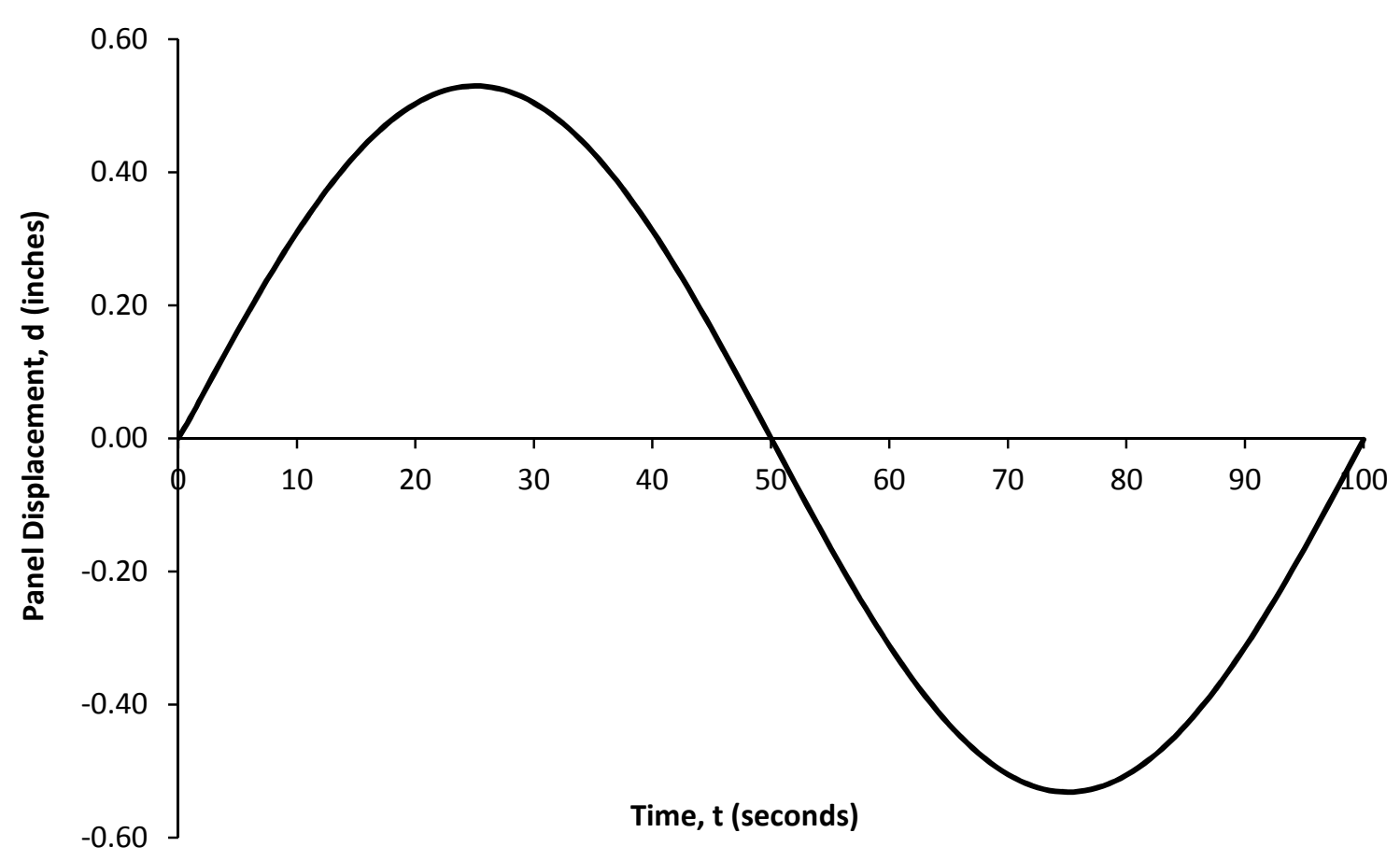

Figure 68. Precast concrete panel displacement in the $\mathrm{X}$ direction versus time.

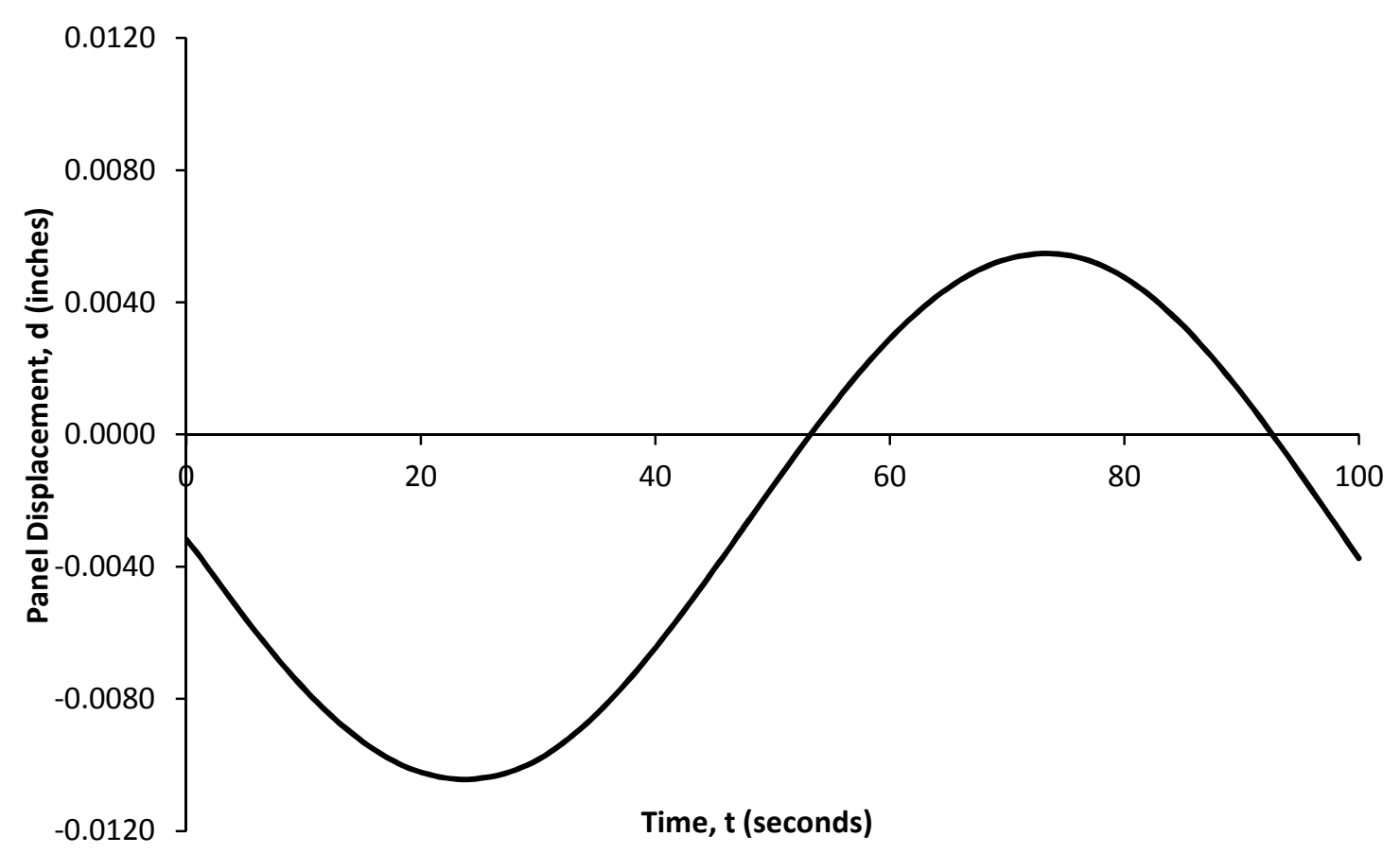

Figure 69. Precast concrete panel displacement in the $\mathrm{Z}$ direction versus time. 


\subsubsection{Top links analysis result for Model MD 2 under dynamic load for a}

period of 1 second in the in-plane direction. Figures 70 and 71 show the force-

deformation relationship for the top links. Figure 70 is for Link 1, and Figure 71 is for

Link 2. In both graphs, a hysteretic behavior exists as the structural frame undergoes one cycle of displacement loading. Link 4 has an identical graph to that of Link 1, and Link 3 has an identical graph to that of Link 2. An unloading and reloading cycle of the flexing rod link exists at six separate displacements for Links 1 and 4. A separate unloading and reloading cycle exists for Link 2.

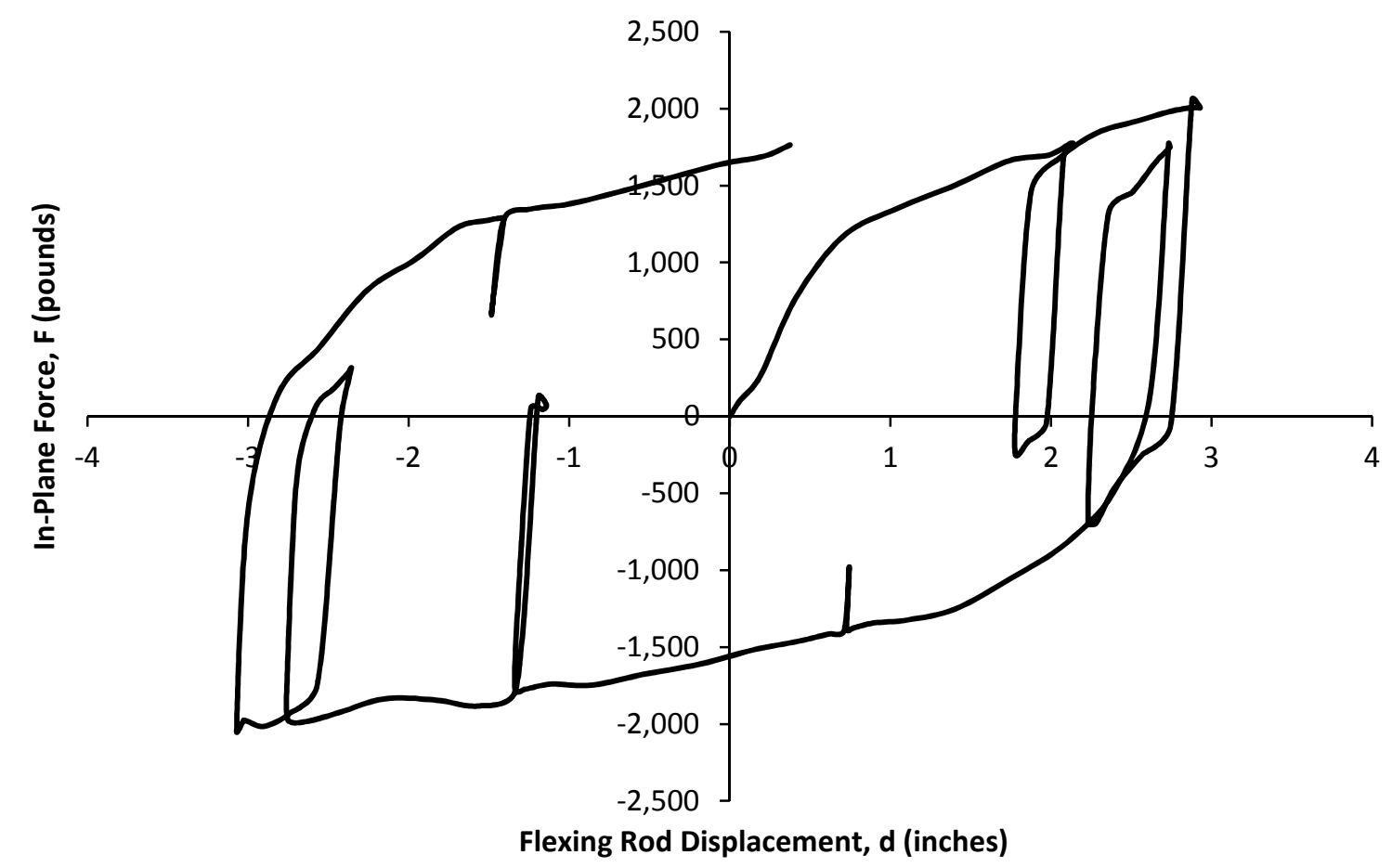

Figure 70. Force developed in the exterior flexing rod versus the exterior link displacement. 


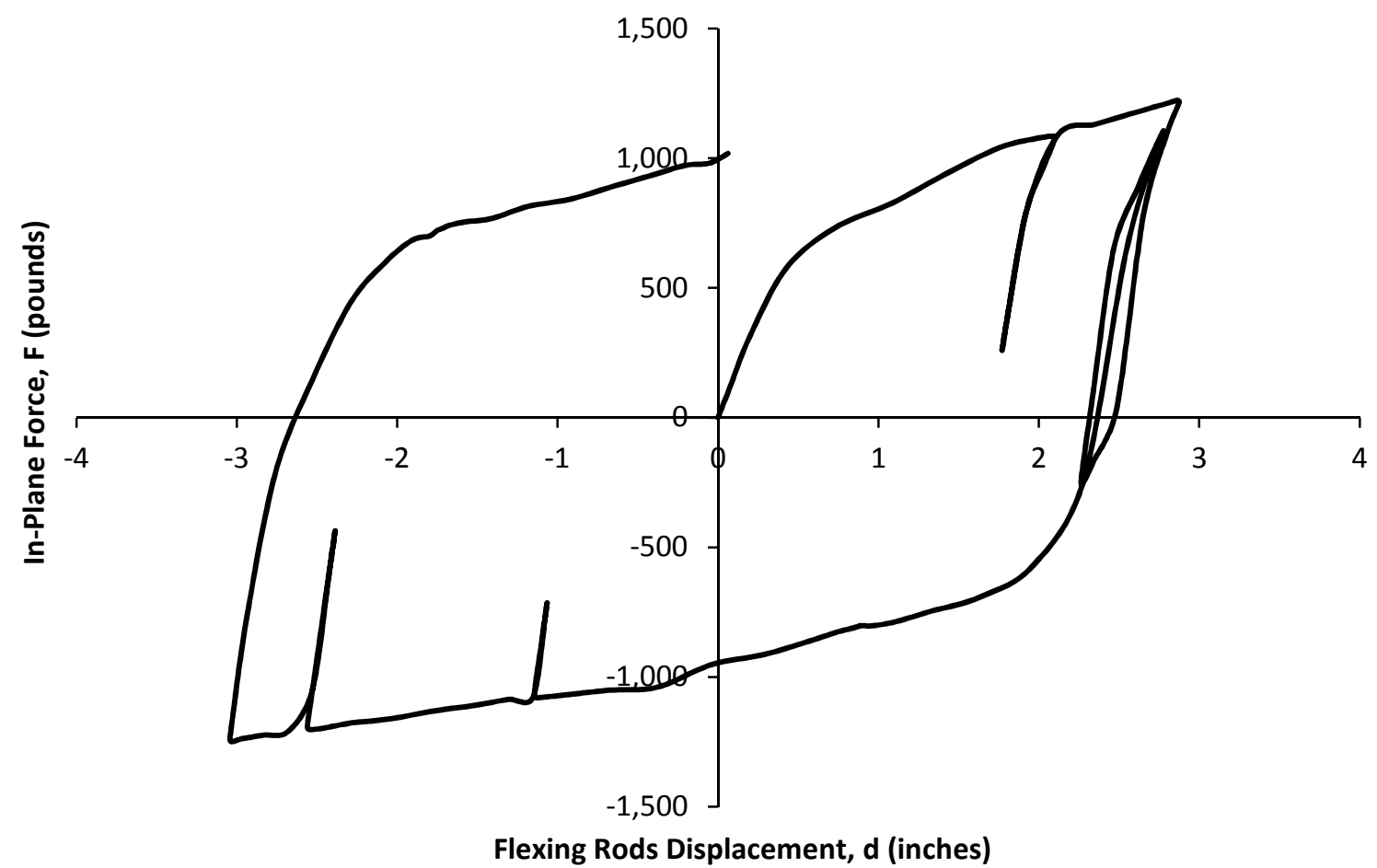

Figure 71. Force developed in the interior flexing rod versus the interior link displacement.

The force-deformation relationship for the two bottom links is linear. Table 26 shows the relationship type and domain for each link.

Table 26

Force-Deformation Relationships for Bottom Links in the X Direction

\begin{tabular}{llll}
\hline Link No. & $\begin{array}{l}\text { Relationship } \\
\text { Type }\end{array}$ & $\begin{array}{l}\text { Displacement Domain } \\
\text { (inches) }\end{array}$ & $\begin{array}{l}\text { Slope } \\
\text { (kips/in) }\end{array}$ \\
\hline Link 5 & Linear & {$[-0.00126,0.00127]$} & 10000 \\
Link 6 & Linear & {$[-0.0031,0.00309]$} & 1000 \\
\hline
\end{tabular}




\subsubsection{Bottom links analysis result for Model MD 2 under dynamic load for a}

period of 1 second in the vertical direction. The force-deformation relationship in the $\mathrm{Z}$ direction for the two bottom links is linear. Table 27 shows the relationship type and domain for each of bottom links.

Table 27

Force-Deformation Relationships for Bottom Links in the Z Direction

\begin{tabular}{llll}
\hline Link No. & $\begin{array}{l}\text { Relationship } \\
\text { Type }\end{array}$ & $\begin{array}{l}\text { Displacement Domain } \\
\text { (inches) }\end{array}$ & $\begin{array}{l}\text { Slope } \\
\text { (kips/in) }\end{array}$ \\
\hline Link 5 & Linear & {$[-0.00215,0.0007]$} & 10000 \\
Link 6 & Linear & {$[-0.00239,0.0005]$} & 10000 \\
\hline
\end{tabular}

\subsubsection{Acceleration and displacement result for Model MD 2 under dynamic}

load for a period of 1 second. To determine the acceleration in the $\mathrm{X}$ direction for the precast concrete panel, a similar procedure for Model MD 1 was conducted. The maximum acceleration of the panel in the $\mathrm{X}$ direction was $35.85 \mathrm{in} / \mathrm{sec}^{2}$, or $0.1 \mathrm{~g}$. For the structural frame, the maximum acceleration recorded was $39.4 \mathrm{in} / \mathrm{sec}^{2}$. Based on Equation 4 presented in section 5.2.4, the amplification ratio was calculated. Figure 72 shows the precast concrete panel acceleration time history in the $\mathrm{X}$ direction.

$A P=\frac{35.85}{39.4}=0.909$ 


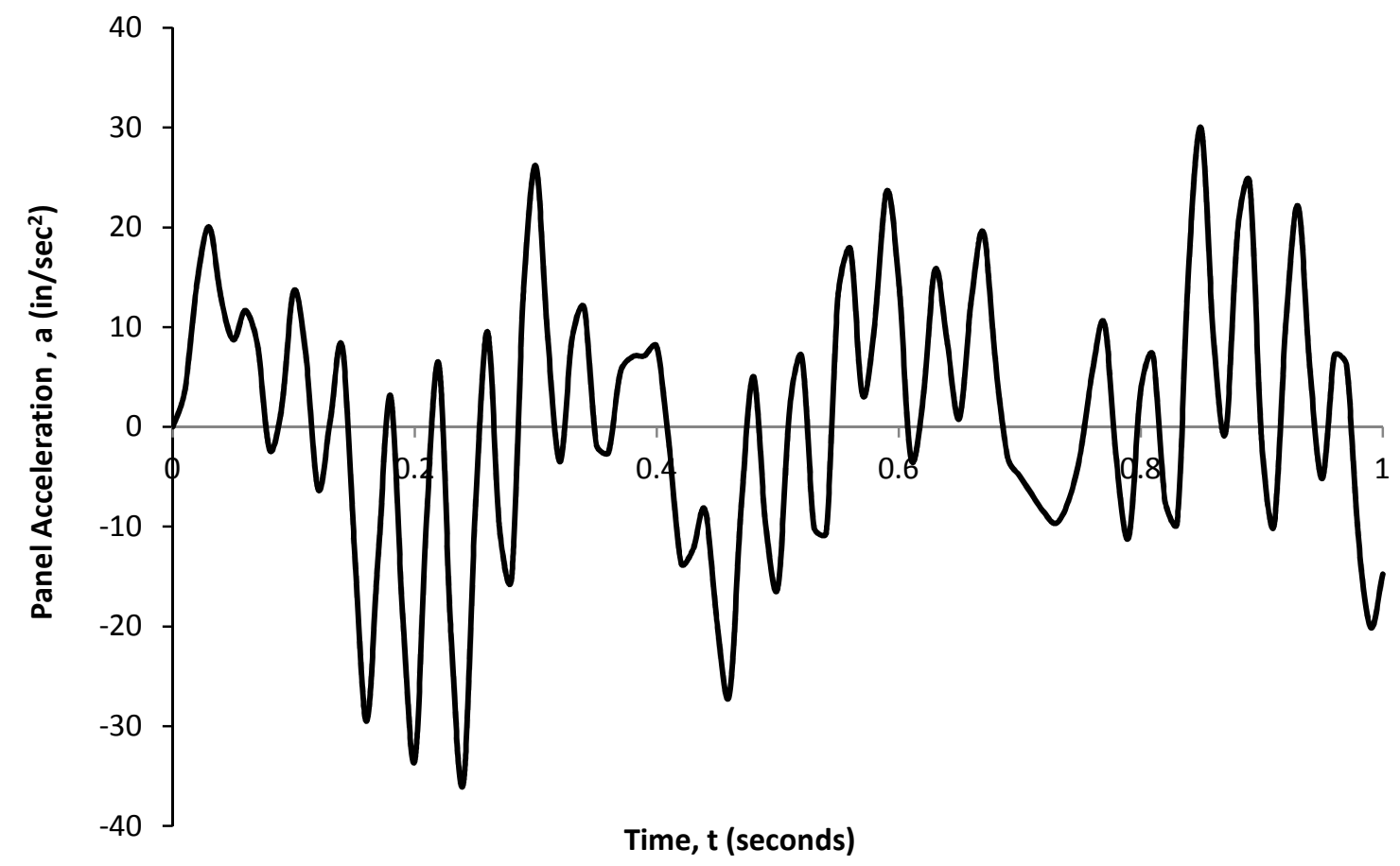

Figure 72. Acceleration of the precast concrete panel in the $\mathrm{X}$ direction versus time.

Figures 73 and 74 show the displacement of the precast concrete panel with respect to time. The displacement of the precast concrete panel in the $\mathrm{X}$ direction is sinusoidal with two distinct vibration components: steady-state response and transient response. The transient response had a period of $0.32 \mathrm{sec}$., which is the period of the maximum mass participation ratio of the precast concrete panel. The displacement in the $\mathrm{Z}$ direction is sinusoidal displacement with two distinct vibration components: steadystate response and transient response. 


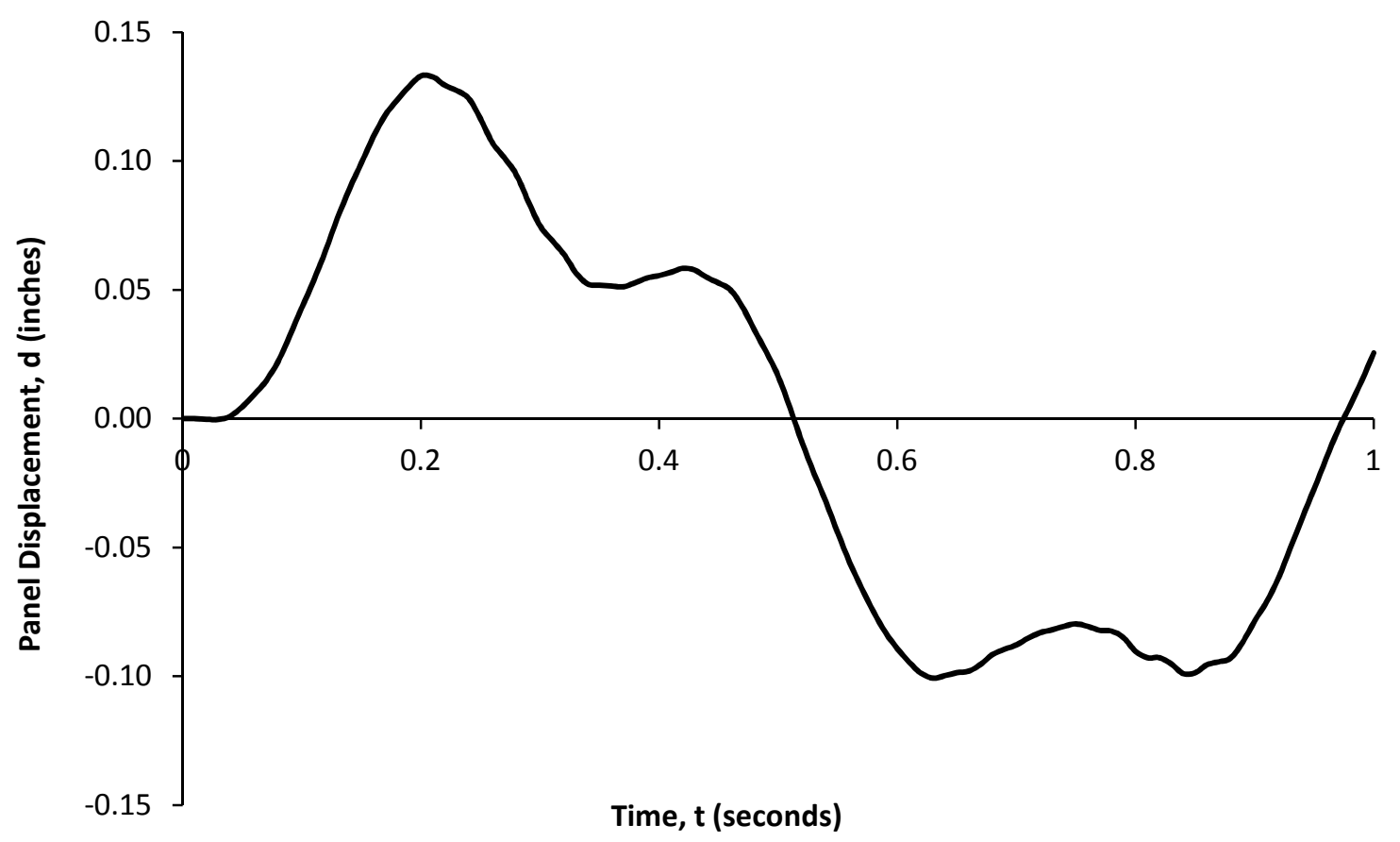

Figure 73. Precast concrete panel displacement in the $\mathrm{X}$ direction versus time.

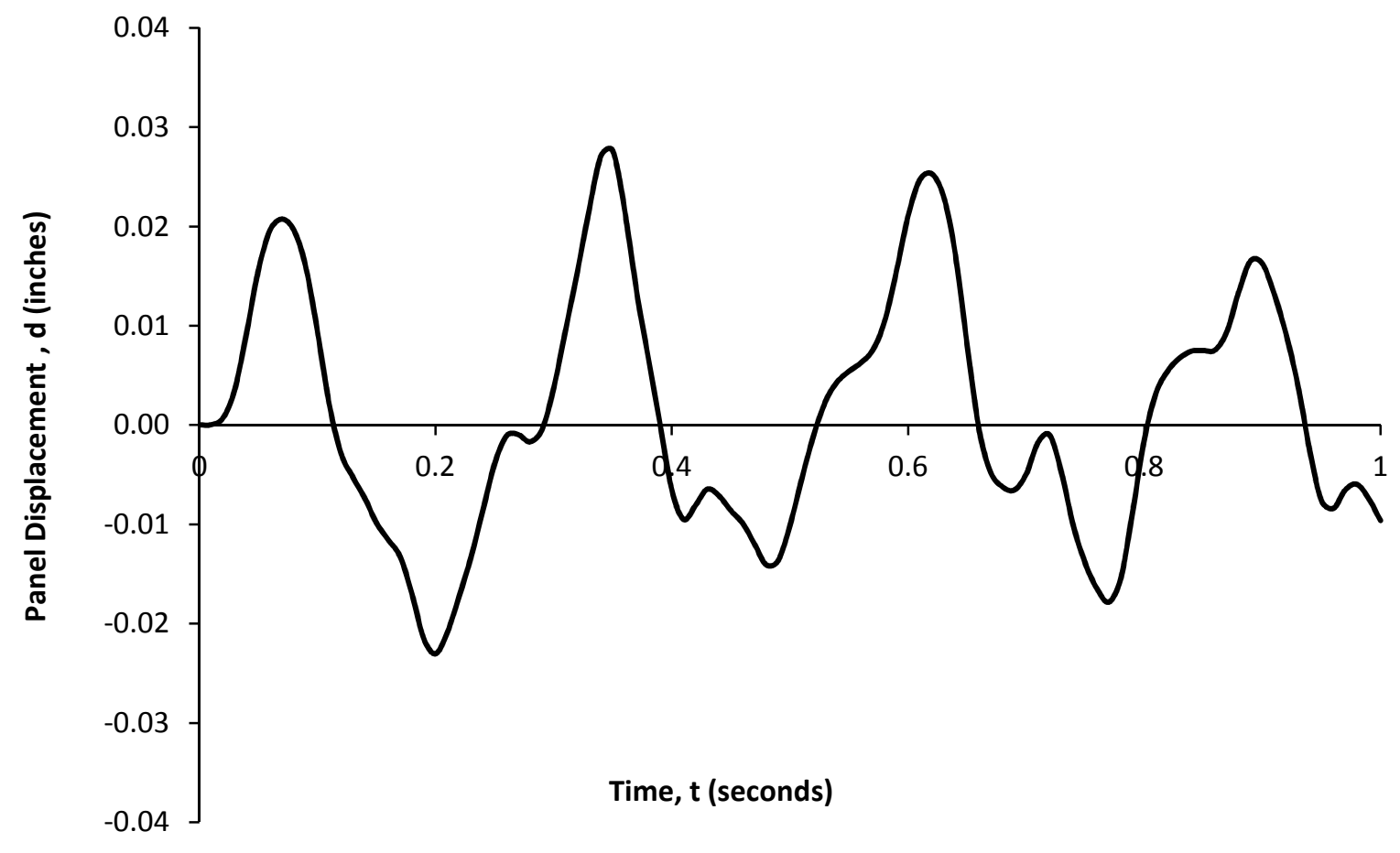

Figure 74. Precast concrete panel displacement in the $\mathrm{Z}$ direction versus time. 


\subsubsection{Top links analysis result for Model MD 2 under dynamic load for a}

period of 0.32 seconds in the in-plane direction. Figures 75 and 76 show the forcedeformation relationship for the top links. Figure 75 is for Link 1, and Figure 76 is for Link 2 . In both graphs, a hysteretic behavior exists as the structural frame undergoes one cycle of displacement loading. Link 4 has an identical graph to that of Link 1, and Link 3 has an identical graph to that of Link 2. As shown in Figure 75, the displacement passes the maximum input value for Links 1 and 4. Therefore Link 1 loses its strength, as shown by the graph.

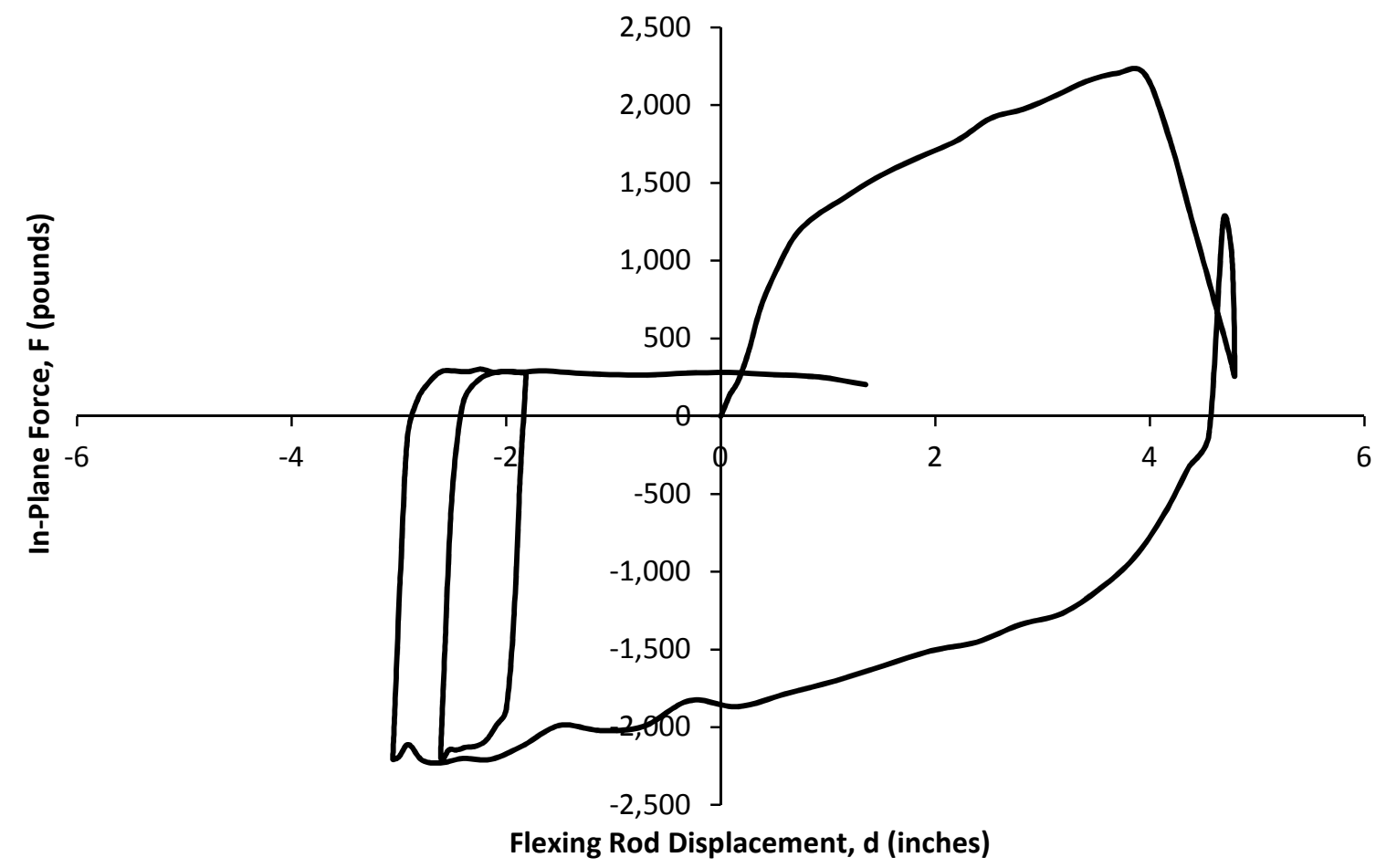

Figure 75. Force developed in the exterior flexing rod versus the exterior link displacement. 


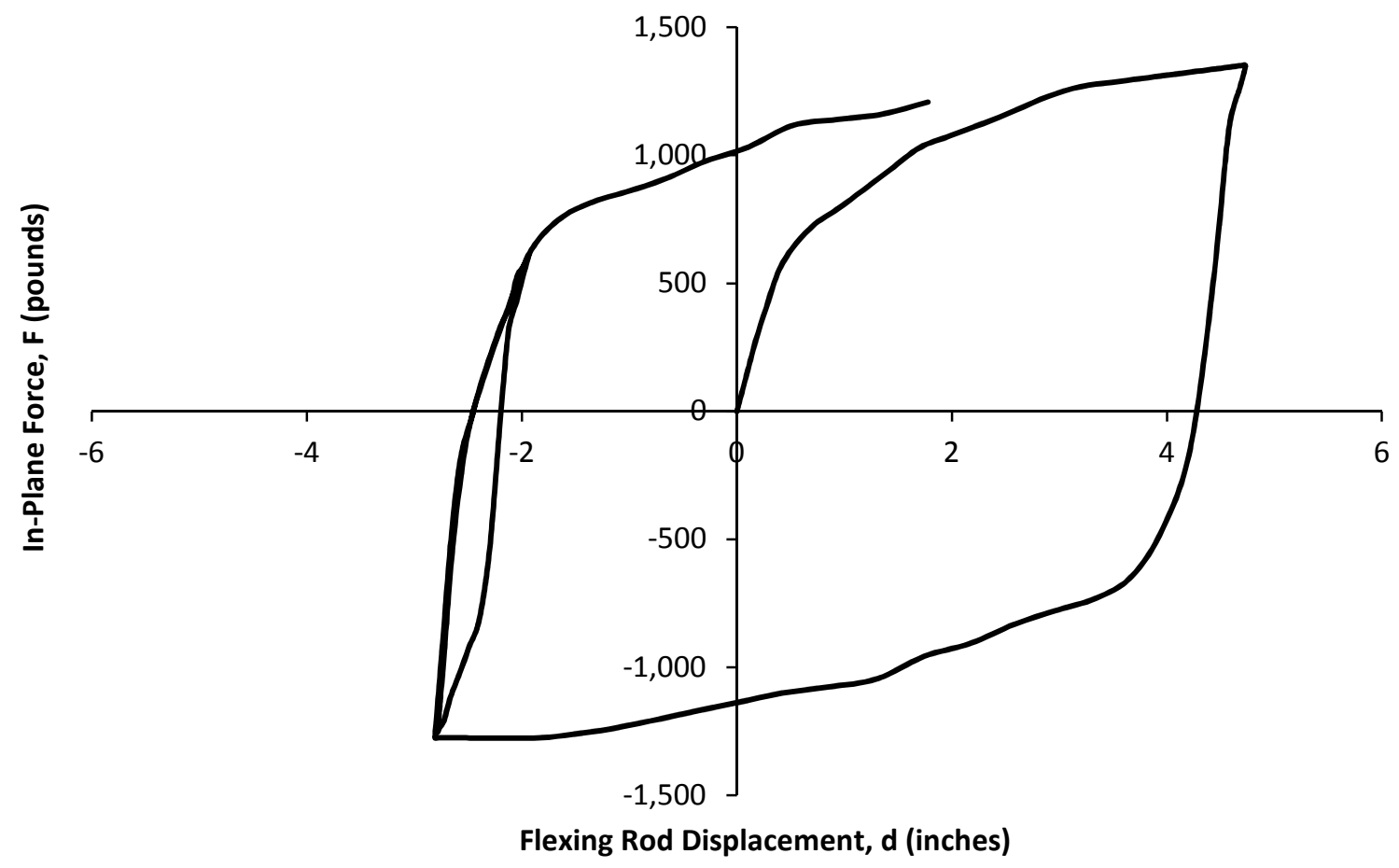

Figure 76. Force developed in the interior flexing rod versus the interior link displacement.

The force-deformation relationship for the bottom links is linear as the structural frame undergoes one cycle of displacement loading. Table 28 shows the relationship type and domain for each link.

Table 28

Force-Deformation Relationships for Bottom Links in the X Direction

\begin{tabular}{llll}
\hline Link No. & $\begin{array}{l}\text { Relationship } \\
\text { Type }\end{array}$ & $\begin{array}{l}\text { Displacement Domain } \\
\text { (inches) }\end{array}$ & $\begin{array}{l}\text { Slope } \\
\text { (kips/in) }\end{array}$ \\
\hline Link 5 & Linear & {$[-0.0012,0.0012]$} & 10000 \\
Link 6 & Linear & {$[-0.0031,0.0030]$} & 1000 \\
\hline
\end{tabular}




\subsubsection{Bottom links analysis result for Model MD 2 under dynamic load for a}

period of 0.32 seconds in the vertical direction. The force-deformation relationship in the $\mathrm{Z}$ direction for the two bottom links is linear. Table 29 shows the relationship type and domain for each bottom link.

Table 29

Force-Deformation Relationships for Bottom Links in the Z Direction

\begin{tabular}{llll}
\hline Link No. & $\begin{array}{l}\text { Relationship } \\
\text { Type }\end{array}$ & $\begin{array}{l}\text { Displacement Domain } \\
\text { (inches) }\end{array}$ & $\begin{array}{l}\text { Slope } \\
\text { (kips/in) }\end{array}$ \\
\hline Link 5 & Linear & {$[-0.0021,0.0007]$} & 10000 \\
Link 6 & Linear & {$[-0.0023,0.0005]$} & 10000 \\
\hline
\end{tabular}

\subsubsection{Acceleration and displacement for Model MD 2 under dynamic load}

for a period of 0.32 seconds. To determine the acceleration in the $\mathrm{X}$ direction for the precast concrete panel, a similar procedure for Model MD 2 was conducted. The maximum acceleration of the panel in the $\mathrm{X}$ direction was $194.9 \mathrm{in} / \mathrm{sec}^{2}$, or $0.5 \mathrm{~g}$. For the structural frame, the maximum acceleration recorded was $385.15 \mathrm{in} / \mathrm{sec}^{2}$. Based on Equation 4 presented in section 5.2.4, the amplification ratio was calculated. Figure 77 shows the precast concrete panel acceleration time history in the $\mathrm{X}$ direction.

$A P=\frac{194.9}{385.15}=0.506$ 


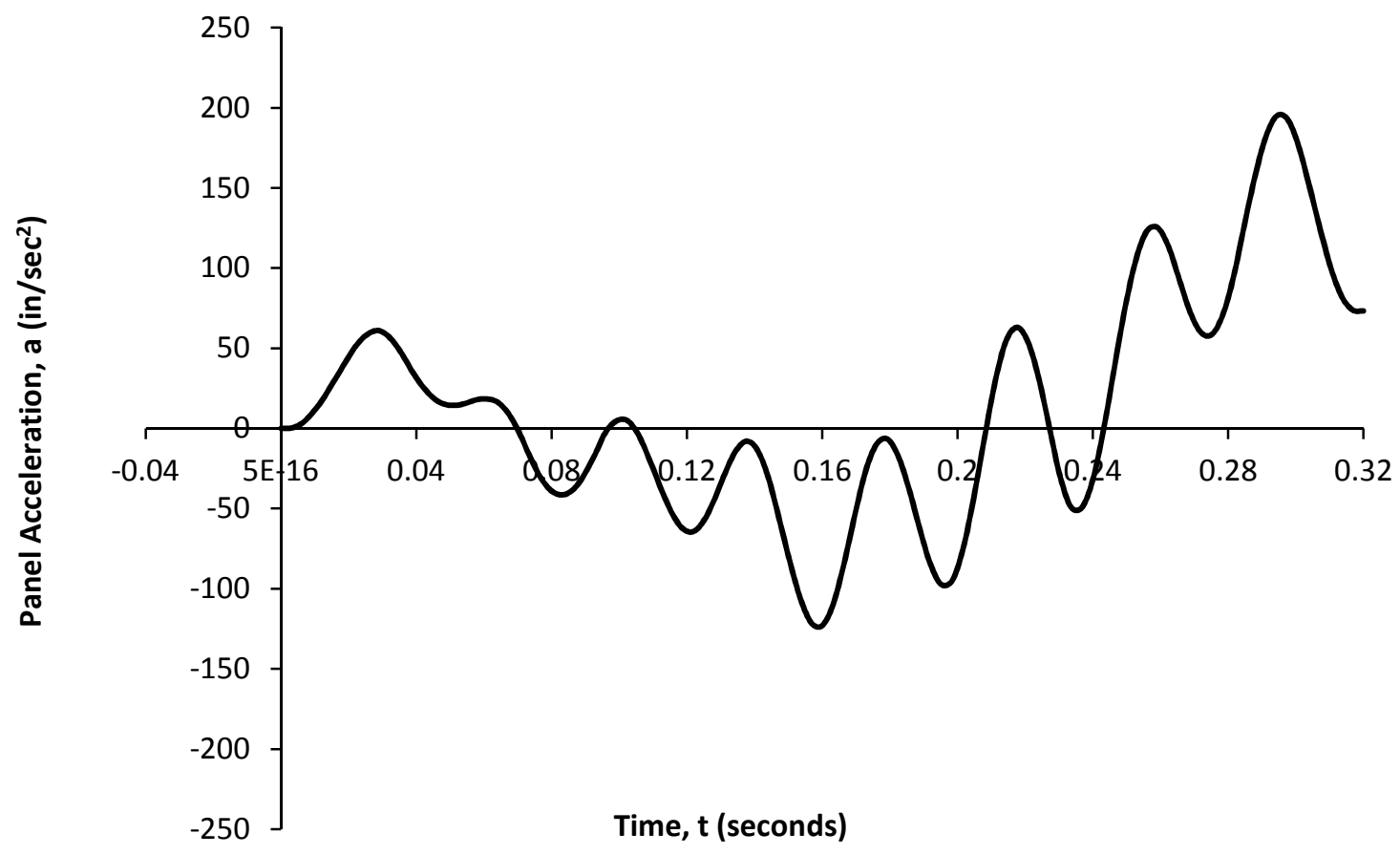

Figure 77. Acceleration of the precast concrete panel in the $\mathrm{X}$ direction.

Figures 78 and 79 show the displacement of the precast concrete panel with respect to time. The displacement of the precast concrete in the $\mathrm{X}$ direction is sinusoidal, and the amplitude of the displacement increases for each time increment. The displacement in the $\mathrm{Z}$ direction is sinusoidal with two distinct vibration components with similar frequency: steady-state response and transient_response. 


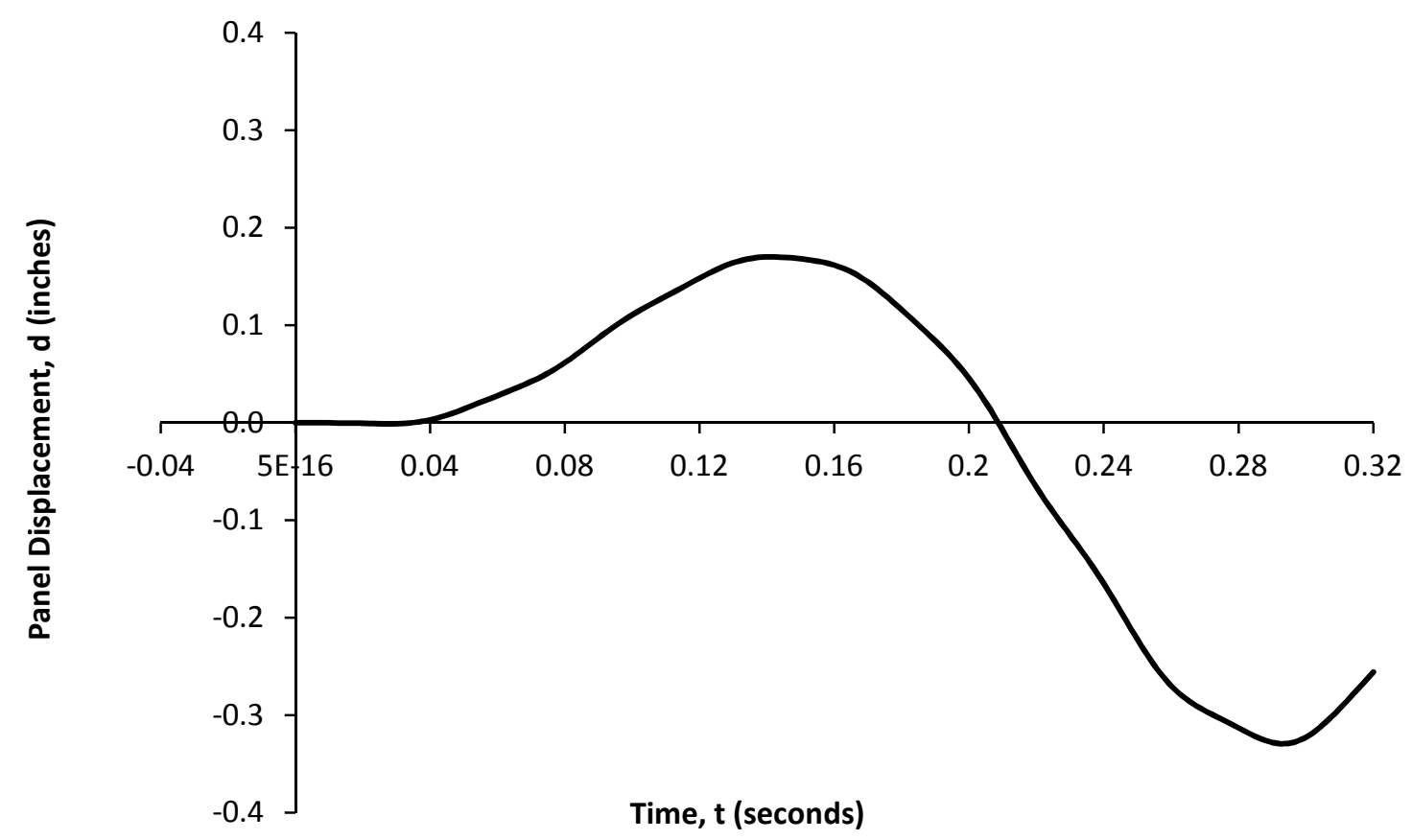

Figure 78. Precast concrete panel displacement in the $\mathrm{X}$ direction versus time.

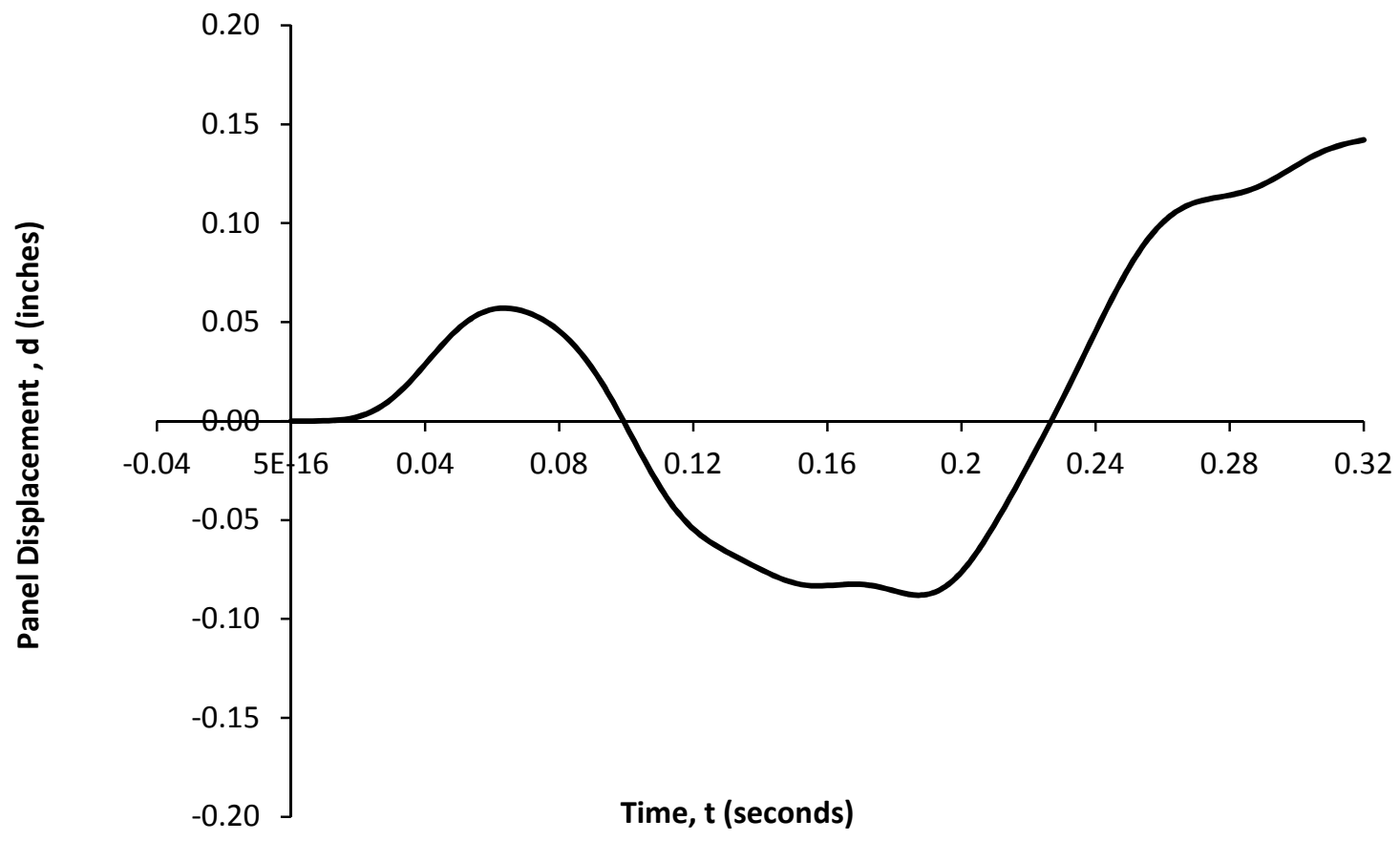

Figure 79. Precast concrete panel displacement in the $\mathrm{Z}$ direction versus time. 


\section{Conclusions and Recommendations}

The inelastic behavior of a one-story, one-bay precast concrete cladding façade system of a solid panel for in-plane loading was successfully evaluated in this project. Drift ratios for a static analysis and the amplification factor were defined and quantified for both models. The research achievements were as follows:

1. Development of a nonlinear analytical model representing a one-story, one-bay precast concrete façade system with different combinations of flexural link elements.

2. Definition of force-deformation relationships for flexing rods for in-plane direction (X direction).

3. Comparison of the results of a static pushover analysis with a displacementcontrolled time history analysis.

4. Review of the dynamic behavior of the precast concrete panel for three periods of vibration.

\subsection{Research Findings}

1. The behavior of both models for the positive and negative static analyses was similar for the in-plane direction for all of the flexing rod elements, even though the system was asymmetrical.

2. The summation of the link forces in the static pushover analyses was close to the values of the dynamic analyses when the period of input vibration was 100 seconds. 
3. Based on the results of the dynamic analysis, as the period of input vibration nears the fundamental period of vibration of the panel, the acceleration of the panel in the in-plane direction increases. The maximum value of the link forces also increases as acceleration increases. With further study it may be found that the bottom links have the potential to fail as periods of input vibrations near the fundamental period of vibration of the panel.

4. The amplification ratio is defined in Chapter 5. For Models MD 1 and MD 2, the amplification ratios were recorded, as shown in Table 30. For periods of input vibration of 100 seconds, both the structural frame and precast concrete frame accelerations were small, and the division of two small number results in a high value for the amplification ratio. For the period of input vibrations 1 and 0.32 seconds, the amplification the ratios' value starts to decrease for both models. It can be seen that as the period of input vibration of the structural frame nears the fundamental period of vibration of the panel, the value of the amplification ratio decreases.

Table 30

Amplification Ratios With Respect to Periods of Input Vibrations

\begin{tabular}{lccc}
\hline & \multicolumn{3}{c}{ Amplification Ratio } \\
\cline { 2 - 4 } Model ID & $\mathrm{T}=100(\mathrm{sec})$. & $\mathrm{T}=1$ (sec.) & $\mathrm{T}=0.32$ (sec.) \\
\hline MD 1 & 207 & 2.70 & 1.87 \\
MD 2 & 84.61 & 0.909 & 0.506 \\
\hline
\end{tabular}


5. Models MD 1 and MD 2 show that as the period of input vibration of the structural frame nears the fundamental period of vibration of the panel or for periods of vibration 100,1 , and 0.32 seconds, the flexing rods have 2,6 , and 3 local maximums for their force values, respectively.

6. Static analysis results are comparable only with a dynamic analysis with a slow input period of vibration, i.e., a period of 100 seconds.

\subsection{Recommendations for Future Work}

Upon reflection of the work conducted, I propose the following list of recommendations, which will help predict the characteristics of the precast concrete façade system more accurately:

1. Perform more displacement time history analysis for the analytical models with varying periods of input vibration for sinusoidal displacement input to more accurately capture the real effect of the interaction of the supporting frame displacement with the precast concrete panel.

2. Experimental testing of the bearing connections or bottom links to quantify the force-deformation relationship to increase the accuracy of the analysis.

3. The precast concrete panels in a building will interact not only with the structural frame but with other nonstructural components as well, i.e., adjacent precast concrete panels. Therefore, this panel-to-panel interaction may change the dynamic response of the precast concrete panel. Future studies could try to model this situation. 
4. Validation of the analytical results provided by SAP2000 software with actual experimental results were found at UCSD. 


\section{References}

Cheung, K. (2010). Nonlinear pushover analysis of a one-story precast concrete cladding system (master's thesis). Available from SJSU ScholarWorks. (Paper 3754).

Computers and Structures, Inc. (2011, February). CSI analysis reference manual for SAP2000, ETABS, SAFE, and CSiBridge. Retrieved from http://docs. csiamerica.com/manuals

Computers and Structures, Inc. (2013, June). Displacement time history records. Retrieved from https://wiki.csiamerica.com/display/kb/Displacement+timehistory+record

Computers and Structures, Inc. (2014, February). Material nonlinearity. Retrieved from https://wiki.csiamerica.com/display/kb/Material+nonlinearity

McMullin, K., \& Nagar, P. (2012). Full-scale dynamic testing of precast concrete cladding panels. National Bridge Conference. PCI. Nashville, TN.

Nagar, P. (2012). Precast concrete cladding with punch-out windows: Nonlinear displacement time history analysis and damage events. Independent Study Report - CE298. Department of Civil and Environmental Engineering, San José State University. San Jose, CA. 


\section{Appendix A}

Force-Deformation Experimental Data for Flexing Rods

\begin{tabular}{|c|c|c|c|c|c|}
\hline \multicolumn{6}{|c|}{ Flexing Rod } \\
\hline \multicolumn{2}{|c|}{$16 \times 1$} & \multicolumn{2}{|c|}{$16 \times 3 / 4$} & \multicolumn{2}{|c|}{$12 \times 3 / 4$} \\
\hline $\begin{array}{l}\text { Deflection } \\
\quad \text { (in.) }\end{array}$ & $\begin{array}{l}\text { Load in } \\
\text { Actuator } \\
\text { (pounds) }\end{array}$ & $\begin{array}{l}\text { Deflection } \\
\quad \text { (in.) }\end{array}$ & $\begin{array}{l}\text { Load in } \\
\text { Actuator } \\
\text { (pounds) }\end{array}$ & $\begin{array}{l}\text { Deflection } \\
\quad \text { (in.) }\end{array}$ & $\begin{array}{l}\text { Load in } \\
\text { Actuator } \\
\text { (pounds) }\end{array}$ \\
\hline 0.000 & 0 & 0 & 0 & 0.000 & 0 \\
\hline 0.002 & 16 & 0.06 & 63 & 0.203 & 320 \\
\hline 0.035 & 81 & 0.08 & 80 & 0.227 & 352 \\
\hline 0.073 & 123 & 0.09 & 86 & 0.256 & 389 \\
\hline 0.101 & 160 & 0.11 & 97 & 0.290 & 422 \\
\hline 0.161 & 225 & 0.13 & 103 & 0.302 & 445 \\
\hline 0.201 & 280 & 0.14 & 143 & 0.359 & 496 \\
\hline 0.220 & 331 & 0.19 & 171 & 0.379 & 542 \\
\hline 0.276 & 452 & 0.20 & 188 & 0.397 & 556 \\
\hline 0.282 & 503 & 0.24 & 205 & 0.408 & 561 \\
\hline 0.300 & 568 & 0.28 & 222 & 0.454 & 603 \\
\hline 0.365 & 670 & 0.29 & 245 & 0.515 & 635 \\
\hline 0.371 & 698 & 0.33 & 257 & 0.522 & 640 \\
\hline 0.431 & 809 & 0.34 & 274 & 0.587 & 677 \\
\hline 0.478 & 892 & 0.37 & 280 & 0.624 & 686 \\
\hline 0.484 & 892 & 0.39 & 302 & 0.641 & 695 \\
\hline 0.530 & 953 & 0.41 & 319 & 0.713 & 728 \\
\hline 0.607 & 1045 & 0.44 & 325 & 0.743 & 737 \\
\hline 0.646 & 1101 & 0.45 & 359 & 0.823 & 751 \\
\hline 0.649 & 1096 & 0.49 & 365 & 0.908 & 783 \\
\hline 0.650 & 1092 & 0.50 & 399 & 0.965 & 797 \\
\hline 0.692 & 1161 & 0.54 & 405 & 1.016 & 802 \\
\hline 0.798 & 1245 & 0.55 & 422 & 1.024 & 811 \\
\hline 0.840 & 1263 & 0.58 & 439 & 1.093 & 830 \\
\hline 0.841 & 1249 & 0.61 & 434 & 1.166 & 862 \\
\hline 0.850 & 1259 & 0.63 & 439 & 1.270 & 890 \\
\hline 0.941 & 1328 & 0.66 & 468 & 1.346 & 918 \\
\hline 1.014 & 1337 & 0.66 & 479 & 1.375 & 927 \\
\hline 1.209 & 1435 & 0.67 & 491 & 1.431 & 946 \\
\hline 1.224 & 1435 & 0.71 & 519 & 1.459 & 950 \\
\hline
\end{tabular}




\begin{tabular}{|c|c|c|c|c|c|}
\hline \multicolumn{6}{|c|}{ Flexing Rod } \\
\hline \multicolumn{2}{|c|}{$16 \times 1$} & \multicolumn{2}{|c|}{$16 \times 3 / 4$} & \multicolumn{2}{|c|}{$12 \times 3 / 4$} \\
\hline $\begin{array}{l}\text { Deflection } \\
\quad \text { (in.) }\end{array}$ & $\begin{array}{l}\text { Load in } \\
\text { Actuator } \\
\text { (pounds) }\end{array}$ & $\begin{array}{l}\text { Deflection } \\
\quad \text { (in.) }\end{array}$ & $\begin{array}{l}\text { Load in } \\
\text { Actuator } \\
\text { (pounds) }\end{array}$ & $\begin{array}{l}\text { Deflection } \\
\text { (in.) }\end{array}$ & $\begin{array}{l}\text { Load in } \\
\text { Actuator } \\
\text { (pounds) }\end{array}$ \\
\hline 1.230 & 1435 & 0.72 & 531 & 1.517 & 955 \\
\hline 1.318 & 1495 & 0.74 & 548 & 1.548 & 978 \\
\hline 1.425 & 1509 & 0.80 & 559 & 1.588 & 983 \\
\hline 1.432 & 1495 & 0.81 & 588 & 1.628 & 1011 \\
\hline 1.446 & 1500 & 0.86 & 599 & 1.730 & 1038 \\
\hline 1.522 & 1569 & 0.88 & 610 & 1.832 & 1052 \\
\hline 1.623 & 1616 & 0.93 & 616 & 1.946 & 1075 \\
\hline 1.626 & 1602 & 0.98 & 628 & 2.065 & 1080 \\
\hline 1.630 & 1592 & 1.01 & 650 & 2.173 & 1103 \\
\hline 1.671 & 1639 & 1.04 & 645 & 2.271 & 1122 \\
\hline 1.779 & 1676 & 1.09 & 662 & 2.379 & 1136 \\
\hline 1.816 & 1662 & 1.15 & 685 & 2.477 & 1159 \\
\hline 1.821 & 1639 & 1.16 & 690 & 2.535 & 1164 \\
\hline 1.823 & 1620 & 1.21 & 696 & 2.682 & 1196 \\
\hline 1.839 & 1676 & 1.25 & 713 & 2.792 & 1210 \\
\hline 1.894 & 1722 & 1.30 & 725 & 2.911 & 1233 \\
\hline 1.923 & 1694 & 1.36 & 742 & 3.135 & 1256 \\
\hline 1.925 & 1676 & 1.41 & 753 & 3.206 & 1270 \\
\hline 1.912 & 1676 & 1.46 & 770 & 3.293 & 1275 \\
\hline 1.916 & 1676 & 1.50 & 776 & & \\
\hline 1.924 & 1699 & 1.57 & 787 & & \\
\hline 1.958 & 1736 & 1.63 & 816 & & \\
\hline 1.979 & 1713 & 1.66 & 827 & & \\
\hline 1.983 & 1704 & 1.71 & 861 & & \\
\hline 1.986 & 1694 & 1.76 & 873 & & \\
\hline 1.989 & 1704 & 2.05 & 879 & & \\
\hline 1.992 & 1699 & 2.11 & 890 & & \\
\hline 2.032 & 1745 & 2.24 & 907 & & \\
\hline 2.131 & 1778 & 2.30 & 924 & & \\
\hline 2.188 & 1778 & 2.36 & 941 & & \\
\hline 2.189 & 1727 & 2.51 & 958 & & \\
\hline 2.229 & 1806 & 2.57 & 970 & & \\
\hline 2.337 & 1875 & 2.70 & 993 & & \\
\hline 2.363 & 1833 & 2.91 & 1010 & & \\
\hline
\end{tabular}




\begin{tabular}{|c|c|c|c|c|c|}
\hline \multicolumn{6}{|c|}{ Flexing Rod } \\
\hline \multicolumn{2}{|c|}{$16 \times 1$} & \multicolumn{2}{|c|}{$16 \times 3 / 4$} & \multicolumn{2}{|c|}{$12 \times 3 / 4$} \\
\hline $\begin{array}{l}\text { Deflection } \\
\quad \text { (in.) }\end{array}$ & $\begin{array}{l}\text { Load in } \\
\text { Actuator } \\
\text { (pounds) }\end{array}$ & $\begin{array}{l}\text { Deflection } \\
\quad \text { (in.) }\end{array}$ & $\begin{array}{l}\text { Load in } \\
\text { Actuator } \\
\text { (pounds) }\end{array}$ & $\begin{array}{l}\text { Deflection } \\
\quad \text { (in.) }\end{array}$ & $\begin{array}{l}\text { Load in } \\
\text { Actuator } \\
\text { (pounds) }\end{array}$ \\
\hline 2.372 & 1819 & 3.10 & 1015 & & \\
\hline 2.428 & 1889 & 3.14 & 1033 & & \\
\hline 2.529 & 1921 & 3.26 & 1044 & & \\
\hline 2.536 & 1884 & 3.40 & 1067 & & \\
\hline 2.538 & 1857 & 3.46 & 1073 & & \\
\hline 2.544 & 1884 & 3.58 & 1084 & & \\
\hline 2.626 & 1949 & 3.77 & 1107 & & \\
\hline 2.677 & 1921 & 3.86 & 1118 & & \\
\hline 2.715 & 1982 & 3.99 & 1141 & & \\
\hline 2.793 & 1982 & 4.14 & 1147 & & \\
\hline 2.833 & 1972 & 4.19 & 1152 & & \\
\hline 2.886 & 2010 & 4.33 & 1164 & & \\
\hline 2.898 & 1959 & 4.39 & 1181 & & \\
\hline 2.899 & 1940 & 4.55 & 1192 & & \\
\hline 2.917 & 2000 & 4.61 & 1198 & & \\
\hline 3.005 & 2051 & 4.74 & 1209 & & \\
\hline 3.026 & 1963 & 4.90 & 1227 & & \\
\hline 3.054 & 2037 & 4.96 & 1232 & & \\
\hline 3.129 & 2065 & 5.14 & 1209 & & \\
\hline 3.138 & 2000 & 5.27 & 1227 & & \\
\hline 3.159 & 2037 & 5.33 & 1232 & & \\
\hline 3.187 & 2042 & & & & \\
\hline 3.242 & 2084 & & & & \\
\hline 3.243 & 1968 & & & & \\
\hline 3.252 & 2033 & & & & \\
\hline 3.330 & 2144 & & & & \\
\hline 3.345 & 2088 & & & & \\
\hline 3.346 & 2042 & & & & \\
\hline 3.358 & 2112 & & & & \\
\hline 3.408 & 2186 & & & & \\
\hline 3.418 & 2112 & & & & \\
\hline 3.424 & 2093 & & & & \\
\hline 3.453 & 2186 & & & & \\
\hline 3.484 & 2195 & & & & \\
\hline
\end{tabular}




\begin{tabular}{|c|c|c|c|c|c|}
\hline \multicolumn{6}{|c|}{ Flexing Rod } \\
\hline \multicolumn{2}{|c|}{$16 \times 1$} & \multicolumn{2}{|c|}{$16 \times 3 / 4$} & \multicolumn{2}{|c|}{$12 \times 3 / 4$} \\
\hline $\begin{array}{l}\text { Deflection } \\
\quad \text { (in.) }\end{array}$ & $\begin{array}{l}\text { Load in } \\
\text { Actuator } \\
\text { (pounds) }\end{array}$ & $\begin{array}{l}\text { Deflection } \\
\quad \text { (in.) }\end{array}$ & $\begin{array}{l}\text { Load in } \\
\text { Actuator } \\
\text { (pounds) }\end{array}$ & $\begin{array}{l}\text { Deflection } \\
\quad \text { (in.) }\end{array}$ & $\begin{array}{l}\text { Load in } \\
\text { Actuator } \\
\text { (pounds) }\end{array}$ \\
\hline 3.516 & 2167 & & & & \\
\hline 3.581 & 2200 & & & & \\
\hline 3.618 & 2162 & & & & \\
\hline 3.632 & 2144 & & & & \\
\hline 3.702 & 2218 & & & & \\
\hline 3.780 & 2218 & & & & \\
\hline 3.844 & 2172 & & & & \\
\hline 3.845 & 2084 & & & & \\
\hline 3.859 & 2125 & & & & \\
\hline 3.912 & 2190 & & & & \\
\hline 3.990 & 2218 & & & & \\
\hline 4.057 & 2195 & & & & \\
\hline 4.069 & 2121 & & & & \\
\hline 4.074 & 2061 & & & & \\
\hline 4.078 & 2051 & & & & \\
\hline
\end{tabular}




\section{Appendix B}

\section{Summary of Figures for Analyses}

Table B1

Summary of Figures for Pushover Analysis

\begin{tabular}{|c|c|c|c|}
\hline Model ID & Figure Number(s) & Type & Member \\
\hline \multirow[t]{8}{*}{ MD 1} & 14 & \multirow{5}{*}{$\begin{array}{c}\text { Force- } \\
\text { Deformation } \\
\text { (X Direction) }\end{array}$} & All Top Links \\
\hline & 15 & & Exterior Top Link \\
\hline & 16 & & Interior Top Link \\
\hline & 17 and 18 & & Left Bottom Link \\
\hline & 19 and 20 & & Right Bottom Link \\
\hline & 21 & \multirow{2}{*}{$\begin{array}{l}\text { Force- } \\
\text { Deformation } \\
\text { (Z Direction) }\end{array}$} & Left Bottom Link \\
\hline & 22 & & Right Bottom Link \\
\hline & 23 & Drift Ratio & $\begin{array}{c}\text { Shear Strain of Panel vs. } \\
\text { Drift Ratio of Structural } \\
\text { Frame }\end{array}$ \\
\hline \multirow[t]{8}{*}{ MD 2} & 25 & \multirow{5}{*}{$\begin{array}{c}\text { Force- } \\
\text { Deformation } \\
\text { (X Direction) }\end{array}$} & All Top Links \\
\hline & 26 & & Exterior Top Link \\
\hline & 27 & & Interior Top Link \\
\hline & 28 and 29 & & Left Bottom Link \\
\hline & 30 and 31 & & Right Bottom Link \\
\hline & 32 & \multirow{2}{*}{$\begin{array}{l}\text { Force- } \\
\text { Deformation } \\
\text { (Z Direction) }\end{array}$} & Left Bottom Link \\
\hline & 33 & & Right Bottom Link \\
\hline & 34 & Drift Ratio & $\begin{array}{c}\text { Shear Strain of Panel vs. } \\
\text { Drift Ratio of Structural } \\
\text { Frame }\end{array}$ \\
\hline
\end{tabular}


Table B2

Summary of Figures for Dynamic Analysis for a Period of $T=100$ Seconds

\begin{tabular}{|c|c|c|c|}
\hline Model ID & Figure Number & Type & Member \\
\hline \multirow[t]{8}{*}{ MD 1} & 36 & Force-Time & Exterior Top Link \\
\hline & 37 & (X Direction) & Interior Top Link \\
\hline & 42 & Force-Deformation & All Top Links \\
\hline & 43 & (X Direction) & Exterior Top Link \\
\hline & 44 & & Interior Top Link \\
\hline & 45 & $\begin{array}{l}\text { Acceleration-Time } \\
\text { (X Direction) }\end{array}$ & Panel Acceleration \\
\hline & 46 & $\begin{array}{l}\text { Displacement-Time } \\
\text { (X Direction) }\end{array}$ & Panel Displacement \\
\hline & 47 & $\begin{array}{l}\text { Displacement-Time } \\
\text { (Z Direction) }\end{array}$ & Panel Displacement \\
\hline \multirow[t]{8}{*}{ MD 2} & 58 & Force-Time & Exterior Top Link \\
\hline & 59 & (X Direction) & Interior Top Link \\
\hline & 64 & Force-Deformation & All Top Links \\
\hline & 65 & (X Direction) & Exterior Top Link \\
\hline & 66 & & Interior Top Link \\
\hline & 67 & $\begin{array}{l}\text { Acceleration-Time } \\
\text { (X Direction) }\end{array}$ & Panel Acceleration \\
\hline & 68 & $\begin{array}{l}\text { Displacement-Time } \\
\text { (X Direction) }\end{array}$ & Panel Displacement \\
\hline & 69 & $\begin{array}{l}\text { Displacement-Time } \\
\text { (Z Direction) }\end{array}$ & Panel Displacement \\
\hline
\end{tabular}


Table B3

Summary of Figures for Dynamic Analysis for a Period of $T=1$ Second

\begin{tabular}{|c|c|c|c|}
\hline Model ID & Figure Number & Type & Member \\
\hline \multirow[t]{7}{*}{ MD 1} & 38 & Force-Time & Exterior Top Link \\
\hline & 39 & (X Direction) & Interior Top Link \\
\hline & 48 & Force-Deformation & Exterior Top Link \\
\hline & 49 & (X Direction) & Interior Top Link \\
\hline & 50 & $\begin{array}{c}\text { Acceleration-Time } \\
(\text { X Direction })\end{array}$ & Panel Acceleration \\
\hline & 51 & $\begin{array}{c}\text { Displacement-Time } \\
\text { (X Direction) }\end{array}$ & Panel Displacement \\
\hline & 52 & $\begin{array}{c}\text { Displacement-Time } \\
\text { (Z Direction) }\end{array}$ & Panel Displacement \\
\hline \multirow[t]{7}{*}{ MD 2} & 60 & Force-Time & Exterior Top Link \\
\hline & 61 & (X Direction) & Interior Top Link \\
\hline & 70 & Force-Deformation & Exterior Top Link \\
\hline & 71 & (X Direction) & Interior Top Link \\
\hline & 72 & $\begin{array}{l}\text { Acceleration-Time } \\
\text { (X Direction) }\end{array}$ & Panel Acceleration \\
\hline & 73 & $\begin{array}{l}\text { Displacement-Time } \\
\text { (X Direction) }\end{array}$ & Panel Displacement \\
\hline & 74 & $\begin{array}{l}\text { Displacement-Time } \\
\text { (Z Direction) }\end{array}$ & Panel Displacement \\
\hline
\end{tabular}


Table B4

Summary of Figures for Dynamic Analysis for a Period of $T=0.32$ Seconds

\begin{tabular}{|c|c|c|c|}
\hline Model ID & Figure Number & Type & Member \\
\hline \multirow[t]{7}{*}{ MD 1} & 40 & Force-Time & Exterior Top Link \\
\hline & 41 & (X Direction) & Interior Top Link \\
\hline & 53 & Force-Deformation & Exterior Top Link \\
\hline & 54 & (X Direction) & Interior Top Link \\
\hline & 55 & $\begin{array}{c}\text { Acceleration-Time } \\
(\text { X Direction })\end{array}$ & Panel Acceleration \\
\hline & 56 & $\begin{array}{l}\text { Displacement-Time } \\
\text { (X Direction) }\end{array}$ & Panel Displacement \\
\hline & 57 & $\begin{array}{l}\text { Displacement-Time } \\
\text { (Z Direction) }\end{array}$ & Panel Displacement \\
\hline \multirow[t]{7}{*}{ MD 2} & 62 & Force-Time & Exterior Top Link \\
\hline & 63 & (X Direction) & Interior Top Link \\
\hline & 75 & Force-Deformation & Exterior Top Link \\
\hline & 76 & (X Direction) & Interior Top Link \\
\hline & 77 & $\begin{array}{l}\text { Acceleration-Time } \\
\text { (X Direction) }\end{array}$ & Panel Acceleration \\
\hline & 78 & $\begin{array}{l}\text { Displacement-Time } \\
\text { (X Direction) }\end{array}$ & Panel Displacement \\
\hline & 79 & $\begin{array}{l}\text { Displacement-Time } \\
\text { (Z Direction) }\end{array}$ & Panel Displacement \\
\hline
\end{tabular}

